\title{
Soothing Sounds: An investigation into the value of music in Palliative Care
}

\author{
by \\ Karen Anne Hall
}

A thesis submitted to the Victoria University of Wellington in partial fulfilment of the requirements for completion of the degree Masters of Arts (Applied) in Nursing

Victoria University of Wellington

2003 



\section{Overture: Abstract}

Music has almost turned full circle in its application for people whose physical, emotional, and spiritual well-being needs to be addressed, particularly in palliative care. Music has been used for centuries to enhance everyday life, and offer therapeutic properties to heal the body and the soul. Since the development of palliative care as a specialised area of medicine and nursing in the 1970s there has been an increased awareness in providing total or holistic care. This acknowledges the patient as a whole person, and the multitude of difficulties that patients and their families may face. Music can be useful in helping individuals to cope with the physical, emotional, mental, and spiritual pain that accompanies dying. Because of music's non-threatening nature, it can often 'speak' where words are sometimes difficult. Music is tied closely to human emotions, and often music can be the catalyst to 'lift the lid' off these emotions in a safe, supportive environment.

This qualitative study focuses on van Manen's theory of the 'lived experience' in relation to two families and asks the first thesis question. What is the value of music in the care of someone who is dying? Over the course of their loved one's illness these families provided music in the patients home as part of their care. The study also captures the experiences of two nurses who work in the palliative setting, and their use of music in providing holistic care to their patients. Their experiences relate to the second question. How can nurses be assisted in introducing music into their planned care of patients? The results demonstrate the effectiveness of using taped music for someone who is dying, and the reduction in symptoms, such as anxiety, and pain. It also highlights the importance of the individual's choice, and the special moments that can be achieved for both patient and families when music is used in a caring, supportive environment. This encourages communication, especially in the sharing of emotions. This study may be the first qualitative study in New Zealand, that addresses the value of music in palliative care, therefore there is a need for continued research into this therapy as a treatment modality as part of planned care in palliative nursing. 


\section{Acknowledgements}

There are so many important people to acknowledge for the completion of this work. Without their support, encouragement and guidance, this personal milestone would never have been achieved. My sincere thanks firstly to my incredible family who have been there with me every step of the way. My husband Matthew, who could never really understand why I wanted to do this, but was always supportive both emotionally and financially, I could not have managed without your love and understanding.

To my children,

Matthew, who had to give up the computer to his mother during his weekends at home and miss out on his games. Thank-you for your help when I needed assistance with those technical 'moments' on the computer.

Neresa, who always seemed to know when I needed those words of encouragement, and a card would arrive in the mail. Thank-you for your invaluable teacher skills in English when it came to grammar and proof reading. Ronelle, my soul-mate in nursing who always believed I could do this and was always eager to read my assignments and offer suggestions and encouragement to keep writing. Even when you were miles away I could feel your love and support, Thank-you so much.

Rachael, Brendan and James, (my Aussie supporters) who kept up with my progress via email and supplied some light relief with those humorous and inspirational emails.

To my mother who at 87 , was always willing to provide a bed for me in Christchurch, and see me off to the airport at 6am on the trips to Wellington. Thank-you for being interested in what I was doing.

This journey into postgraduate study would not have been possible without the encouragement and support of my friends and colleagues. Christine, who was my catalyst into postgraduate study nearly 20 years ago. Without your enthusiasm and determination to practise at an advanced level, I might not have moved from my comfort zone and discovered the wealth of knowledge that is out there to learn and share. 
My thanks to Dale, my manager, when I first began my studies, who offered all the encouragement she was able with study support and provided opportunities to put my learning into practise.

Kate, my role model from many years ago when I first ventured into learning, particularly my introduction to Palliative Care, whose 'gentle' persuasion and confidence in my ability has made sure I got there. Your true friendship and faith in me has always made me believe I could achieve this goal, and we did.

Margi, my inspirational and gentle friend who has encouraged me from my first day at Vic. Margi, your ability to teach us how to delve deep into our hearts and minds and discover what we do as nurses, is indescribable. You have an amazing gift that you so generously share with so many, I feel incredibly fortunate to have been part of this harmonious duet of friendship and learning.

My thanks to my supervisors Rose McEldowney who started with me on this journey, and Professor Bev Taylor (Australia) who continued until the completion of the work. Your guidance and suggestions were invaluable especially when I got stuck and was not sure where to go next. Even in your busy schedule you always maintained regular contact. Thank-you for your understanding and support.

A special thanks to my classmates who have shared this journey with me. To my 'sisters in the convent' who shared a few wines, meals, discussions and many kilometres over the last four years. I will always hold wonderful memories of our special friendship, Sisters Roberta, Yvonne, Kate, Sarah, and Elsa. To the three out of nine of us who began four years ago, we were determined to finish, Roberta, Debbie and myself.

I would like to acknowledge my colleagues at work who expressed their positiveness about what I was doing. Special mention to Pam, who was also studying and was able to relate to the pressure of working, being a mum and writing assignments. Thank-you to you all.

To the community of Ashburton who through their generous support of the fundraising efforts of the Altrusa club enabled me to apply and win their 
scholarship in 2001. This generous grant paid for one of my papers that year which was very helpful, Thank-you for all you do.

To the General Manager of Ashburton Health Services, who also granted some funds to pay for one of my papers in my second year. Your assistance was much appreciated. 


\section{DEDICATION}

To all those patients and families who have enriched my nursing practice by sharing a very personal time in their lives. Without their experiences this thesis journey would not have been possible. 


\section{Note}

In this work I use the word patient rather than client as I do not want to devalue or undermine the partnership role that is critical in palliative care which is the inference if the origin of the word, client, meaning from the Latin cliens = retainer, depending on another's patronage, is used. My preference to use the word patient, reflects the value of the caring partnership in palliative care and the acknowledgement of the stage that the person is experiencing on their life's journey. The origins of the word patient, is from the Latin pati $=$ to suffer and ent $=$ denoting a state or existence (Collins English Dictionary, 1990). 


\section{AD LIBITUM (At pleasure)}

\section{Harmonising the piece}

Music is the universal language of mankind

(Henry Wadsworth Longfellow, 1807-82)

I want to take you on a musical journey of discovery, enabling you to grasp some understanding of the power and beauty of music. I have included a compact disc with this written work which you can play while reading. This compact disc includes some of the music that I have used over the years that has proven to be favourites with some people. As you listen to the music, allow it to move around you, through you, about you, and in you. As you listen think about the place that music plays in your life - Does it bring back memories of places, people, events, holidays, parties, happy or sad memories, laughter, tears? This thread of music is within each of us, and you may have just discovered it.

My hope for you as you read, is that these feelings you experience will help you understand the possible value of music for a person who is dying. Music has that wonderful ability to transcend time and space and transport one to a place where memories are rekindled and can be shared. This work is a living piece, a crafted text inviting you to share in this musical composition of lived experiences and 'soothing sounds'. 


\section{MUSIC AS A METAPHOR}

My idea is that there is music in the air, music all around us, the world is full of it and you simply take as much as you require

(Edward Elgar 1857-1934)

If you are reading this text with very little knowledge of music theory, I would like to explain my use of music as a metaphor throughout the thesis. I want this project to be a living piece, full of the wonder and joy of music which you can listen too as well. By using terms that are related to music, I hope you, as the reader will become completely absorbed in the emotional message that music is capable of developing in a person. Music is not easy to define so using musical terms will give a clearer understanding and confidence to the reader, enabling you to enjoy and appreciate this project.

I have used a number of musical metaphors throughout this thesis and particularly as titles for chapters or sections. They include the following:

Ad Libitum - at pleasure;

Coda - final section;

Cadence - concluding harmonies;

Fantasia - work that is free from rules-composers fancy;

Opus - chronological sequence of composer's output;

Overture - short piece generally preceding main work- single, self-sufficient work;

Piece - small section/s of the whole composition;

Prelude - introductory piece;

Score - written version of composition, details of parts; and

Theme - changes in mood of music, giving different meanings. 


\section{SCORE}

\section{Opus (Table of contents)}

Overture

Acknowledgements

Dedication

Note

Ad Libitum vii

Music as a Metaphor viii

Score ix

List of figures xiv

\section{PIECE ONE Prelude: Introductions and reflections}

Introduction

Research intentions

Definitions

Palliative Care

4

Music Therapy

5

Music Therapist

5

Personal introduction

Way Back

At home

At church

At school

Death and dying

Student nurse 
$\begin{array}{ll}\text { Fantasia } & 14\end{array}$

$\begin{array}{ll}\text { Developing the use of Music Therapy } & 14\end{array}$

Summary 26

$\begin{array}{ll}\text { Music as a part of life } & 27\end{array}$

Music in our life $\quad 27$

Aesthetic of practice $\quad 29$

Summary $\quad 35$

\section{PIECE TWO: Literature review}

$\begin{array}{ll}\text { Introduction } & 37\end{array}$

$\begin{array}{ll}\text { Overview } & 38\end{array}$

Ancient History of Western Music 39

Introduction $\quad 39$

$\begin{array}{ll}\text { Greek history } & 39\end{array}$

$\begin{array}{ll}\text { Roman history } & 40\end{array}$

Christian Church 41

Music therapy as a concept in medicine 42

Music therapy in palliative care 43

Explanations of the effect of music on physiology 44

Influence of music on pain $\quad 47$

Patient's pain $\quad 48$

Music therapy and pain $\quad 49$

The use of music to reduce anxiety and encourage communication 52

Patient anxiety, communication and music $\quad 53$ 
$\begin{array}{ll}\text { Nursing and the art of caring } & 57\end{array}$

$\begin{array}{ll}\text { Nursing concerns related to caring } & 57\end{array}$

Developments in nursing knowledge $\quad 59$

$\begin{array}{ll}\text { Conclusion } & 65\end{array}$

\section{PIECE THREE Methodology, Methods and}

\section{Processes}

Introduction $\quad 66$

Methods debate $\quad 66$

$\begin{array}{ll}\text { van Manen's method of phenomenology } & 70\end{array}$

Summary $\quad 77$

$\begin{array}{ll}\text { Ethical considerations and approval } & 77\end{array}$

$\begin{array}{ll}\text { Selecting participants } & 78\end{array}$

Compact disk permission $\quad 80$

$\begin{array}{ll}\text { Method of data collection } & 80\end{array}$

$\begin{array}{ll}\text { Research diagram } & 82\end{array}$

$\begin{array}{ll}\text { Data analysis } & 84\end{array}$

$\begin{array}{ll}\text { Interpretation } & 87\end{array}$

Issues of rigour $\quad 88$

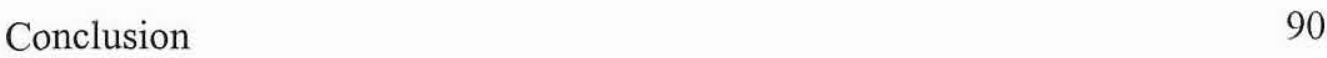

\section{PIECE FOUR Theme: Analysis and Interpretation}

Introduction $\quad 91$

Identifying themes $\quad 92$

Discovering the themes 93

Introduction of family participants $\quad 97$

$\begin{array}{ll}\text { Ngaire } & 97\end{array}$

$\begin{array}{ll}\text { Joan } & 98\end{array}$

Interpretation of family texts 98 
$\begin{array}{ll}\text { Insights from the texts } & 111\end{array}$

$\begin{array}{ll}\text { Family texts } & 111\end{array}$

The phenomenon of music for someone who was dying: the families 112

$\begin{array}{ll}\text { Introduction of nurse participants } & 118\end{array}$

$\begin{array}{ll}\text { Sondra } & 120\end{array}$

$\begin{array}{ll}\text { Christine } & 120\end{array}$

$\begin{array}{ll}\text { Interpretation of nurses' texts } & 121\end{array}$

$\begin{array}{ll}\text { Insights from the texts: the nurses } & 142\end{array}$

$\begin{array}{ll}\text { Conclusion } & 146\end{array}$

PIECE FIVE Coda: Discussion, Implications and Conclusions

$\begin{array}{ll}\text { Introduction } & 148\end{array}$

$\begin{array}{ll}\text { Discussion } & 148\end{array}$

$\begin{array}{ll}\text { What did the stories tell us? } & 148\end{array}$

Implications of music in the future for palliative care 153

For patients 153

$\begin{array}{ll}\text { For nurses } & 154\end{array}$

Research limitations 156

Cadence: Concluding harmonies $\quad 157$

$\begin{array}{ll}\text { Tapestry } & 160\end{array}$

\section{APPENDICES:}

1. Music therapy in palliative care- reference booklet for Ashburton Hospital. 161

2. Ethics approval from Canterbury Ethics Committee. 163 
3. Letters for participants entering the research. 164

4. Information sheet for nurses. 165

5. Information sheet for participants. 167

6. Contact details. - 169

7. Consent to participate in the research. 170

8. Compact disc approval 171

9. Confidentiality Agreement 173

$\begin{array}{ll}\text { REFERENCES } & 174\end{array}$ 


\section{List of figures}

Figure 1: Mr T's Environmental Corner 25

Figure 2: Crossed fingers 30

Figure 3: Barriers 31

Figure 4: Partial Acceptance $\quad 32$

Figure 5: Support on the journey 33

Figure 6: Research Diagram $\quad 83$

$\begin{array}{ll}\text { Figure 7: Tapestry } & 160\end{array}$ 


\title{
PIECE ONE
}

\section{Prelude: Introductions and reflections}

\author{
Music is itself
}

(Eduard Hanslick, 1825-1904)

\section{Introduction}

The opening Piece or Prelude introduces the intention of this research and describes the use of music in palliative care in New Zealand and overseas. It also defines the questions that this work will answer about the value of music in palliative care and the role that nurses play in using music in the planned care of their patients. The personal introduction explains my practice and how music has been a life-long interest following through into my nursing career. This is reflected by a section entitled, 'Way Back' which gives an in-depth history of my life and the part music has played. The memories of my childhood and nursing training have left lasting impressions which I believe have influenced my career and steered me in the direction of palliative care. 'Fantasia' is the progression of my interest in music therapy and how I have applied it in my practice over the last 18 years. This includes stories of patients I have cared for where music has been used in their care. From these experiences my aesthetic of practice has developed and my interest in music and nursing has increased as I continue to expand my knowledge about the topic. Definitions that are relevant to this thesis are also explained.

\section{Research intention}

The intention of this research is to present a project that will have its validity recognised by both nursing and medicine to achieve an understanding of the value of the aesthetic practice of music in palliative care. By using patients' stories and nurses' experiences, I present to health professionals, especially those involved in oncology/palliative care, the significance of music in terminal care. 
There is a plethora of overseas literature relating to music therapy in palliative care, but as far as I can ascertain there is no research in New Zealand. It has been acknowledged by Brooks and O'Rourke (1992, p.1) who are co-writers about music in the care of the elderly, that "there are very few trained music therapists in New Zealand available to work in the various health settings". It has been acknowledged in the literature that anyone who has an interest in music and is aware of its therapeutic value is capable of introducing it in the care of their patients. As Munro and Mount (1978) state "any motivated person, irrespective of training, may effectively use music in ministering to the sick" ( $p, 1029)$. Because of the lack of music therapists in New Zealand, I assume that the use of music in palliative care is not widely understood or acknowledged, especially in the smaller centres. A number of larger Hospices have access to a music therapist, usually on a part-time basis as a member of a multidisciplinary team. In those areas where there is no music therapist available, nurses seem to be the obvious choice to develop the skill and enable patients to benefit from this highly effective treatment modality. This is because nurses are in the privileged position of working alongside patients as they journey on the palliative care pathway and because of this closeness are involved in the holistic care of the patient. I am assuming that if there is a shortage of qualified music therapists, patients' needs for music are not being met in a sustained and effective manner.

It is my personal position that nurses working in palliative care are disadvantaging patients if they do not take every opportunity to ensure that the experience of music therapy is made available. The outcome of the research will emphasize to nurses and all those who have an interest in palliative care, the therapeutic value of learning the skill of assessing people for the inclusion of music therapy in their care planning. Because this research may be the first project that examines the use of music in palliative care in New Zealand, it is imperative that the voice of the patient and of those caring for them are heard in their own contexts. This is why I have chosen a qualitative approach to this inquiry, namely phenomenology, to hear the stories of patients and nurses who have used music in the care of someone who was dying. To explore the contribution music can make in the palliative care setting I interviewed two families and recorded their perceptions of how music may have met their family members' 
needs during their illness and up to the time of their dying. I also spoke with two nurses and asked them how they use music in their care of patients in the palliative care setting.

Many of the articles written about music therapy describe beautiful narratives about the positive benefits that music can have for people who are dying. Mandel (1991), a hospice music therapist from Ohio mentions six short scenarios about palliative care patients who have used music. In her article, Music therapy in the Hospice: 'Musicalive' it describes how music can aid relaxation, assist breathing and encourage communication with family. Some stories reflect the patient's ability to cope with the magnitude of emotions faced within a terminal condition through the use of music. Fears concerning pain, loss of control, vulnerability, loneliness, mental and physical anguish, are all common to many terminally ill patients. Munro (1984) describes a young man dying of cancer of the kidney. Throughout the terminal phase of his illness music was his constant companion. He refused drugs, using sonatas and symphonies as his sedatives. He use to say, "the great thing with music is that you can enjoy it even when strength fails you" (cited in Munro, 1984, p.5). Fears may be difficult for patients to vocalise with family and staff, and they may be overlooked in the rush of everyday practice. These patient stories need to be told so that music can be an acceptable choice in the management of patients' needs. My intention to include patients' families and their 'lived experience' of music reflects the uniqueness of the individuals and their response to music as it touches the whole person, including body, mind, heart and soul.

A further purpose of this research was to unfold the perspective of nurses working in palliative care, who are not trained as music therapists. There are a number of discussion papers on the potential benefits of the use of music as a therapy which encourage nurses and other health professionals to consider using music in the care of their patients. Zimmerman, Pozehl, Duncan and Schmitz (1989), explored the effects of music on patients with chronic cancer pain while two other significant papers discuss the positive effects of music on patients who are suffering from anxiety, (Bolwerk, 1990; Updike, 1990). From my experience the two symptoms, pain and anxiety, are usually foremost concerns of nurses who are working in palliative care. 
Therefore the two main questions addressed in this thesis are:

- Does music have any value in the care of someone who is dying?

- How can nurses be assisted in introducing music into the planned care of their palliative care patients?

\section{Definitions}

Palliative care, music therapy and, music therapist are relevant to this work so they require definition.

\section{Palliative care}

The New Zealand Hospice definition encompasses y the World Health Organisation, as well as the Australian and United Kingdom Hospice Associations palliative care definitions.

Palliative care operates from the time it is acknowledged that the aim of treatment is no longer curative and that a person's death is very likely. It is the total active care of people by a multidisciplinary team when a person's disease is not responsive to curative treatment and;

Affirms life and regards dying as a normal process.

Aims to neither hasten or postpone death.

Aims to provide relief from distressing symptoms.

Integrates physical (tinana), social (whanau), emotional (hinengaro), and spiritual (wairua) aspects of care.

Offers help to the family (whanau), and carers, during the person's illness and their bereavement ( Palliative Care Strategy Document, 2000 ). 


\section{Music therapy}

Two definitions clearly describe the use of music for people who are dying. According to Munro and Mount (1984, p.104) "Music therapy is the controlled use of music, its elements and their influences on the human being to aid in the physiologic, psychologic and emotional integration of the individual during the treatment of an illness or disability".

A second definition written by Kenny (1982), focuses more on the values music can portray for someone who is unwell;

Music is a resource pool. It contains many things-images, patterns, mood suggestions, textures, feelings, processes. If selected, created and used with respect, and wisdom, the clients will hear what they want to hear in the music, and use the ritual as a supportive context. (p. 5)

\section{Music therapist}

A music therapist is a person who has a degree in music and psychology and plans "the controlled use of music, its elements and their influences on the human being to aid the physiologic, psychologic and emotional integration of the individual during the treatment of an illness or disability" (Munro, 1978, p.104).

It is hoped that this thesis will create a better understanding of the value of music in palliative care in the New Zealand setting and inform the potential for improved care of palliative care patients from the patients' viewpoints and nurses who have experienced the use of music in their plan of care. 


\section{Personal introduction}

I am a clinical nurse specialist who has worked with palliative care patients in the community for the last 18 years. This has occurred in my capacity as a District Nurse, working 10 years as a part-time evening nurse, and the following eight years as a full-time nurse working during the day. My job as a district nurse is part of the service offered by a small 107 bed hospital in a basically rural community of 15,000 people. The hospital has just been accredited for the fourth time, which does emphasize the staff and managements' commitment to strive to provide 'excellent care' to the community.

My interest in music has been life-long, as it has been part of our family as I grew up and continues with my children and now my grandchild. It is part of our everyday lives and has opened many doors to varied experiences and friendships. Combining music with palliative care has only developed in the last seven years as I ventured into postgraduate study and discovered, by reading overseas studies, on the value this modality could have for palliative care patients.

\section{WAY BACK}

In truth, there is nothing like music to fill the moment with substance

(Johann Wolfgang von Goethe, 1829).

This section provides personal insights into the memories that have shaped my thinking about music and palliative care. These memories focus on primary influences in my life, such as home, the church, school, death and dying attitudes and life as a student nurse in the early 1970’s.

\section{At home}

My earliest recollection of music in my life was hearing the gramophone playing in our home most of the morning while my mother went about her daily routine. I do not recall whether I 
liked or disliked any particular music. The fact was it was always playing and it was just part of our lives. My mother would gently hum along to the tunes in her beautiful Scottish lilt, which always sounded gentle and loving. She always sang favourite songs and tunes to my brother and I, and most of them I have continued to sing to my own family and to many other children over the years.

The second memory I have of music in our home, was the weekly Sunday night around the fire, singing mainly Scottish songs and listening to someone playing the piano. The time would disappear so quickly and I remember always trying to stay up just a little longer to hear one more favourite song. Because the adults continued with the music, as children we were lulled to sleep by the melodious tunes that emanated from the lounge.

As the years past, I became part of the performance as my love of music grew. I learnt to play the piano and fortunately inherited my mother's love of singing. I vividly remember my mother's response to a song I learnt for her, Bless this House, which I thought she would really enjoy, but she listened to the whole song with tears in her eyes. I had yet to learn the emotional reaction music could cause to someone listening and whose memories were stirred, and that tears did not always mean sorrow.

My paternal Grandmother was also blessed with musical talent. She played the piano for the silent movies at the theatre. I can still hear her rendition of the Robins Return which amazed me as a child, because she seemed to play every note on the piano and at such speed. It was not until I was older that I realised what it meant to play for silent movies and how gifted she must have been, to improvise all the way through a film, with no musical score. Even as my grandmother's health deteriorated, she found the energy to play and it appeared to enable her to relive some of those early memories of her playing, which she loved to share with her grandchildren.

This love of music has continued throughout my life and I believe has opened doors to experiences and opportunities that otherwise would not have occurred. 


\section{At church}

Our family was regularly involved in the church and it was a wonderful place to be part of music. Music has a well-documented history in its involvement with religion and church performances and "hymn singing is the earliest recorded activity of the Christian church" (Grout \& Palisca, 1996, p.19). Church choirs were always a great way to learn the famous choral music and sing with experienced people. My involvement with choirs has enabled me to gain valuable experience with music, and the opportunity to see first hand the impact music can have on the people performing the music and those listening. The choirs I joined offered a variety of challenges and chances to sing various types of music such as the great choral works, unaccompanied singing, and contemporary works.

The chance to learn to play a pedal organ in the church as an accompanist was a further challenge, which I decided to take on. As well as playing for the Sunday congregation, I also played at weddings and funerals. Weddings were usually very traditional and the music tended to be very repetitive. For example, The Wedding March, and Amazing Grace were favourites.

At that time too, family members had very little input into the type of music that was played at the funeral of a family member, so it tended to be music that really had no relevance to the person who had died. Over the years this has changed and people are encouraged to plan their own music for funerals now which means the music has significance for the people attending and adds a personal touch that is remembered for years to come. I have continued to this day with a musical involvement in the church mainly in the capacity of teaching new congregational hymns and preparing the choir for Easter and Christmas celebrations. There is something incredibly moving and special about music that is performed in a church, which has wonderful acoustics, by people who give of their time and talent freely for the sole/soul purpose of communicating music to others.

\section{At School}

I was fortunate to receive my education at a convent school, where music was an important and valued part of the curriculum. Most students were encouraged to participate, regardless 
of musical experience. It was an ideal environment to foster an enjoyment of music. I was surrounded by religious women who could all sing and many of them were very talented musicians. I remember listening in awe to the glorious harmony the Sisters sang so effortlessly and with such natural ability. I could never really work out who was singing which part, they blended so well. I discovered later that it was a skill that many choristers find difficult to emulate. Every student was usually involved in the annual school productions, which included, singing, dancing and acting. I vividly remember the first solo I was given. I really do not recall if I sang it that well, though my mother cried tears of love and joy throughout the entire performance. What I do remember is the swish of the beautiful blue hooped satin gown and matching bonnet; the title and words of the song; the exact lines that were said before I came onto the stage to sing; all my classmates who were on stage with me; the brightness of the lights as I stepped out; and, my mother in the audience. It is firmly etched in my mind, I was ten years old.

As my school life continued, my appreciation and love of music continued to develop. There was very little time to be bored, because choir practices, piano, recorder group, guitar and singing occupied most of my week. About the time I was in the fifth form, (year eleven today), we were stunned by the arrival of our first male teacher. He was not only a six foot two, good looking German, he was also an exceptional pianist. Suddenly music was the class everyone wanted to be in. Everyone would quietly creep up to the hall doors when he was practising, to listen to the music, of course! The Sisters soon realised how this talent could be used to the advantage of the school. Wolfgang's (his name) father was a choir conductor and they worked together as conductor and accompanist. Wolfgang and is father established a school choir. After many days of auditions the lucky 50 were chosen, and so began my first true magical experience of the power and beauty of music. The talent and skill shared with those men will always remain with me, because they gave us an appreciation of music and the confidence to perform music from the heart. The choir became well known for its performances of classical and contemporary music throughout Christchurch. This musical grounding that I was privileged to receive as part of my schooling is something I will always treasure. 


\section{Death and dying}

From an early age I always wanted to be a nurse, certainly through no influence from anyone I can remember. I have no family members who were or are nurses, except now I have a daughter who is nursing. My mother may not have had the ability to deal with traumatic injuries, but her empathy and concern for others was very obvious when I was growing up. Her influence about death being part of everyday life, and not something to be afraid of, has played a huge part in my career choice of caring for the dying. This is coupled with a strong faith and belief that dying and death is not something of which to be fearful. The one comment that my mother made regarding death has always stayed with me and is something I have shared with my children as they grew up. She said, "it is not the dead that hurt you, it is the living."

I grew up not being afraid to be in a house where someone was dying and being cared for by their family and friends. Neighbours provided support, food, and a listening ear to the people who were dying and also for their families. It was not a morbid curiosity on my mother's part, but a genuine desire to be there for people if they needed help and actively do something that was useful. It was not an uncommon part of community living in New Zealand 40 years ago, when most married women were at home and had more opportunity to give their time freely when it was needed in a generous and caring way. Part of this experience was also attending the funeral after the person died, a time of celebrating and being thankful for the life they had, and again offering care and support to the grieving family.

Actually seeing people who were dead was not something I feared either, because it was usual for the casket lid to be left off the night before the funeral when people gathered in the church to pray. This was, and still is the tradition when a member of a religious order dies, for example, a priest or nun. At the conclusion of the service the congregation are encouraged to come to the coffin and express their farewells, which may include making physical contact with the body, for example, touching their hands or kissing their forehead. 
I have vivid memories of being at a service for our parish priest when I was about ten or eleven. It was not the first time I had been to a rosary when the coffin lid was off, but it was the night I remember, like something straight out of a scary film. The weather was atrocious, with thunder, lightning and a howling wind, which buffeted the windows and whistled through the cracks. The church was small, old, wooden, and had doors that banged in the wind. It was difficult to keep the candles alight and everyone was dressed to keep out the cold, as there were no heaters in those days. At the conclusion of the service, I took my place in the ritual queue proceeding to the open casket. It was quite spooky as the wind dropped and it was incredibly quiet for most of the time but as I arrived at the casket, there was an enormous clap of thunder and the lightning lit up the priest's body like a torch, which made him look transparent. It took all my resolve not to scream and run out the church, and it was my mother's hand on mine that enabled me to keep calm and remain there. I do remember that I could not quite find the courage to touch him but quickly and quietly left the church with my family. We laughed about it later and how it would have been the perfect script for a play or film.

\section{Student nurse}

My training as a nurse began in 1969, a time when nurses were employed in the ward for four days and had one study day a week. It was the time when nurses were totally focused on the 'task' of nursing with very little understanding of why and how to care for patients. This was also the era of the mainly male dominated medical profession, who preferred to discuss the patient as ' the appendix in room one' rather than call them by their name. Patients were seen as an object in a bed with no need to have any explanations about their condition or treatment, the doctors viewed nursing students the same, only there to be a handmaiden when they needed something. It was incredibly difficult to maintain any sort of relationship with patients as nurses were so busy, making sure beds were kept straight on the 'green line', no creases in the bed clothing, giving out meals and flowers, bed sponging, and all this before the doctor's round at 9am. The ward sisters were usually feared above all else, especially if you were the junior nurse. Our main job was keeping the stainless steel sinks and benches meticulously clean, and the bedpans, wash bowls, teeth mugs sterilised and ready at all times 
for use. As you can imagine there was very little time for actually involving one's self in meaningful communication with patients, and even less chance to develop a relationship with someone who was dying.

The first encounter I had with a dying patient will be forever etched in my mind and helps me to realize how far we have developed care of the dying in the last 30 years. It saddens me too, to think how many of those patients must have died painful, lonely deaths without the love and care of their family and friends around them. I must also emphasize the fact that I did see some nurses try to make a difference for their dying patients, but other tasks always interfered and took priority.

I was in my first three months of nursing training (as a 'prelim nurse'), working in an acute surgical ward, mainly abdominal surgery. As 'prelim nurses' we were assigned to the most junior nurse on the shift and most of our day included making beds, taking the morning and afternoon tea and meals around, and cleaning. The ward sister was renowned for her ability to stand in the middle of the ward and 'yell' for the nurse who had had the misfortune to do something wrong. Her policy was to strike fear into the hearts of all nurses by questioning them about the patient's diagnosis, while she dished out the lunch. It was a terrifying ordeal that caused everyone to have complete amnesia just at the time you got to the 'bainmarie' from where lunch was distributed. Fortunately for student nurses, we did not have to have indepth knowledge of diagnosis or treatment, but we were expected to know basically which part of the anatomy was affected and how. We worked in pairs when giving out lunch, because most of the patients needed assistance to sit up and that was something we could manage. Another student and I were given lunch for Mr. Smith, (pseudonym) and proceeded to his room pleased that we had managed to remember his diagnosis. On entering his room he was asleep, so I attempted to gently wake him, but he did not stir. We decided that we would lift him carefully up in the bed and that would undoubtedly wake him. He was most nonco-operative and flopped around like a sack, and suddenly blood came out of his mouth. We looked at each other and the realisation dawned on both of us. We left the room hurriedly and ran into the linen cupboard, too scared to breathe and even more scared to let anyone 
know what we had done! We heard the customary 'yell,' but continued to be invisible. Eventually sister found us, demanding that we come out of the cupboard at once. We knew we were in trouble, but her response to our frightening experience did nothing to reassure us or help us deal with our feelings about what had happened. Her comment was: "pull yourselves together and go and have lunch, and don't be late back". Lunch was the last thing we felt like. Nobody ever talked about the fact that Mr. Smith had died. His bed was empty when we returned to the ward, and we never mentioned it to anyone and no-one discussed it again.

It was many weeks later before my colleague and I discussed the issue. We both spent some time together trying to fathom why we reacted the way we did. It was not the fact that the patient was dead, but that we had not received any guidance about what to do or what was expected of us as students. We were convinced that in some bizarre way we were to blame. The reaction and response of the ward sister was completely unsympathetic, and we were never acknowledged as people who may have wanted to discuss our thoughts and feelings. Our display of emotion was totally unacceptable and seen as unprofessional. Thankfully, nursing has a come a long way since then, in our care of our patients and each other, but we must not become complacent. As nurses, we must continue to acknowledge death and dying as an inevitable part of living, and be aware of death from a global perspective inclusive of all cultures and religious beliefs, and endorse palliative care as a specialised area of medicine and nursing care.

\section{Summary}

This section has highlighted my reflections and memories about my early childhood and education, and the people and places that have influenced my thinking and attitude towards music, and death and dying. It also gives some insight into the nursing training of the time, and the gaps in that training that made it extremely difficult to develop close relationships with people who were dying. It provides the stepping stones that have been significant in my personal and professional development throughout my life, as an adult and a nurse. 


\section{Fantasia}

After silence, that which comes nearest to expressing the unexpressible is music

(Aldous Huxley, 1931)

This part of the thesis is named 'Fantasia' which is a musical term for 'at the composers fancy'. I have chosen this term because this section continues from the previous one, by expanding on, and describing how my personal interest in music therapy has evolved, and how I developed this interest in my nursing career. It is essentially my reflections about the experience of music in everyday life that I have observed and been a part.

Because nurses are practising at advanced levels in many areas of care, for example, intensive care, palliative care, paediatrics, I believe it is important for nurses at this level to develop their personal philosophy about what they do. The advanced practitioner has the opportunity, because of their knowledge and skill base, to reflect on, and challenge practises of the past, and be active in implementing best practise that offers a valuable contribution to the nursing profession as well as improved patient care. This is the reason that $\mathrm{I}$ have included with this written work, photographs, (with explanations), that describe my aesthetic philosophy of practice. This section also includes stories of people I have nursed who have used music during their illness, and illustrates, with words and photographs, the effect music had for them during their care. It gives some insight into how I introduced music therapy into the hospital where I work. It also gives an overview of the music therapy teaching sessions that I share with nurses who are undertaking study in the New Zealand Hospice modules. These four modules are a recognised palliative care qualification that can progress on to the post graduate certificate and Masters in palliative care.

\section{Discovering the use of music therapy}

My interest in music therapy began back in 1990 when I was completing an Advanced Diploma in Nursing. Included in the study was a requirement to undertake a 'special topic'. 
The objective of the assignment was to write about a topic that had relevance to your place of work, and one that held a particular interest for you as a nurse. It was quite by chance that I discovered a book in my department at work, entitled Music Therapy in Palliative/Hospice Care,(1984) by a Canadian music therapist, Susan Munro. After reading the book I was convinced that this was an area I could develop in my practice and introduce to my work colleagues who work in palliative care.

It was an exciting discovery, that music could be utilised in this way. I had already embarked on the journey in palliative care and decided this was the area of nursing in which I wanted to work. The combination of these topics enabled me to indulge in the two areas I had a passion about, palliative care and music.

As I progressed with the study, I discovered the New Zealand databases were devoid of any research on the topic of music therapy in palliative care. During 1991, I attended a palliative care conference in Christchurch. One of the keynote speakers was Balfour Mount, a palliative care specialist from Canada. He spoke about the role of music therapists on the palliative care team and the valuable contribution they make in patient care. I wrote to Balfour, explaining the study I was undertaking and my area of interest, and asked if he could forward any information that would be useful for my study. Consequently I received a large package of articles from the music therapist in Balfour's team and some helpful comments. This information gave me the basis on which to write my 'special topic', The use of music therapy in palliative care. Included in the requirements for the 'special topic' was searching through the research and writing a literature review. There was information regarding the use of music as a treatment modality in other areas of medicine, such as aged care (Brooks, 1990), physically and mentally challenged care and obstetrics, (Harcourt, 1988), grief reactions, (Bright, 1978), and for people with Alzhiemers ( Cooper 1991), but no reference to music in the care of the dying. It was also mentioned that a trained music therapist in the mentioned disciplines usually initiated the use of music therapy.

I contacted the Music Therapy Association, which informed me that there were not sufficient music therapists in New Zealand to maintain every area where it was appropriate to use 
music. It was a relatively new concept and there was no-one specifically providing music in the palliative care setting. The required education for a music therapist in New Zealand is an undergraduate degree in music and psychology. Most music therapists primarily involve patients in therapy by playing music for them, encouraging the patient to become involved with the music selection of their choice, or actually playing an instrument themselves. Using familiar tunes and composing their own words, can be an excellent avenue for patients to express their feelings and as a way of communicating with their family.

Music, in its many forms is part of everyday life, and it affects us all as it is tied closely to our emotions and reflects our experiences. O'Callaghan (1996), in her paper entitled, 'Music and wellbeing' discusses how music can stimulate memories. She states, "Patients may project their feelings onto the music, or reflect upon the associations of the song lyrics with their own lives" (p.7). The singing of lullabies by mothers to infants was common before the introduction of musical toys that play Brahms Lullaby. My mother has repeatedly sung a Scottish lullaby to her own children, seven grandchildren and a great grandchild, and many other babies over the years with wonderful effect. There are no words and the tune is repeated many times, but to the distressed infant the sound must be soothing and full of love that they are able to go off to sleep. I have continued this tradition with my own children and many children of friends over the years, usually with very positive results. As my daughters grew, they too have used the technique on many occasions when babysitting other children.

I remember a personal incident that involved my mother singing to one of my children. This story is firmly etched in my mind as it was one of the first times I gained some understanding of the importance of the mutual trust that is vital between the patient and the carer when music is involved in planned care.

My third daughter had been awake most of the night with a temperature, and I was not sure what was causing the high temperature. I tepid sponged her and gave her medication but she still continued to cry and remain restless throughout the night. Even the singing of the Scottish lullaby had no effect. It had been a very stressful night and by morning I had called my mother to come and assist until I could take my 
daughter to the doctor. To enable me to care and console my daughter, I had moved her cot into the kitchen. On my mother's arrival, she went straight to the cot side and began singing to her and within minutes my daughter was peacefully asleep. I was totally bewildered as it was what I had tried all through the night with no results. On reflection, after reading about the positive effects of music therapy, I believe that because I was stressed about my daughter, that stress was transferred in my attempts at singing and my daughter was able to perceive that emotion and therefore the singing was ineffective. My mother was successful because she was able to relate feelings of calmness and soothing. (Journal entry)

I believe that someone who is nearing death and needs to feel that presence of comfort and peace can achieve that same effect with the use of music.

Another area where music plays an important role is in church services. This music often reflects feelings of reverence and faith. Every time I attend a wedding and hear those familiar wedding tunes my memories return to my own wedding day and the happiness shared with everyone on that day. These emotions are surely experienced by other people, and I believe that music is the life thread from the past to the present enabling music to connect us to past events by creating a memory that travels time and brings us to the present.

Funerals are another time when music is very symbolic. I think there is a trend now to include music that has significance for the person who has died and for their family and friends. In my experience as a palliative care nurse, many more patients are planning their own funerals, and in particular the music. This can be a wonderful opportunity for families to come together and share a very special time with their loved one, and also enable the patient to be involved and have some control on what will happen after they die.

At the funeral of a teenage boy I attended a few years ago, we had the traditional hymns during the service, but as the coffin was carried from the church, the ' ghetto blaster' was switched on and the latest track from Guns and Roses filled the church. This must have 
related well to the young people in the congregation and will have particular significance for those teenagers when they hear it in the future, as they recall the memories of their friend.

Christmas is a season where familiar tunes and music stir the emotions in people to remember places and people with whom they have spent previous Christmases. Music paints such vivid pictures and can travel through all of time. I always find it easy to visualise the stable in Bethlehem, the cold night, the cattle and the shepherds, the feelings of warmth and love in that stable. All this can be imagined with the words of the favourite carols, which tell the story of Christmas, especially if they sung by a group of children in appropriate costume in a stable scene.

The following exemplar is a story about one of the first patients and their family, with whom I was involved as a district nurse. The family initiated the use of music for their husband and father who was dying. I will always remember him and his family as we began caring for him at Christmas time.

Mr L was a fifty-two year old who had been diagnosed with a brain tumour. He had two operations to remove the tumour, but without success. He and his family had discussed where he wanted to be cared for when he became incapacitated. They all agreed they wanted to care for him at home. Each time I visited as the district nurse, I noticed the music tapes were always playing. During the weeks following, I discovered the importance music had played in Mr L's life. He had been a schoolteacher and had conducted many choirs during his career. Music had always been an interest for him. Both he and his wife had a strong religious commitment and enjoyed similar music in this area too. During Christmas $M r L$ went into a coma and his wife played all the favourite Christmas carols and music. Playing festive music during this time helped the family and the many visitors who came to the house. The house was 'alive', not dreary and sad. This was important for the family, as they wanted visitors to accept that, as a family they were living life to the full even though it was only from day to day. 
A further aspect of the use of music was the effect it had on Mr L's condition. His pain was well controlled, but there were periods when he became restless. His wife noticed many times that her husband's restlessness was replaced with sleep if she played his favourite music. A special song became their 'theme song' for the last months, it was 'One Day at a Time'. They both latched on to this song and it seemed to give them an inner strength to cope. Another favourite for $M r L$ was, 'You Can't be a Beacon, if Your Light don't Shine'.

Mr L died at Easter, a time that had special religious significance for them both. The 'Messiah' was played many times and they listened to all the recorded Easter church services together. Again friends and family who knew Mr L was close to dying were greeted at the door with music. This background music helped these people immensely to cope with their own grief and realise the home was still 'living'.

A very special tape was played in the evenings for $M r L$ and his wife. Their wedding anniversary was the 6th of May. They played the tape of their wedding with all the familiar hymns and prayers many times in those last few weeks, and this was so special to them both. From my perspective as a nurse, I saw a person who died the way he lived, with his family and his music around him. (Journal entry)

From the overseas studies, I discovered that in the last 20 years, most palliative care teams in Britain and Canada were employing music therapists (Munro \& Mount, 1978). The fact that New Zealand did not have sufficient music therapists further encouraged me to learn more about the modality and share that knowledge with other nurses. Because nurses are the principal carers in patient care, it seemed logical that they could learn the principles of the therapy and apply it in the planned care of their patients. The first opportunity to discuss this concept of music as a complementary therapy was with nurses in my work place. I was encouraged by our previous palliative care nurse specialist to be part of a study day related to palliative care principles, and to talk about the use of music for palliative care patients. The teaching session was successful and well received, especially by those nurses working in 
palliative care. With assistance from the literature I was able to write some objectives and music suggestions into a pamphlet for nurses to use as a reference in the wards (Appendix 1).

Our town is very community orientated and a number of service groups wanted to hear about the concept of using music in care of the dying. I began speaking to a variety of community groups and explaining the use of music in palliative care. They were all enthusiastic and I found it was both an enjoyable and rewarding experience as I too learnt about the value of music in other peoples' lives. It also emphasized what I had learnt from the literature about the diversity of music and how important it is to support the individual's choice. MacClelland (1979, as cited in Cook 1982) discusses the personal factors that influence the individuals response to music;

Basic personality traits, traditions or language or culture, and geographic, economic, religious and education factors influence individual responses to music. Usually the degree of pleasure experienced helps to determine the extent of emotional arousal, with familiar music being more relaxing and pleasing.

One of the groups approached me and asked if they could provide funds to develop my project as they could see the important value of the therapy for patients in the community as well as the hospital. After further discussion they agreed to purchase two audio-tape decks that were both battery and mains powered, and a selection of tapes that I could choose. These items were labelled for palliative care patients to use following musical assessment. Documentation was recorded so details were available to keep track of the items. The Lions Club of Ashburton donated $\$ 300$, which was deposited in the palliative care fund, and I was able to access it to pay for the items. It was a very generous donation that enabled the palliative care team to gain a valuable library of music and the means of providing a tape deck if patients did not have one.

In 1995 I was asked to present a session at the Christchurch Hospice conference about my topic, which stimulated much interest among the nurses present. Subsequently, I was invited to present teaching sessions to post-graduate students who are enrolled in the New Zealand 
Hospice palliative care modules on a regular basis each year, which I have continued for the last seven years.

The session begins with the participants relaxing, closing their eyes if they wish to, while I play some music for them to listen to. While they are listening, I try to explain the value that music may have in their lives and the positive effects it can play in relation to relaxation, calming, and how that can be obtained for their patients. Also included is how my interest in the subject of music therapy began and how it has evolved over the years to my present study. The goals and objectives of the teaching session are stated at the commencement as well as defining terms, such as 'music therapist', 'music therapy' and 'palliative care'. I also explain the value of their contribution to the sessions by sharing their experiences, if any, of music therapy in palliative care. The importance of these sessions is the sharing of the knowledge, the value of music in their workplace and their own personal lives, that is brought into the classroom by nurses from all the varying work environments. The emphasis of the session is on the practical aspect of playing tapes and compact discs that are appropriate for music therapy and asking the class to make comments about personal likes or dislikes of the music. The reactions are always interesting and varied.

Every day I hear or witness the use of music in peoples' lives, either at work or at recreation. During these teaching sessions the nurses frequently tell me of the importance that music has in their every day lives as a means of relaxation and unwinding. As we discuss this issue, it becomes more apparent how music can benefit the patients for whom they care, as the nurses become more aware of the value of music and how it can alter a person's mood and release emotions.

The object of this particular exercise is to demonstrate the individuality of music and the differing responses to certain types of music. At the conclusion of the session, I hand out a copy of the pamphlet I have developed which lists music that may be effective for nurses to use for their patients. (Appendix1).

Even though there is overseas research to promote the effective use of music in palliative care, for example, Munro and Mount (1978); O’Callaghan (1996); (Trauger-Querry and 
Highihi (1999); Biley (2000); Hogan (2001), it is equally important to remember that not every patient will benefit from it. In my teaching sessions I explain how I introduce the concept of music therapy to patients when I am admitting them to our service. Music is discussed just as I would discuss any aspect of their care; their family, their interests, their past history. It has happened a few times, when I am admitting a patient that they speak up quite firmly about not using music in their care. Perhaps this is because I live in a small town, and many patients know who I am and what my job is, and they feel comfortable telling me. When I meet this reaction we discuss the reasons for their comment, and their preference is documented. Often the reason is the involvement the patient has had with music in their lives and at this stage of their illness they have not yet accepted the prognosis. The thought of using music when they are unwell reminds them of the fact that their life has taken another direction and they do not want to be reminded of what use to be. This is a very human response to their situation and needs to be acknowledged. From experience though, many patients change their minds further down the track and are happy to welcome music into their care. This fact is discussed in the music sessions, because like all principles of care, a nurse revisits any treatments given to assess the effectiveness and encourage patient choice, which can change frequently, day to day and sometimes hour to hour. I am still passionate about the subject and have personally experienced the positive effects of music on many of the patients for whom I have cared. Work colleagues have also related times to me when music has been valuable in their care of a patient who was dying.

Another story, told in the following exemplar provides an example of the way some families go that extra mile to reach out to someone who needs them and how nurses can build up that special patient/nurse trust that is crucial in palliative care. This patient and his family are people I remember with great admiration and fondness, because of what they did as a family.

During his illness, Mr T's family went to great lengths to express their affection for their father by using their imagination and keeping in touch in a very special way. As a District Nurse, I was privileged to be part of their caring by using music as part of the families overall plan. Mr T was an outdoor man, who had lived and worked in the forest areas of the South Island. He loved fishing, hunting and tramping. During his 
late fifties, he was diagnosed with cancer of the liver, which was not treatable. He and his partner had come to a small rural town to retire. His grown up family, consisting of two daughters who lived in Australia and one who lived in another New Zealand town, were most concerned about the distance between them and their father during his illness. Mr T remained relatively well enough to carry on with his daily activities for a number of months allowing me time to build up a good rapport with him and learn something about his life and family. This is always a special time as patient and nurse develop a partnership and learn from each other and begin to build on that personal bond of trust. We often spoke about what he wanted to achieve before he died, he was open about this and included his family in all his decisions. His one concern was his possible inability to be able to smell the outdoors and hear the sounds of nature, sensations that were extremely important to him. His daughters visited from Australia and shared some valuable quality time with their father, taking him to places he wanted to see.

On their return to Australia they sent him a very heavy concrete fishpond, which was to be set up in their father's room. Their intention was that each time someone visited and wanted to bring something, they were encouraged to bring an article that could be added around the pond to simulate a woodland area. Over the weeks, one corner of $\mathrm{Mr}$ T's room began to take on the effect of a piece of native forest, with coloured pot plants, cacti, small stone animals, goldfish in the pond, ferns, furry animals and flowers. It became such a talking point for all those who visited Mr T which he thoroughly enjoyed and appreciated.

On one of my routine visits, I made the comment that all Mr T needed now to make his woodland area complete was the sounds of birds and running water. I explained to him that I had a selection of environmental tapes that produced the sounds of mountain streams, bird song, together with softly played music. He was not really that interested in the suggestion so I did not pursue the issue. In hindsight, I realised the timing was not right, because Mr T was still able to wander outside and hear the sounds of nature in reality. 
As Mr T's health began to decline he gradually became confined to bed and was unable to sit outside in his garden. About three weeks before he died, Mr T asked me if I could bring some of those environmental tapes for him. The woodland corner of his room was now completely covered with momentos of nature and as we played the first of the tapes which featured running water and bird calls, Mr T suddenly began to reminisce about the walks he use to walk as a deerstalker and tramper. He lay with his eyes closed and described with great eloquence the beauty of the places he was walking through, the names of the trees, the calls of the different birds, the smells of the undergrowth, the vibrant colours of the bush and flowers, all that he could visualise as the sounds of the music enabled him to recollect his memories. It was one of those special moments that, as a nurse, you want to hold forever, that absolute faith and trust a patient has in you, as they share a very personal time. Both of us were close to tears as he recalled the important time of his life that was now not possible to physically experience again, the realisation that he was close to dying. As the music concluded we both sat without speaking for some time, no words were needed as the music had taken MrT to the area he wanted to be and experience again the enjoyment of his favourite place. From that day he continued to play the tapes I had supplied for him, and even asked his partner to buy some more. Every time I visited the tapes would be playing, he took great delight in explaining to me "where he was today". He had told his family about the tapes, and how, with the beautiful woodland area they had started in his room and the music he could transport himself to his favourite places most days. This was greatly appreciated by his daughters as they felt they were doing something for their father, even though they were not there with him.

A few weeks after Mr T's funeral, his partner asked me to visit, when she presented me with the environmental tapes that she had bought. She told me that Mr T had wanted me to have the tapes to add to my collection so other patients may have the same opportunity to perhaps experience what the music had enabled him to do. (Journal entry) 


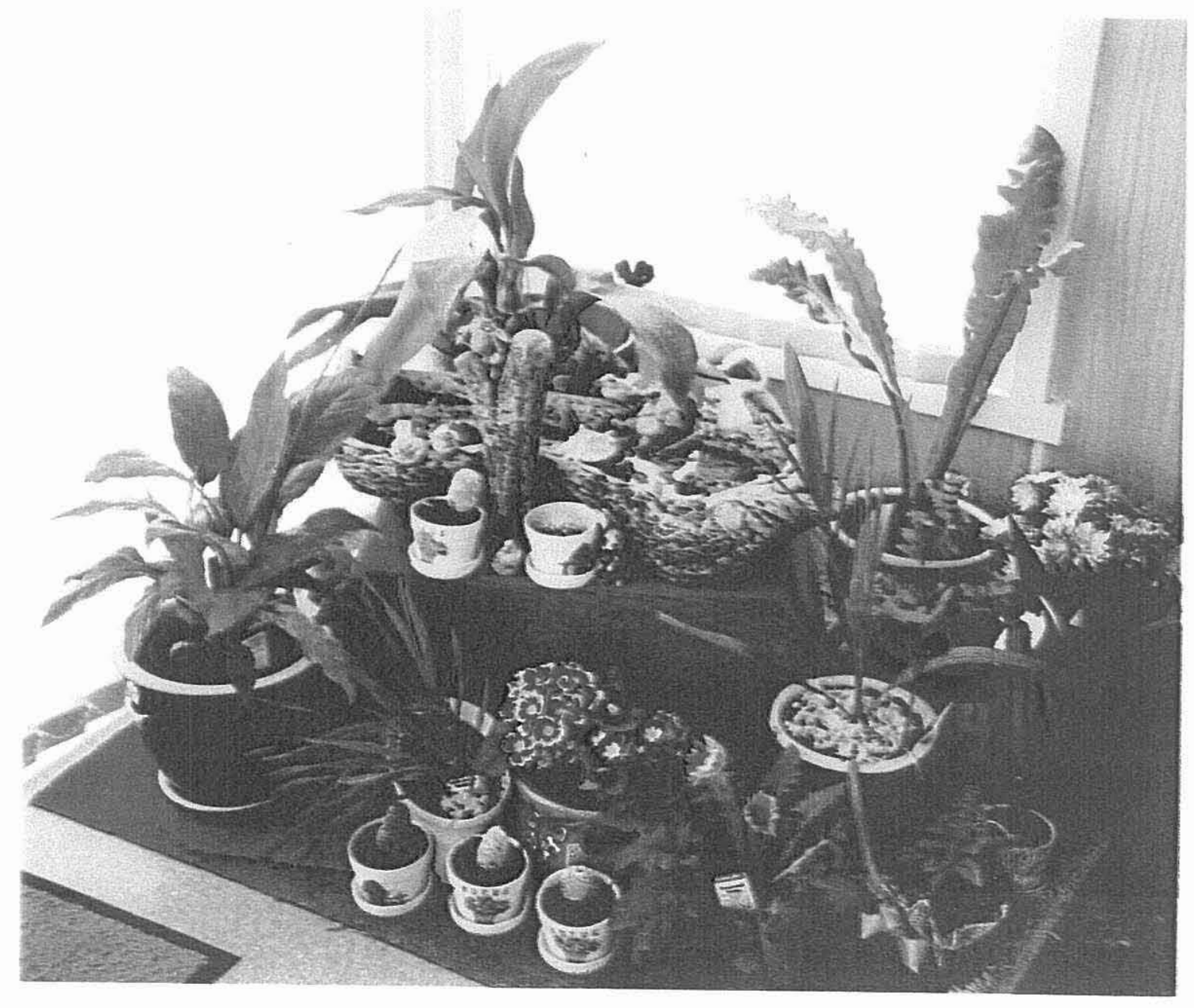

Figure 1: Mr T's environmental corner

The ever-growing, colourful, and tranquil corner of Mr.T's room that together with the environmental tapes was a source of life memories, and visualization for him.

During my music therapy teaching sessions, I frequently talk about $\mathrm{Mr} \mathrm{T}$ and his family and how the use of music was effective for him. Included are overheads of the special corner of his room. His partner allowed me to take photographs of the woodland area in his room so 
other nurses and families could have some idea of what might be achieved with a little imagination and thought about providing what is important for the patient.

This experience of using music emphasized to me how music is often able to give comfort where words are inadequate and not really appropriate. My belief in music as a modality for patients who are dying has increased over the years and I believe nurses can do much to foster this complementary therapy. If this intervention is to be applied in patient care settings, then it is nurses who have to be aware of its use, assess its effectiveness by participating or initiating research that identifies music's appropriateness.

This belief in the value of music in palliative care has been my focus for all these years. I believe I now have a responsibility to myself as a palliative care nurse, to the many patients who have already experienced the effect of music in their care, and to the nursing profession to substantiate my belief by actively researching the potential use of music in palliative care.

\section{Summary}

'Fantasia' is a section about my discovery of the use of music therapy. It explains my first encounter with Susan Munro's book (1984) entitled, 'Music Therapy in Palliative Care', which had a lasting impression on me, and initiated my interest in the topic. The section continues to explain the use of music and the effect it can have at certain times of our lives. These explanations are endorsed with stories of patients who I have cared for who have found music to be beneficial for them and their families. I have also included a photograph to give a visual display of what was achieved by one family for their father.

Munro and Mount (1984) state "A nurse, sensitive to music and its role and place in people's lives, can discover the "music person" in her patient just as the music therapist would as long as she is familiar with this concept"(p.62). Munro and Mount have encouraged nurses to take on the challenge of music therapy in palliative care if they wish to, so the teaching sessions that I have described in this section, focus on the education of nurses for this role. I will now discuss the role that music has throughout our everyday lives and the influence music can have on us personally, and as a community. 


\section{Music as part of life}

"Throughout history, music has been used in a variety of ways for therapeutic purposes, having long been recognized for its physiological and psychological effects" (Cook, 1981, p. 252). This section goes some one to explaining how music can have an impact on our daily lives, at work, at rest and purely as entertainment, and how music can be beneficial to people who are dying as it is tied closely to our emotions. To further clarify the work of a palliative care nurse and the many emotions experienced by people who are facing a life threatening illness, I have included four photographs, with explanations, to give a visual explanation of my work. I have included these photographs, explanations and song in this study because I believe nurses are in an enviable position because they have the skills and knowledge to encourage the body and mind of their patients to heal, but alongside this they have the opportunity to develop a close relationship that enables nurses to share and care for the intimate feelings of a patient too. This relationship of 'knowing' a person can sometimes be the most memorable part of a patient's care. These could be the moments when patients may be open to sharing their thoughts about complementary therapies such as music, as an adjuvant to their treatment.

\section{Music in our life}

It is important to have an understanding of the value of music in our everyday lives to better describe the benefits for someone who is nearing death, and for those who are involved with the dying person. Music has been part of peoples' lives for centuries, in fact most momentous episodes in our lives are accompanied by music. Church music is significant for many people when celebrating births, marriages and deaths. Usually significant time is spent by couples who are planning a marriage and who want to incorporate music that has special meaning for them, especially songs with words that portray the meaning of love and happiness. The traditional western wedding music is often still played as it holds sentimental value for all those attending the wedding too. Music is often referred to in relation to falling in love, especially in films and the latest popular songs. Theme music or songs from films have become a tradition in the industry, as the popular singers or musicians of the day are 
encouraged to write or perform songs or music that relate to the film, thus ensuring the success of the film as the song/ music tops the music charts. It is not difficult to recall those special songs that remind us instantly of a particular film we have seen, for example, who does not think of the 'Titanic' when Celine Dion's magical voice is heard singing the theme song, 'My Heart Will Go On', there is an instant recollection of the story and the actors.

Anniversaries of all kinds, personal and public usually involve music. The majority of couples will have a special song that reminds them of their courting days. Popular music is the culture of the young and sustains them through study, and provides the necessary background for parties and dates. From personal experience the majority of teenagers have a stereo-system in their room, which usually remains on most of the day and through the night. The use of a 'Walkman' is common amongst the young, and not so young as they pursue other activities such as walking, running, exercising, biking. More recently the ethos of enormous rock concerts, opera singing in public parks, special charity concerts, plus the fact that they are all televised, has widened the availability of different types of music to the whole world. Music is a multimillion dollar industry which has in many incidences, provided the vehicle for raising millions of dollars for worthy causes. The emotions are stirred when a large group of well-known stars perform, free of charge, to raise money for the hungry children of the world or to promote peace. The use of music in these settings taps straight in to the emotions such as happiness, sadness, security and love. Music is unique in its ability to communicate to people of different languages, cultures and ethnicity, young and old, male and female, from all walks of life.

Music is readily available today, and most people will have access to music in some form, whether its listening to audiotapes, compact discs, performing music as an individual or as a group, attending concerts, watching television, films, driving in our cars. Music is played in shopping malls to help us to relax and therefore encourage us to purchase goods. Restaurants play music for the same reasons, to encourage relaxation so we will stay longer and purchase more food. Many business firms are using music in the workplace to promote an environment that lessens the stress levels for their workers. In many ways this is exactly how music was used hundreds of years ago by the Romans, as they used music to influence the 
people of the country in their day-to-day living. This will be further discussed in the following Piece. If music can play such an important part in our living, especially in the way it is tied so closely to our emotions and our memories then surely the same effect can be achieved for someone who is dying.

The range of emotions that are experienced by palliative care patients are varied and complex. I decided to describe the scope of practice that I work within and try to include the patients emotional responses to a life threatening illness. During my four year study towards the Masters we were given the opportunity to write about conceptualising the aesthetic of our own practice. After considerable thought about defining what I believed my practice to be, I focused on music and hands. Nurses use their hands in all their dealings with their patients on a daily basis. Hands are central in greeting people as they enter the ward, guiding them to their rooms, assisting them into beds, taking recordings, assisting with hygiene, administering medication, massaging, holding their hands when they are need reassurance and when they are dying.

\section{Aesthetic of practice}

I chose to visually explain my job as a palliative care nurse by using the two mediums of photographs and music. The words of the song are words I wrote to explain some of the everyday 'pictures' I see when caring for my patients. I chose the tune, 'The Streets of London' as the music because the original words talk about, "let me take you by the hand and lead you through the streets of London". The photographs depict the aspects of palliative care that I have seen on a daily basis over many years. They are images of hands, expressing the experiences of a palliative care patient as they move from everyday life, though a diagnosis of a life threatening illness, to their reaction to the diagnosis, and finally to some degree of acceptance. I have chosen four photos to demonstrate the emotions that are expressed by some patients, but it is important to remember not all patients will move through these stages in this order, or at the same time as others, or experience the same emotions. Patient's individualism means they will make their own choices about their abilities to deal with a situation in their own way, in their own time. 


\section{Summary}

This introductory Piece entitled Introductions and reflections is a culmination of my personal life memories from childhood, through school and nursing training. These memories highlight the importance of music throughout my life and the impact music has had on my practice as a palliative care nurse over the last 20 years. This personal experience of music does affect my practice and my appreciation of how music can be used as a complementary therapy in care of the dying. Life and death experiences as a young person, and the influence of significant people in my life also contribute to my personal and professional understanding of caring for the dying.

I have explained the reason for the research, outlined the thesis questions and discussed the purpose of the methodology chosen for this research. The Piece continues with 'Fantasia', a section relating to my continuing interest in music therapy and how I perceive music in everyday life as well as in care of the dying. This section is highlighted with personal 'journey entries' of patients I have cared for over the last few years who have used music therapy.

The pictures and song included in the last section go some way into explaining the work of a palliative care nurse and the importance of developing a partnership of trust. The photographs and song are related to my own personal experiences over the last twenty years of caring for people who are dying and reflect my personal philosophy about palliative care.

There has also been discussion regarding the most appropriate people to provide music therapy and the apparent lack of music therapists in New Zealand to provide this service to palliative care patients. In a budget-orientated health care system, it is a requirement to provide the best possible care with limited resources. It may not be possible for all palliative care/hospice teams to employ a trained music therapist so this research may validate the education of appropriate staff, such as nurses, to use this important intervention. Nurses are continually being required to listen to the needs of their patients and respond to those needs. Music is often able to provide comfort and security where words are inadequate or inappropriate. Munro (1984) suggests: 
Words often fail to express the difficulties and struggles in the transition of the dying patient. The unique non-verbal qualities of music often reach deeper than anything else. The full extent of the impact of such communication between an individual and the music remains as much as a mystery as the process of dying (p.48).

Because music can have very personal meaning for people, staff need to be aware of its power to 'let the lid off' emotions and be alert to patients feeling and needs at that time. Careful assessment is imperative, as with all nursing assessment, when introducing music into patient care.

The growing upsurge in music and other complementary therapies in nursing and other disciplines, and an increase in the investigations to determine the efficacy of these therapies in providing patient outcomes, have increased over the last 20 years. Snyder and Chaln (1999, p.19) encourage researchers to "build on the findings and recommendations of previous studies in order to build the scientific base for the use of music." They further state, with the growing emphasis in health care on cost-effectiveness outcomes, and the increasing attention being given to the use of complementary therapies, it is critical that nurses be able to provide a sound basis for the use of music therapy.

This Piece has illustrated a portion of the use of music on a personal 'note' and the patient's stories enhance its use in the palliative care setting that I have been fortunate to experience. I have also described my use of musical terms and metaphor, which will encourage the readers to share in this musical composition of lived experiences and, 'soothing sounds'.

The following Piece is a literature review related to many dimensions of music therapy and palliative care. 


\title{
PIECE TWO:
}

\section{LITERATURE REVIEW}

\author{
When it happens that I am moved more by the music than the words \\ which it accompanies, I confess I am guilty of a grave sin.
}

( St. Augustine, Confessions, c. AD 600)

\section{Introduction}

This literature review explains the use of music from ancient times to the present day, and the use of music in palliative care and the art of caring, which is fundamental to nursing. It is beyond the scope of this thesis to delve too deeply into a complete history or in-depth review of all that has been written about music, palliative care and caring, but there are a number of writers whose names frequently appear in relation to the topic of music therapy in palliative care. Mount and Munro,1978,1984; Munro,1978; Cook, 1981; O'Callaghan, 1984,1996; Mandel, 1991; Lane,1992; Salmon,1993; Snyder \& Chlan 1999; Starr,1999; Biley, 2000; Hogan,2001. These researchers will provide the main source of reference for this piece in relation to the literature.

Other writers' contributions will also be included so a broad overview of music therapy, including history, quotations and palliative care will provide an understanding of music in palliative care. The section continues with a brief international history of western music to equip the reader with the knowledge of the importance that music has had throughout the ages of the known world, and its effect on people, and leaders of nations and countries. Music therapy in palliative care is introduced through the available literature, and the effects music can have on patients who are in pain, anxious and unable to communicate effectively is discussed. The second question to answer in the work is the role nurses can play in developing music in their planned care. With this focus in mind, I will review the literature relating to nursing and the art of caring, which I believe is pivotal to nursing. A critique of 
the literature and its relationship to caring will demonstrate the importance of approaching nursing care from a holistic perspective, a vital component of palliative care nursing.

A literature search was initiated using a number of sources such as the computerized CDROM indexes of CINAHL, the Nursing and Allied Health Index, MEDLINE, the Medical ONLINE Index and Proquest. The key words used to find information were, music, music therapy, palliative care, music and dying and caring. Library searches were also made by checking book catalogues related to music and palliative care. The time frames included the years 1990's to 2001. I also had the articles sent to me by the music therapist on Dr. Balfour Mount's palliative care team that I had received when I completed my Advanced Diploma. I also acknowledge that I am focusing mainly on the qualitative research that is available, and that other observational research methods may provide more thorough, scientific understanding of the topic. A further consideration is to recognise that music is used in various health care settings, and not just the domain of palliative care. However, for the purpose of this study, palliative care is my focus.

\section{Overview}

Music is not a new modality in its use for people who are dying, as it has been around for centuries and used extensively in all facets of living as well as dying. In early cultures for example Roman and Greek, music was usually associated in daily life in a prescribed way as it was used in religious exercises, festivals, and theatre. "Music, rhythms, songs and dances played a vital part in magic healing rites which were secret, either individual or shared by the whole community" (Alvin, 1966, p. 28). Music has already been recognised over the centuries as a useful tool in promoting health. A review by Maranto (1993) details how "music has influenced health from the time of the Egyptians, who used music for healing incantations, to the emergence of empirical investigations into the physiological and psychological responses to music in the $19^{\text {th }}$ and $20^{\text {th }}$ century" (p.407). 


\section{Ancient history of music}

The following pages describe music throughout the early civilisations of Greece, Rome and the influence music had on western religions of the past. This background will explain the progression of music through the centuries to the present to illustrate the fact that music and medicine is not a new concept of the $21^{\text {st }}$ century but has been in existence for many years.

\section{Greek history}

Music had divine beginnings in Greek mythology as it was linked to gods such as Apollo, the god of music and medicine (Alvin1966). The peoples of this time held music in awe, as it was linked to magical power, healing the sick, and purifying the mind and body of evil spirits. Music and musical instruments were thought to be gifts from the gods, "the Greeks used it to address the gods and to propitiate them, hoping that it would reach them and they would respond" (Alvin, 1966,p.36). There are well known accounts of the power of music being effective in healing the mind. Two accounts occur in the Bible including the story of David playing his harp to soothe the mind of Saul (1 Samuel 16: 14-23), and the walls of Jericho tumbling down because of the trumpet playing of Joshua (Joshua 6: 12-20).

The western world of today has developed the ancient culture of the Greeks and Romans, which includes art, literature, philosophy, and music and studied the value and importance these played in their lives.

Greek and Roman music was lost to a certain extent during the Middle Ages, although their art literature, statues and buildings have stood the test of time and are visible proof of their way of life.

According to Grout and Palisca (1996), two musical historians, who have studied and written about the history of music, music development throughout the world and the periods of music:

about forty complete pieces or fragments of Greek music have been recovered, ranging over about seven centuries. No authentic specimens of ancient Roman music survive, but we know from written accounts, bas-reliefs, mosaics, paintings, and 
sculptures, that music occupied an important place in Roman military life, theatre, religion and ritual"(p.1).

The instruments of the time were a stringed instrument called a lyre and a single or double reed instrument called an aulos. Often these instruments were used to accompany the singing of poems, at the beginning of the performance of Greek dramas. From the sixth century BC both these instruments were played as solo instruments. "An account of a musical competition held at the Pythian games in 586 B.C. tells of Sacadas playing the Nomos Pythicos, a composition for the aulos that musically portrays the combat between Apollo and the serpent Python" (Grout \& Palisca, 1996, p. 2).

As is evidenced by these early writings there was a common theme about the value of music enabling stories to be told, through the readings of poems, and the varying ways music could be used to stir the emotions by performing at religious ceremonies or in theatre. There was also a belief that music "possessed moral qualities and could affect character and behaviour" (Grout \& Palisca, 1996, p.6) This is exactly what music therapists of today try to achieve when matching music to the individual's needs, particularly in palliative care where the use of music to promote relaxation may reduce anxiety and pain. "Aristotle believed music to be an emotional catharsis, reasoning that since the soul rules the body, and music is akin to the soul, appropriate melodies, harmonies, and instruments will affect both the body and the soul" (Meinecke, 1948, cited in Cook 1981, p. 254 ). Homer recommended music to avoid negative emotions such as anger, sorrow, worry, fear, and fatigue (Cook, 1981). These early philosophers were aware of the potential power that music could have over the mind and body, something that music therapists and nurses of today are rediscovering in their care of patients who are dying.

\section{Roman History}

It is thought that Roman music did not survive because the early Christian church leaders did not want the memory of the music and its affiliation to theatre, festivals and primitive rituals 
to continue ( Grout \& Palisca, 1996 ). The Romans also used music specifically to influence the behaviour of their citizens as it was included in all public gatherings and ceremonies, "Cicero, a Roman writer, felt song and music could influence Roman behaviour" (Cook, 1981, p. 254 ). Alexander the Great believed "that it (music) created true men, filling them with inspiration and energy. It was used to arouse armies to battle and to calm them down afterwards"(Meinecke, 1948, cited in Cook, 1981, p. 255). There are reports of competitions, festivals, orchestras and large choral groups, especially in the reign of the emperors who were interested or practised music themselves. Nero was one emperor who was well known for his musical abilities ( Grout \& Palisca, 1996). As the Roman Empire declined in the third and forth centuries, so did the extravagant musical productions that had been part of the great days of the Empire. Quietly in the background another culture was steadily growing and spreading its beliefs, the Christian church. The church did bring with it a history of Greek music but it did not want to encourage Christians to perform or listen to music just for enjoyment or pleasure as had been the case with the Greek festivals, competitions and performances. The church did not want their members to listen to music that reminded them of their non-Christian past.

\section{Christian Church}

The development of music in the early church was seen as a part of the worship of Christians as they sang daily psalms and sacred texts, "hymn singing is the earliest recorded musical activity of the Christian church" (Grout \& Palisca 1996, p.19) and "hymns and music carried the patient's supplication for help and healing" (Alvin,1966, p. 39). The early church writers were powerful, clever men who wrote guidelines for the church and writings about the translation of the Bible stories for the 'ordinary' people to understand. The value of music, they believed, "lay in its power not only to inspire divine thoughts, but also to influence for good or evil the character of its listeners" (Grout \& Palisca, 1996, p. 25). Music was seen only as a means of expressing the written word of Scriptures and therefore only suitable in a church setting where the thoughts of the people would remain pure. Even then there was an understanding of the power that music had in its ability to stir the emotions, causing people 
to laugh or cry, to feel happy or sad. "Thus man became aware of the power of music over his psychological and spiritual state, since it could arouse the best in him, harmonise and purify his emotions, and even sublimate his instinctive urges" (Alvin,1966, p. 41). Music, instruments, the development of harmony, and singing with an accompanying instrument continued throughout the Middle Ages and spread across the known world as invading countries brought their own music with them. It is easy to understand why music can be seen as a 'bridge to communication' when looking back on all those centuries. Music was played to rid the body of evil spirits, was thought to have magical powers according to (Alvin, 1996). Music was able to perform miracles, soothe the mind and body, impart stories of wars, love and travels, recount ways of life, offer entertainment. It could be said that music is played for exactly the same reasons today, in the $21^{\text {st }}$ century.

\section{Music therapy as a concept in health care}

"Recorded history relates stories of man's use of music to soothe the soul, mind, and body" (Magill-Levreault, 1983, p. 43). From the Renaissance onward music and its effects, became an interest of the medical profession. The physician, Dr. Robert Burton was one of the first of this period to "observe and write on the healing powers of music, especially concerning melancholia" (Alvin, 1966, p. 53). Studies were also carried out at this time related to "physiological effects on pulse rate, respiration, blood pressure, and digestion" (Munro, 1978, p. 258). The laboratory studies were seen as accepting music as a therapy.

Even Florence Nightingale recognized the power of music to aid the sick. Nightingale (1859) noted the effects of different types of music, "recommending wind instruments including the human voice, and stringed instruments, capable of continuous sound, have generally a beneficial effect...an air...will sensibly soothe"(p.57). One of the first uses of music in a hospital setting was to strengthen the morale of wounded or shell-shocked veterans of World War 11 (Van de Wall, 1948 as cited in Cook, 1981). Music has been used in a variety of areas of medicine to achieve therapeutic results. It has been used for its soothing effects as background music in hospital waiting areas, operating rooms, delivery rooms, nursing homes, and physician offices. Dentists were one of the first professions to use music in their 
surgeries, realising that music was useful in relaxing patients and diminishing the sound of the drill (Cook, 1986). After the invention of the phonograph in the 1800 s, hospitals used recorded music to aid sleep, to ally anxieties associated with surgery, and to assist with the administration of local anaesthesia (Cook, 1986 ). Snyder et al (1999) reports:

that there has been an increase in the number of published research articles related to music therapy between the years, 1980 through 1996. Only one paper was published in 1981. The number increased to eight in 1990 and 17 in 1995 (p.4).

This increase indicates the growing interest in music and other complementary therapies in nursing, and other disciplines, and an increase in investigations to determine the efficacy of music in achieving patient outcomes. The above report confirms the statement made regarding the available information related to music therapy when I undertook the first literature search and review in the early 1990s. The increase in the data available now is indicative of the growing interest in music as a therapy for patients.

\section{Music therapy in palliative care}

Of the many articles I have collected and read over the years relating to music therapy, there are a number of writers, for example Munro and Mount (1978,1984); Munro, (1978); Cook, (1981); O’Callaghan (1984, 1990, 1996); Salmon (1993); Starr (1999); Snyder and Chlan (1999); Biley, (2000) and Hogan (2001); who have all consistently produced writings and research about the topic. Of significance also are the growing number of qualitative studies, particularly phenomenology, using patient stories to explain the use of music in palliative care. As mentioned it is beyond the scope of this work to provide a complete theoretical and historical description of music therapy in palliative care. However, an overview of the principles and contributions of those authors who are recognised as leaders in the field of music therapy will be included, to provide some background to the use of music as a modality for someone who is dying. 
The first proponents of the use of music in palliative care were, Susan Munro, a Canadian music therapist, and Dr. Balfour Mount, a palliative care specialist from Montreal, Canada in 1978. It has been recorded that "the Cluney monastery developed a series of infirmary practices concerning the care of the dying (and the use of music) that predate palliative medicine by 800 years, (Schoeder-Sheker, 1993, p. 37).

Munro and Mount (1978, p. 258) described "how music could increase patient's physical, social and spiritual wellbeing". The emotions that are experienced by patients at this stage of their journey are extremely difficult to share and finding ways of expressing these feelings to their family and the staff can cause frustration. The use of music can be beneficial at this point and assist the patient to sometimes "express the inexpressible" (Huxley, 1931, p.19).

The research to support this theory of music in palliative care has grown considerably over the last few years, as the rush of technological advance has become so expensive, and people are seeking complementary therapies to aid healing, alongside traditional medicine. Articles include music facilitated pain control (O'Callaghan, 1996), music to relieve anxiety and promote relaxation (Mandel, 1991), guided imagery (Salmon, 1993), music for children with cancer, (Daveson, 2000), music to support counselling, and (Bailey, 1984), music for caregivers/staff. Most of the articles originate from the United States of America (US) and the United Kingdom (UK), where the majority of Hospices and palliative care services employ music therapists.

\section{Explanations of the effect of music on physiology}

There have been a number of attempts to explain the effects music can have on the physical body. Janet Cook's (1986) article entitled, 'Music as an intervention in the oncology setting', reports on an address given by Esther L. Gatewood, Ph.D., in 1920. It states: 
According to this theory (neurological process) two separate stimuli which enter the nervous system at the same time will neutralize each other, with the stronger one making the impression. If one's attention is focused on the stimulation of music, all other stimuli may be negated ( Cook, 1986, p. 24).

In 1989 Fernandez and Turk, (sixty years later) support the same concept, "that competing stimuli (distraction) reduce pain perception. They propose that one's capacity for attention is finite when exposed to stimuli". They conclude this after their, "meta-analysis study of the utility of cognitive coping strategies for reducing pain perception" by using imagery strategies which included the use of thinking about music (Fernandez \& Turk, cited in Cook, 1989, p. 123-135). Brody offers a further explanation in Cooks article.

Music appears to influence the brain network that determines emotional experiences, (the limbic system). Aesthetic pleasure received by the right brain can cause the pituitary gland to release endorphins, the body's natural opiates; thus pain is relieved. The level of catecholamines (such as adrenaline) seems to be lowered by soothing music; thus, the levels of the heart rate, blood pressure, and free fatty acids may be lowered. (Brody, cited in Cook, 1986, p. 24).

More recently there has been a study(2001) which focuses on the bodies immune system by measuring salivary immunoglobulin A ( $I$ Ig A) as a means of assessing stress and mood levels in patients with cancer. In a quantitative pre-post test pilot study written about the therapeutic effects of music therapy at a cancer help centre in 2001 by Burms, Harbuz, Hucklebridge and Bunt, they concluded that, "statistical evidence supporting both the psychological and physiological measures taken throughout this study strongly indicates there is a link between the effects of music therapy on positive emotions and the immune system of cancer patients" ( p. 11).

A second quantitative study undertaken by Evans (2002) consisted of a systemic review of nineteen studies to evaluate the effectiveness of music as an intervention in hospitals. For the studies to be considered for the review they had to have investigated the use of music, the participants were adult hospital patients and used a random controlled trial design. They also 
had to measure outcomes such as "anxiety, satisfaction, pain, mood, and vital signs" (Evans, p.1). The study was further divided into two categories of patients, those who were inpatients in a hospital setting, and those who were receiving out-patient procedures or treatments. The group did not include any palliative care patients but initially did include some patients who were receiving chemotherapy, but they were excluded following critical appraisal. A summary of the evidence indicated that those patients in hospital appeared to benefit to some extent from the use of music.

Hospital patients noted that the use of music did reduce their anxiety, produced a small reduction in the respiratory rate and improved their mood. Whereas, those patients listening to music, while having unpleasant procedures as out-patients, did not experience a reduction in anxiety, nor did they experience any impact on heart rate or blood pressure. Neither did they experience any effect on the severity of the pain. There was some suggestion that during unpleasant procedures music may reduce the need for sedation and analgesia. A further consideration is that the patients were only exposed to one episode of music whereas in most hospital settings music would be offered on a regular, personal basis over a period of time. It was suggested at the conclusion of this study "that this aspect of using music over time was an area that warranted further investigation" (Evans, 2002, p. 16).

As evidenced by the this literature review there have been a number of writers who have already undertaken research in regards to music therapy, which highlights the interest that the medical and nursing profession have in this modality. Because of music's non-threatening nature it can be used in a variety of clinical settings.

People who are dying, and their families must deal with a multitude of difficulties, including role changes, financial problems, side effects of treatment, pain and thoughts of death. Common emotional reactions to these problems are fear, anxiety, resentment, anger and depression. Although these thoughts are normal, these feelings are sometimes suppressed as being unacceptable or repressed in an attempt to maintain a courageous front. (Cook,1986, p.25). 
Music can be used in a variety of ways to deal with these emotions. Background music can aid in the creation of an atmosphere conducive to such expression. Familiar and pleasing sounds reminiscent of the normality of life beyond the hospital or home walls can act as a 'bridge for communication'. Particularly in the hospital setting, the use of music can sometimes take away that feeling of insecurity in unfamiliar surroundings. Patients' relatives also feel more comfortable visiting, as there is a distraction in those awkward moments of silence.

Munro's (1984) book is mainly comprised of stories about the effective use of music for dying patients. Many of the stories mention the decrease in the amount of pain relief needed when music was introduced, the sharing of stories with family members, (that became extremely important after the patient had died), the companionship of music for those patients on their own, and the releasing of emotions when music was played Munro (1984) states,

Only if we contemplate music as an integral thread running through life will we see all its potential as a therapeutic agent in terminal care. The dying process affects the whole person; body, mind, heart and soul. Music's intricate association to all of human experience throughout the ages enables it to touch the "total person" (body, mind, heart and soul) like a mythic artery.

\section{Influence of music on pain}

Pain is a huge topic and it would be unrealistic to assume that all the available data could be searched and mentioned in this work. A general overview of pain will be discussed but the main focus will be related to those studies which talk specifically about pain, and the holistic approach for pain management and music therapy. 


\section{Patient's pain}

The individualism of pain and its consequences for the palliative care patient are a documented fear of many patients. In a 2001 multicenter trial involving more than 9000 seriously ill patients, focusing on communication with patients at the end of life, Quill (2001) reported " $50 \%$ of the patients who remained conscious at the end of life experienced moderate to severe pain at least half the time in their final three days of life" (p. 3). According to Wright (1987), an American nurse at Rush University College of Nursing, Chicago, who has written about the use of therapeutic touch in the treatment of pain states:

It appears that under the current system of health care, treatment of pain is rarely a priority to the health care professional. However, most patients indicate the treatment of pain is at or near the top of their priority.

(1987, p. 706).

It is worth including two well documented definitions of pain so that nurses and doctors, who work in palliative care, keep focused on what pain is to a person, and not loose sight of the impact that pain can have on our patients. Merskey and the International Association for the Study of Pain (ISAP) (1979) state " Pain is and unpleasant sensory and emotional experience associated with actual or potential tissue damage, or described in terms of such damage". (Merskey and the ISAP sub-committee on Taxonomy, 1979, 249-52). McCaffery (1972) recognises the subjectivity of the pain experience and states "Pain is anything the experiencing person says it is, existing whenever he says it does" (p. 11).

Nurses are usually the primary caregivers and therefore are in the unique position of being with patients most of the time. This close relationship enables nurses to identify with patients concerns, and fears, and the raft of other symptoms that they may experience. The correct assessment of pain as a symptom is vital so that appropriate information and treatment can be effective. Palliative care patients often experience the concept of 'total pain', which can include physical, mental, emotional and spiritual pain. MacLeod (1998) describes in a conference paper, entitled 'Assessment and Management of Pain at the End of Life', presented in Dunedin, New Zealand. 
Three quarters of people with advancing cancer will experience pain, which of course means that one quarter will not. Of those that have pain, one-fifth will have only one pain. One third will have four or more pains and this is important to remember when making an assessment. (p. 4)

\section{Music therapy and pain}

Pain is a major concern for patients, as already mentioned, as it is for the people caring for them, particularly for those patients in the terminal phase of an illness. A vicious circle of complications can be averted if pain, whether, physical, psychosocial, emotional, or spiritual can be assessed and treated appropriately. From personal observation of palliative care patients over many years, pain can impact on the patients quality of life as it can prevent mobility, decrease appetite, cause nausea and insomnia, make communication difficult with staff and family members, and exhaust patients.

Other professionals who work in the field of palliative care substantiate this observation. O'Callaghan (1996), an Australian music therapist with many years of experience confirms with her statement about patient's pain and the need for teams to use the holistic approach to care. "The origin of an individual's pain experiences are multifaceted, hence palliative care team members need to be able to draw upon a wide variety of pharmacological, physical, and psychological modalities for its effective treatment"(p. 48). Music can contribute to relieving pain in many palliative care patients. There has been growing interest in the use of music as a therapy in the treatment of pain throughout the last 20 years by a number of researchers, for example, O’Callaghan, 1989a; Martin, 1989; Mandel,1991; Lane 1992; and MagillLeverault, 1993.

The physiological effects of music have been investigated and found to be beneficial to animals and plants as well as to humans. (Tompkins, 1973, cited in Cook, 1981) "found that sound waves affect the growth, flowering, and seed yield of plants" (p.257). Alvin (1996) reports the response of animals to music when stating that "Animals are also influenced by the sound of music, as demonstrated by the response of a cobra to the sound of a flute, or the fact that cows generally yield more milk when background music is played" p. 23). In a 
paper written by Cook is a review of the experimental literature through the 1930 s related to studies about the effects music can have on the physiological processes. Two writers, Diserens and Fine (1939) came to the following conclusions about music as a therapy:

Music increases bodily metabolism, increases or decreases muscular energy, accelerates respiration and decreases its regularity, produces marked but variable effects on volume, pulse, and blood pressure, influences the internal secretions (p. 253).

As with all treatments prescribed for patients it is imperative that each person is assessed as an individual as they will respond in an individual way. Music therapy is no exception. Farnsworth (1969) refers to this and cautions against generalisation about the use of music, stating "From what is known, we should expect enormous individual differences to exist in physiological responses to music" (p. 213).

One researcher who frequently appears in the literature related to music therapy and pain is, Bailey, and who now writes under the name Magill-Levreault. According to MagillLevreault (1993)

Music can engage, activate and alter affective, cognitive and sensory processes through distraction, alteration of mood, improved sense of control, the use of prior skills and relaxation.... The diverse qualities of music potentiate its effectiveness as a medium to be used to soothe pain and ease suffering. (p. 47)

Bailey's article, (2000) 'The effects on patient wellbeing of music listening as a nursing intervention', gives a systematic review of the studies related to music in most health settings, including palliative care and cancer-related pain. In a study, included in this article by Zimmerman et al (1989),

Forty patients with chronic cancer related pain were exposed to an experimental condition (darkened room, lying down, listening to music with the initial suggestion 
that this would help them to relax) or acted as a control (using the same conditions without the music). Music had a significant effect on reducing the amount of reported pain. (p. 672).

Two researches who have written many accounts of the value of music in palliative care are O' Callaghan (1996) and Munro (1984). Both music therapists recount stories of patients they have cared for who have found music beneficial and how important it is to acknowledge the patients choice of music.

O'Callaghan (1996) provides case studies of creative music therapy techniques, which can be helpful in alleviating pain for patients and those families, and friends who are with them. One story conveys how music can evoke pleasant memories of past experiences that may lessen anxiety and therefore reduce pain.

A 58-year-old Greek lady was admitted in extreme pain, groaning and rigid all over. She did not have any family and only one friend known to the hospital. She was referred to the music therapist to see if she could assist in her pain control. The music therapist played a tape of Nana Mouskouri singing tranquil Greek songs and she immediately relaxed, stopped groaning, smiled, and sang along. This was played for the next two weeks up till her death. (p. 48).

O'Callaghan (1996, p. 47) also offers advice about the "adverse effects" of music and the need for careful assessment, especially those patients with "cerebral metastases or lesions from ischemic attacks". Sometimes those patients who once enjoyed music as part of their life, now find it upsetting to listen to. Patients with Alzheimers will occasionally show aggression or distress when a particular piece of music is played. Because it is not always possible to discuss issues with these patients, music chosen by someone else may be totally inappropriate, and possibly recall personal memories that will cause anguish or sadness.

Music has different meanings for each individual and as professionals, nurses need to respect the patients wishes. Music that appears appropriate for staff, or families will not necessarily 
be the choice of the patient. Music preferences can change throughout life and also during the time of an illness. In her book Music Therapy in Palliative Hospice Care Munro (1984) presents in one of her case studies the story of a young man with lymphocytic lymphoma who was admitted with severe back pain, intermittent colicky abdominal pain, intractable nausea, vomiting, and emotional stress for the patient, family and staff. During previous admissions to the hospice he had good results with music therapy in lessening his anxiety and his pain.

His choice of music at those times had been 'rock music'. As his pain and agitation increased he became intolerant of 'his' music. The music therapists' notes following the first use of music, which included a tape with selections of Bach, Schubert, and Mozart read: " The patient was frantic to get more medication but was also tense and afraid that he couldn't relax at all anymore. The music and relaxation techniques helped to calm him in approximately ten minutes without extra medication" (p. 108).

This tape was played repeatedly at the patient's request in the last days of his life and discusses the way music was able to control his pain and anxiety. "Analgesics were discontinued, and the patient was managed with relaxation techniques and music therapy only. He was quite comfortable, not anxious and able to talk with his family and visitors". (Munro, 1984, p.108).

The impact of music on people's lives can differ vastly. The challenge of using music for someone who is terminally ill, is that, as health professionals, we need to be aware of the hidden qualities of music. The ability that music has to 'lift the lid' and expose emotions or memories that perhaps the patient and or their family were unaware of. This exposure of emotions needs to be supported by staff and families and not just seen as music being the cause of someone crying or becoming upset. This opportunity to communicate with staff or family may be the first or only chance the patient will have to express fears, and concerns or share memories with those they love. At all times nurses need to respect the patient's own way of expressing emotions. 


\section{The use of music to reduce anxiety and encourage communication}

As nurses gradually develop their own theories of practice, and move away from the medical paradigm, the patients receive the benefits. Nursing theories such as those of Benner, (1989) and Watson (1995) are informing nurses about the importance of developing partnerships that enable the patient and nurse to have equal participation in planned care. Communication is the basis of this partnership, and is paramount if this human-to-human process is to eventuate. When people are dying the range of emotions they experience is vast. Feelings of "shock, disbelief, denial, anger, lack of control and a sense of loss" are some mentioned in the literature (Hogan, 1998, p. 24). Verbalising these emotions can be just as traumatic as experiencing them, this is where music can sometimes be valuable in "expressing the inexpressible" (Huxley, 1931, p. 19).

Music therapy in the care of cancer patients and their families, aims to promote comfort, develop meaningful communication, and resolve issues. During a music therapy session Bailey (1984) suggests "The music therapist aims to soothe and energise, stimulate the expression of thoughts and feelings, help integrate families and persons in to their social environments, provide sensory stimulation, and diminish pain".( p. 6).

\section{Patient anxiety, communication, and music}

Communication is the foundation on which people build relationships, friendships and connectedness to other human beings. When palliative care patients are dealing with overwhelming emotional issues, sometimes the ability to express these feelings becomes difficult to communicate to others. Music therapy may be an avenue for some patients to verbalise these feelings and regain some connectedness to their family, friends and the people caring for them. O’Callaghan, (1996, p. 4) suggests “in palliative care, music therapy offers non-intrusive opportunities for people to connect with and express their feelings in their own creative way and at their own pace. It may foster supportive interactions between the patients and their loved ones."

Since Mount and Munro first wrote about music therapy and palliative care in 1978, there have been many writers who have taken up the challenge to research the topic. In the areas of 
reducing anxiety and assisting communication, some of the following names appear frequently in the literature related to music therapy. Munro and Mount, 1978; Munro, 1984; O’Callaghan, 1989,1996; Beck, 1991; Lane, 1992; Snyder and Chlan, 1999; Biley, 2000; and Burns et al,2001.

According to Snyder and Chlan:

Music therapy has been tested extensively alone or in conjunction with other interventions for purposes of anxiety/stress reduction and relaxation promotion. A variety of physiological and psychological outcome variables were used to measure the achievement of this outcome $(1999$, p. 5).

Music therapy has been used in many clinical settings to ally feelings of anxiety, an emotion that is frequently experienced by palliative care patients as they deal with the multitude of changes in their lives and those of their families. Updike, (1990, cited in Snyder and Chlan, 1999) reports

Various psychological measures (heart rate, respiratory rate blood pressure) have been used to determine if music therapy produces relaxation and stress reduction. Blood pressure decreased and mood improved following subject-selected music listening in a small sample of intensive care unit patients (p.6).

Beck's (1991, p.1327) crossover study to evaluate the use of music for 15 palliative care patients with pain, who were receiving analgesics, using the McGill Pain Questionnaire found "support for the use of music as an independent nursing intervention to relieve pain". A further study combining quantitative, (using saliva testing) and qualitative, (group interviews) methods in 2001 at a Bristol Cancer Help Centre, "investigated the potential use of music on positive emotions and the immune system of cancer patients" (Burns, Harbuz, Hucklebridge \& Bunt, 2001, p.48). The 29 participants were residents at the centre and all had cancer at varying stages. All the patients had, or were going through "surgery, radiotherapy, chemotherapy, hormone therapy, immunotherapy, or a combination of these 
therapies" (Burns et al, 2001, p. 50). The research was done in two stages over a three-month period. The conclusion of this study indicated that:

statistical evidence supporting both the psychological and physiological measures taken throughout this study that strongly indicates there is a link between the effects of music therapy on positive emotions and the immune system of cancer patients. This evidence is further reinforced by the qualitative data collected at the focus group discussions (p. 58).

Patients with brain tumours or cerebral metastases or those who have neurological disorders find their decreased cognitive ability extremely frustrating. They are usually keenly aware of what they want to communicate, but because of their impaired brain function unable to express it. The frustration is further compounded for the patient as they watch their family members, friends and staff strive to understand what they are trying to verbalise. O'Callaghan (1996) offers some explanation of how music may be effective for these patients in assisting them to communicate with those who are important in their lives.

Broadly, for most people, language is mainly the function of the left hemisphere and music is more a function of the right hemisphere of the brain. When using music and language therapeutically with brain-impaired patients, one can access wider ranges of their cognitive function than when using language alone. A multisensory music therapy approach offers a heightened opportunity to access intact neurological pathways, often enhancing supportive communications between brain impaired severely ill patients and their families, friends, and caregivers (p.14).

Taylor (1995) qualifies this statement, in her explanation of how the brain's hemispheres affect communication. She states "the left brain communicates more literally and verbally, the right brain more metaphorically and nonverbally or artistically. Like binocular vision, the use of both kinds of language can give depth to understanding a situation or subject" ( p. 42). 
O'Callaghan (1996) concludes that "the use of language and music offers expanded opportunities for these people to experience positive aesthetic experiences and to communicate with others" (p. 15).

Salmon (1993) uses a case study to emphasize the nonverbal attributes of music, and how patients may use music to express what they are feeling. Her patient was a young man with musical ability, who rarely spoke about his feelings, and who had a malignant melanoma. After some hesitation, the patient agreed to improvise on the piano with the music therapist playing the flute.

He began melodically but as the music unfolded, it became more and more atonal, arhythmic, fast and loud. At one point, he was practically pounding on the piano, (which the music therapist interpreted as tremendous rage). After a few minutes of this, he abruptly changed the music, returning to a chorale-like harmonization in $\mathrm{C}$ major. It ended quietly and peacefully. Then he suggested that they play spirituals, and ended the session with the song "Let it Be" (pp. 5 \& 6).

Salmon states: "Although this patient rarely verbalised his feelings, he was able to express his sadness, anger, spirituality, and hope through music-making" (p. 6).

The type of music played of course varies, as much as the impact of the music on the individual. This is where careful musical assessment is required by the person caring for the patient, for example, the place music has in their lives, and that of their family, and the preferred type of music, and also what music they do not like. Enduring 30 minutes of music that is unpleasant to the ear, and not able to be stopped by the patient can cause extreme agitation and annoyance. O'Callaghan (1996) suggests "that tapes should be trialled with patients first. For example, some patients find particular accents annoying" (p.11). The tempo of the music is important, as it has already been noted in research mentioned in this work. Lane (1992, p. 864) states "music can have a definite effect on increasing or decreasing blood pressure and heart rate. I offer audio-cassettes of music with tempos of 6072 beats per minute that help to stimulate relaxation and reduce anxiety". 
Biller et al, (1974, cited in Biley, 2000) conducted research related to two songs considered to be 'happy' and 'sad' music and the possible effects of anxiety, using the State-Trait Anxiety Inventory. There was " no significant differences in state or trait anxiety between the happy or sad songs. However, there was a strong tendency for sad music to lessen state anxiety more than did happy music"(p.674). It was concluded from this research that using 'sad' music appeared to be more appropriate in reducing anxiety.

The above mentioned studies and results do not conclusively support the use of music in reducing stress or assisting in communication, mainly because they consist of small sample size. However overall the effects of music appear to have a beneficial response for patients in the palliative care setting who are suffering from anxiety and communication problems. The increase in the amount of research literature related to music therapy in the last 20 years gives a positive indication of the interest in music as a treatment modality.

\section{Nursing and the art of caring}

Caring in nursing has been traditionally seen as what nursing 'is about', but in the world of technological medical advancement some professionals have lost sight of the meaning of caring. This section of the literature will review the ways that nurses can revisit the art of caring in relation to palliative care in the $21^{\text {st }}$ century by focusing on the theories that have been developed by nurses for nurses, with particular focus on holistic care. Caring appears to have been devalued and seen as unimportant in this modern era of advanced technology, and budget driven health services. There are a number of writers who have written about caring (Benner and Wrubel, 1984; Watson, 1998; Leininger, 1986; Montgomery, 1993; Street, 1995).

\section{Nurse's concerns related to caring}

The definition of care as defined in the Collins English dictionary states, "to be worried or concerned; have regard or consideration for; to look after or provide for; careful or 
serious attention; protection or charge; affection or consideration for; to provide physical needs, help, or comfort for (Collins Dictionary, 1990, p.121). Benner (1991) also offers a definition of caring. "Care is defined as the alleviation of vulnerability; the promotion of growth and health; the facilitation of comfort, dignity, or a good and peaceful death" (Benner, 1991, p.2).

In our rapidly developing technological world, care is devalued. As Leininger (1986) points out, "the economic value of observing, comforting, and remaining with clients is receiving considerable less attraction and less financial value compared with high technology in medical services" (p.9). The word 'care' has been undermined through advertising everything from promoting cat food to washing wool. Another definition by Manning (1992) explains the importance of partnership in caring "the ethic of care involves a morality grounded in relationship and response"( p.1). As professionals, nurses must not lose sight of the importance that caring has for patients, especially those whose illness cannot be cured, even with advanced skills and knowledge. Data collected from New Zealand Hospices in 1998/1999 indicate:

Hospices cared for 4886 people who were dying; approximately 90 percent of these patients had a diagnosis of cancer. This would also suggest that there were 1800 other cancer patients who required palliative care, and who were possibly not receiving palliative care or are receiving care by other providers, who are likely to be hospitals.

(New Zealand Palliative Care Strategy, 2000, p. 34)

With the increase in the expected life span, there are more elderly people, more patients with chronic diseases, and more people requiring support in the process of dying. (New Zealand Palliative Care Strategy, 2000) states in the issues relating to lack of palliative care approach in New Zealand:

With $39 \%$ of cancer deaths occurring in public hospitals, the palliative care approach perhaps appropriate to the dying person's care may be lacking in the 
hospital environment. Clinical hospitals have a strong curative, interventionfocused culture; institutional settings for the care of older people, and those with degenerative conditions offer scanty provision of palliative care (p.45).

Often these people are seen as a drain on medical resources because technology has failed them, but they still require understanding and a feeling of worth in their community, they need to be cared for. Watson (1998) believes "that we are moving out of an era in which curing is dominant into an era in which caring must take precedence" (p.175). The biomedical model is still to the forefront in most institutions but the price of providing this advanced technology is increasing all the time. This does not mean nurses are not involved in this model of curing and the knowledge that it requires, but the commitment to care is just as important. This is the key focus of Benner and Wrubel's work (1989) in which they discuss the commitment to the primacy of the phenomenon of caring in the development of knowledge. "In studying what makes expert nurses effective, we conclude that mere technique and scientific knowledge are not enough" and "caring is nonetheless central to effective nursing practice" (Benner and Wrubel, 1989, p. 4). Nurses are fortunate because they are in the position to work alongside patients and are able to provide additions to the medical model, namely the holistic approach to understanding the needs of patients, one of the meanings of care.

Also evident today is the added problem of not having sufficient staff to deliver this care because of the staff shortages and the casualization of the workforce. The casual workforce does not always have the luxury of building a rapport with patients, as they are not working on a regular basis to build that vital trust that only develops over continual contact. Wilkinson (1995) reported that "environmental stressors such as work overload, lack of resources and staff shortages are increasingly identified by nurses as important factors influencing their ability to provide passionate care to cancer patients" (p.70). Many nurses are leaving the workplace because they feel unable to practice their art, and are disillusioned about the lack of value placed on nursing. "Some feel that this shortage is at least in part a result of the devaluing of care in the present health care system" (Montgomery, 1993, p.11). 


\section{Developments in nursing knowledge}

There has been a move to redefine nursing in the last 15 years. According to Newman, Sime and Corcoran-Perry (1999, p. 21) "recently there has been concentrated emphasis on two concepts as central to nursing: 'health and caring' and 'the concept of caring' also has occupied a prominent position in nursing literature and has been touted as the essence of nursing". Theorists, who have considered caring in relation to health include, Benner (1985); Leininger (1988); Watson (1985) and Montgomery (1993).

The difficulty for the writers has been to develop a concept of care that can be measured and scientifically proved. This is related to the historical association that nursing has as being a female domain, and the nurturing that is seen as caring that women provide naturally. This does not mean women have to abandon these nurturing activities as explained by Tong (1998), who believes "the world would be a much worse place tomorrow than it is today were women to suddenly stop caring" (p.150).

Nurses are not encouraged to document their caring, or discuss it, so the basis for research on the care that nurses give is lost. As effective professionals in the $21^{\text {st }}$ century, nurses need to combine the practical art of nursing with the established theories so nurses can promote understanding and give definition to what they actually do. As Meleis, (1991) suggests:

"scholarliness combines theory, research, philosophy, and in disciplines like nursing, practice"'(p116). The knowledge of dealing with people who are coping with illness and then recover, and the life process of those who do not recover are all lived experiences, which develop and extend nurses as practitioners. As nursing moves into the $21^{\text {st }}$ century there is clear understanding of the connection between theory and practice because nurses are questioning 'what they do' and 'why they do it'. By nurses critically analysing and writing exemplars about their practice they are able to establish their own professional identity and develop the art of nursing caring. Newman et al (1999) confirms this by stating:

Considerable evidence exists that caring, health, and health experience are concepts central to the discipline of nursing. These concepts can be related to each other to identify the domain of inquiry for nursing (p.21). 
It is difficult to define what 'caring' is, and there have been multiple definitions of caring.

Mayeroff, (1971, p. 8) whose written work informed caring developments in nursing, suggests "In caring I experience the other as having potentialities and the need to grow...In addition, I experience the other as needing me in order to grow...". (Benner and Wrubel, 1989, p. 1) elaborate on connectedness in caring by stating "caring, as a word for being connected and having things matter works well because it fuses thought, feeling and actionknowing and being".

Montgomery (1993, p. 13) also stresses the importance of being and relationship by describing how "essentially, caring is a way of being, a state of natural responsiveness to others. Because caring requires personal involvement, it is the antithesis of alienation, detachment or apathy". Street (1995) also researched caring and observed " ...Caring exists when the nurse harmoniously demonstrates verbal caring, non-verbal caring, and technically competent behaviours, and focuses on the attainment and maintenance of health, or a peaceful death" ( p. 20).

From personal observation the thread that connects these definitions related to caring is " being in tune' with those whom nurses care for. A tune is a melody that flows but does not necessarily have to be in harmony to sound good. Nurses meet patients, particularly palliative care patients as strangers, they are both unique individuals with unique needs and thoughts. As trust is established as both work together to achieve the same outcome, the well being of the patient. Being 'in tune' also means "accurate correspondence of pitch and intonation" (Collins Dictionary, 1990, p. 932). Nurses achieve this with careful listening to the patient and responding appropriately to what they are really saying. Another definition of 'in tune' is "to adjust so as to bring into harmony, by making fine adjustments to obtain optimum performance" (Collins Dictionary, 1990, p. 932). Nurses, and other team members who provide the best possible outcomes for patients and their families continually assess patient care. Care does not remain static, it is always changing to meet the required needs. Baker and Diekelmann (1994) state "by remaining committed to the centrality of caring to nursing 
practice, nurses are uniquely situated to attend to the meanings patients and families form around the experience of recovering or of living toward death"(p.66). Patients sometimes 'call the tune' which may mean they want to retain some control over some decisions. It is the nurse's responsibility to enable this to happen by travelling alongside, and offering care and guidance when they are required. This provision of care creates a sense of harmony in body, mind, soul and spirit, which in nursing is called holistic care.

Caring is a relationship that is experienced by both, and nurses cannot impart care if they do not have an understanding of care, and the impact it has on a patients wellbeing. Caring is not seen as an 'ego trip' as Montgomery's (1993) research revealed "the caregivers talked more about their patients than they did about themselves or what they did" (p. 49). Nurses provide the vehicle as the means for patients to achieve their goals. Sometimes nurses are not always aware of the influence they have on a patient's recovery or wellbeing. Montgomery (1993, p. 49) elaborates that "these expert carers allowed themselves to become part of the background rather than the foreground of the patient's experience; therefore what they did was not always obvious, even to themselves".

Sometimes the physical and emotional demands of caring for people who are dying are great, but to share with people and to be trusted by them, revealing all the raw emotions of anger, fear, the achievements and the tears, it is an absolute privilege. To care for someone who is dying means to travel alongside them share the highs and lows that will occur along the way. The use of music therapy may be of benefit to patients during these times as they feel secure and supported at what can be a lonely time. At the Hospice New Zealand Conference, 2000, one of the keynote speakers spoke of " going into the depths" with palliative care patients to truly experience where they are. He explained "we (health professionals) cannot hope to have a clear understanding of the patient's experience if we do not travel with them. Health professionals are unable to be of use to patients if they do not share the experience at a human level" (Dr. Hjelmeland Ahmedzai, 2000, personal communication).

It is an opportunity to be part of a patient's world for a short time and nurses are usually enriched by the experience. An important aspect of caring is to be aware that nurses will not 
always get it right. Nurses are dealing with individuals who come from the many spectrums of life, bringing all the 'baggage' that life can offer. Yates1997) writing about explorations and challenges in palliative care suggests "Individuals respond to dying in many different ways, and will have many different wishes as they proceed through the dying process. Being reflexive is therefore essential if the nurse is to assess continually the differing needs and responses of individuals..." (p111).

An aspect of caring that is not always highlighted is, just being there for the patient. Not all caring has to involve physical touch or verbal communication. Sometimes non-verbal communication is a powerful way to provide care. Unfortunately, this can be viewed as wasting time because nurses are not fulfilling tasks, which is seen as the practical way of helping. This conflict of interests between what nurses see as a valuable part of caring for a dying person, and managements view of managing budget resources can force nurses into compromising their care. Yates (1997) acknowledged this problem of bureaucracy and nurses autonomy in her research, and the problem of insufficient time given to patients, families and nurses to enable preparation for death, which may mean nurses respond inappropriately because of this time restrain "Since tensions will inevitably develop between the maintenance of personal autonomy and the maintenance of a functioning organization, healthcare providers may choose to respond in these ways as their ideal is simply unattainable"(p.110). According to Mullett (1989) "a person cannot truly care for someone if she is economically, socially, and/or psychologically forced to do so. Thus, genuine or full authentic caring cannot occur under conditions characterized by domination or subordination".(p.119). Nurses must have the autonomy to make these skilled judgements in their care planning and assessment of patients needs.

A fear many patients, and their families have, is of patients dying in pain. Having someone there to share those concerns, and who understands, and who can offer assistance with pain management, and assurance, even though it does not change the final outcome, generally provides comfort to the family and patient. Underlying this caring is the nurse's feelings which nurses have not always been encouraged to express. Nurses cannot be expected to share another's life experience and not be moved by it. Whether nurses share that with the 
patient or a colleague is not important, what is important is that nurses acknowledge it. Times have changed and tears and laughter are accepted, and not seen as unprofessional or unwarranted. Nurses should not suppress their feelings or those of their patients. Montgomery (1993, p.129) emphasizes this aspect of nursing by stating "therefore the first way to promote the learning of caring is to create the space needed for human feelings to emerge".

If nurses want caring to be the centre of nursing, it needs to be given the same priority and understanding, and skills as for technical procedures. To enable this to be achieved more research is needed that reveals the importance of caring in nursing. This does not just mean global or even national research, but research in local areas of practice. Nurses need to question practice rather than accepting protocols and procedures, because they have always been done that way. Reflecting on experiences with colleagues, being honest about these experiences, and how it affects practice are vital if caring is to be central to nursing. Nurses have to allow humanistic care to surface and not entirely focus on the technology that is associated with cure. If caring is to become central to nursing again then a modality such as music therapy will be accepted by nurses as part of their patient care. Nurses will have that understanding of holistic care that will encourage nursing to seek out ways to improve patient care and develop their skills in complementary therapies as well as the conventional treatments.

Nurses have the skills to manage technology, however the skill of caring needs to be promoted and developed, so it is acknowledged as central to healthcare. "In the best nursing practice, science and technology are the best tools for caring" (Benner and Wrubel, 1989, p.372). If nurses value care for others then that caring will be valued by those who experience it. If nurses relate this to being 'in tune' with their patients, then this is the harmonizing of self, and those cared for. Caring enriches lives because it is a basic need for everyone, human beings are never closer than when life's experiences are shared, and growth occurs as a consequence. Caring in nursing must be first practiced, then acknowledged and valued. 


\section{Conclusion}

This Piece has focused on a broad overview of the literature related to western musical history, including the history of ancient man and music, Greece, Rome, and the early Christian Church. It connects the use of music from past centuries to the present time to emphasize that music is not a new modality in the area of health and wellbeing. The Piece continues with a section that describes music therapy as a concept in medicine through the earlier years and its continuing interest in latter years.

Music therapy was introduced in relation to the needs of the patient including the physiological effects of music on patients, music therapy and pain, and the use of music in communication, and for patients who are anxious. The section incorporated articles by some well-known researches in this area of music therapy, and included quantitative as well as qualitative research to enable a broad perspective of the use of music in the area of palliative care. The second question in this thesis suggests that nurses may be encouraged to use music in their planned care of patients, so with this focus the final part of the literature review concentrated on the value of caring in nursing, and the opportunity nurses have to provide holistic care which includes physical, emotional, spiritual, and psychosocial care to palliative care patients.

It is evident from the literature review that the use of music in palliative care has developed and increased in the last 20 years, and has had a significant impact on a number of writers who have accepted the challenge to further research this complementary therapy. The future of this treatment modality will continue to evoke discussion and further study, but the opportunity for nurses to read the evidence related to music and its use in palliative care is already available. There is plenty of scope for nurses and therapists to write and develop this therapy further. The following Piece describes the methodology chosen to research the use of music in palliative care. 


\title{
PIECE THREE
}

\section{Methodology, Methods, and Processes}

\author{
Music is the art of thinking with sounds
}

(Jules Combarieu 1859- 1916)

\section{Introduction}

Included in this Piece will be a description of the methodology, and why I chose qualitative inquiry. van Manen's 'lived experience' human science will be introduced as the method of inquiry that was used for this research. I will also discuss the ethical approval process, and the importance of the participants' personal involvement, that was vital for this research to achieve its aims. In addition I have included the research diagram I developed to explain the use of music therapy, and the processes involved, such as the participant selection and composition, and the method of interview. The data analysis, interpretation of the data, and trustworthiness, as an issue of rigour will conclude this piece.

\section{Methods debate}

In my initial reading and thoughts about this research, I had decided that if this proposed research was to be significant, or of value to nursing, I would have to conduct quantitative research, as this has been seen as the approach to scientific investigation that holds the most weight. An added consideration was that, as far as I was aware there has been no previous research related to music therapy in palliative care carried out in New Zealand. It was imperative that this research was recognised by both the medical and nursing profession as palliative care teams involve members from all disciplines. 
Baum (1995) has written about the ongoing debate between the methods approach for studying public health problems and suggests "epidemiological methods have traditionally been seen as the gold standard for studying public health problem" (p.459). This method consists of collating and analysing the data to either prove or disprove the null hypothesis and tends to distance the researcher from the participants. The researcher deals with the statistical evidence, and refrains from personal discussion that may be seen as researcher bias. Denzin and Lincoln (1989, p .4) state that "quantitative studies emphasize the measurement and analysis of casual relationships between variables, not processes. Inquiry is purported to be within a value-free framework". There is a general feeling that the quantitative approach to scientific investigation has worked well for other sciences, and as nursing is seen as a human science, it would be beneficial to nursing too (Packard and Polifroni, 1991).

When considering the question about the use of music therapy for people who were dying, I decided that quantitative research was not going to provide the answers I was seeking about the value of music therapy from a personal perspective. It would only provide a physical response that would be measured statistically and not involve the patients personal feelings about the experience.

Further reading of qualitative articles focused more on the interpretations and meanings of a situation. Rice and Ezzy (2000, p.ix) describe qualitative methods as providing "a sophisticated research strategy to understand how, and why, people act in particular ways" and "they enable researchers to begin to engage with the complexities of meaning that are often emotionally, politically, and technically a very difficult challenge". As my understanding of methodologies has increased, and the literature has been scanned to improve knowledge horizons, it is evident that palliative nurses tend to engage in more qualitative inquiry. This could be related to the fact that they are concerned with the whole patient, including their environment. This does not mean that other areas of nursing do not practice holistic care, but in the care of the dying, nurses are travelling into the unknown 
with their patients and families, sharing the risks of choice and giving of themselves as they participate in their care. Polifroni and Welch (1999, p.500) state "those who favour qualitative methodologies believe that first-hand knowledge experience provides the most meaningful data for nursing science".

My experience of nurses who work in palliative care is that sharing the 'lived experience' with these people is not something that can be measured statistically, as they are unique individuals with specific needs. Story-telling, and sharing experiences through reflective practice have developed in the last few years as nurses are including exemplars in their portfolios as part of their application for practising certificates and entry to post-graduate study. Nurses are finally sharing what their job is about and the impact it can have on their personal and working life. What is interesting is that nurses are the first to admit that these experiences are usually related to the patients for whom they have cared, and the learning gained from the experience. It is not just the hard statistical facts that nurses are sharing, but also the response of one person to the needs of another; the art of caring which also enriches and validates their profession. Care has become a focus for nursing as evidenced by the research that has been undertaken by a number of theorists in the 1980s and 1990s, including, Benner and Wruber (1989) 'The Primacy of Care; Montgomery (1993) The Practice of Caring, Watson (1998) New Dimensions of Human Caring Theory.

The debate about appropriate theories to describe nursing has been active for a number of years now, whether nursing as a human science can be scientifically explained or is it an understanding of human nature, which is not easy to measure or theorise. As Roberts and Taylor (1998, p.97) express in regard to the reason for any research, it is simply a way of "looking for answers to puzzles. The questions that have perplexed humans since the first conceptual conjectures are: 'What is true knowledge'? and "What is the meaning of life"? These questions are still being asked today; hence the reason nurses are expressing a growing interest in 
qualitative research, especially inquiry into the human experiences of their patients and families.

It is noticeable when reading nursing journals that there is an obvious increase in the number of palliative nurses presenting research, which has met the strict criteria for inclusion in professional nursing journals. For example, Jones of the School of Nursing, Midwifery and Health Visiting, Manchester, (UK) undertook an interpretive study in 2001, exploring 'lived experiences' of Macmillan nurses (District cancer nurses) as they recounted clinical supervision sessions. An action research project in 2001 by a group of nurses (McCormack, Cooper, Sutherland, Stewart), examined the safe use of syringe drivers administering pain relief in palliative care.

Narrative studies allow nurses to work closely with patients, developing a trust that enables both to journey into the unknown and discover meanings in the patients' stories. Leight (2002), an American nurse has highlighted this in her research, entitled, Starry night: using story to inform aesthetic knowing in women's health. These are three examples of many studies that are found in international journals of nursing. Denzin and Lincoln (1989) have written a handbook on qualitative research and discuss in great depth the benefits and limitations of qualitative studies. They explain that

Qualitative researchers stress the social and constructed nature of reality, the intimate relationship between the researcher and what is being studied, and the situational constraints that shape inquiry. They seek the answers to questions that stress how social experience is created and given meaning (p.4).

The philosophical debate related to quantitative and qualitative research will continue, and as Roberts and Taylor (1998) state, there are similarities in the two, so caution is needed when stating that they are different. For example, "both 
approaches can use deductive and inductive thinking and both require 'scientific' designs, in that they must both show themselves to be systematic and rigorous" (p.100). Taylor (1998, p.310) also states, "qualitative research in nursing has 'come of age'. It is assured of a secure and respected place not only in the 1990's, but well into the new millennium". Perhaps debates like these are exactly what nursing needs, to keep questioning the means of researching what nurses do, and seeking ways to define it. My decision to focus on patients' responses to listening music in the end stage of illness and the impact music had on their lives at this time seemed more appropriate to a qualitative design. Phenomenology was the method adopted as it allowed the research to be examined and interpreted as it was lived by the participants, giving real understanding of the experience of listening to music.

\section{van Manen's Method of Phenomenology}

In the preface to his book, Researching Lived Experience, van Manen (1990) explains how he became involved in the human sciences, particularly phenomenology, and hermeneutics during the 1960s, while studying in the Netherlands. The Dutch approach of "phenomenological pedagogy" was, as van Manen states "more descriptive or phenomenological in orientation" ( $p$, ix). van Manen (1990) suggests that phenomenology in relation to research is to "question the way in which we experience the world, to want to know the world in which we live as human beings" (p. 5). He claims that if we want to 'know the world' we have to become fully part of the world. He also suggests words such as 'caring' and 'thoughtfulness' in relation to the characteristics of phenomenology - words that many nurses would relate to in caring for the dying. Phenomenology is wanting to know the meaning of what it is to be essentially human, to understand and have an interest in what a particular experience is like for an individual. van Manen (1990) states:

in the human sciences, as conceived in this text, one does not pursue research for the sake of research. It is presumed that one comes to the human sciences 
with a prior interest of, for example, as teacher, a nurse, or a psychologist" (p.1).

This statement encouraged me that inquiry into the experience of music for palliative care patients required a phenomenological approach. van Manen (1990) suggests that " research is a caring act: we want to know that which is essential to being"(p.5).This research related to music therapy has been my focus for a number of years. However, I needed to know if all the articles and books I had read related to using music therapy were relevant to a person or their family, who were actually going through the experience of dying. Did it really have meaning for them? I had seen the results of the use of music on many occasions, but that experience was from the outside looking in. I wanted to know if this part of my 'caring' for dying patients was beneficial for them, and their families. For only by their accounts of their past experience of the phenomenon of music therapy, could I hope to gain some insight into their 'world' as they lived it. van Manen (1990) qualifies this when he states

a person cannot reflect on lived experience while living through the experience. For example, if one tries to reflect on one's anger while being angry, one finds that the anger has already changed or dissipated. Thus, phenomenological reflection is not introspective but retrospective. Reflection on lived experience is always recollective; it is reflection on experience that is already passed or lived through ( p. 10).

I enjoyed the experience of music on a personal level, but again this was my interpretation. Those who are going through the experience can only answer the question of the value of the phenomenon of music therapy, and its use for people who are dying. Only by listening to their stories, can nurses as health professionals fully understand the meaning of families' and nurses' 'lived experiences' of music therapy. 
Hermeneutic phenomenology is a human science, which studies the individual experiences of unique human beings and the 'lifeworld'. 'Lifeworld' is the world of the natural attitude of everyday life, which Husserl described as "the original, pre-reflective, pre-theoretical attitude"(cited in van Manen, 1990, p.7). This preferred method for human science involves description, interpretation, and selfreflective or critical analysis. As Dilthey, states, "we explain nature, but human life we must understand" (cited in van Manen, 1990, p. 4). van Manen was influenced by these classical phenomenologists in the late sixties during his studies in the Netherlands.

In this study the essential question is: What effect does music really have for the person experiencing it, and how can I capture this phenomenon so as to create a visual picture of this person's 'lived experience' which portrays the uniqueness, the sensitivity and the holistic view of the person, and their personal story? Phenomenological research according to van Manen demands to know the very nature of a phenomenon, for that which makes a some-'thing' what it is.

Roberts and Taylor(1998) describe phenomenology and how to go about phenomenological research according to van Manen. In a chapter written by Roberts, she states that it involves:

turning to the nature of the lived experience investigating experience as we live it, rather that as we conceptualise it reflecting on the essential themes which characterise the phenomenon describing the phenomenon through the art of writing and rewriting maintaining a strong and orientated relation to the phenomenon balancing the research context by considering the parts as the whole. ( p.109).

When this is achieved, then we can more fully understand the 'lived experience'. I had experienced first hand the effects of music on ordinary people during an extraordinary time of their lives. The question of how music affected these people 
was the heart of the inquiry that I kept focusing on again, and again. van Manen (1990) suggests, "even minor phenomenological research projects require that we not simply raise the question and possibly drop it again, but rather that we 'live' this question, that we 'become' the question" (p. 43).

It may be argued that my personal knowledge of music therapy, and my involvement in the practical application of music may exhibit itself as researcher bias. As the researcher I was concerned that my preconceived ideas about music therapy may influence the findings of the study, but as van Manen (1990) suggests, it is the participant's description of the experience that gives us the answers, not what the researcher conceptualises or theorises about. He also states that, as the researcher, we need to be 'up front' about this acquired knowledge of the phenomenon. Further, van Manen (1990) explains that the experiences of the researcher are not only essential to phenomenological research, but they are the logical starting point for this research approach. He says " if we simply try to forget or ignore what we already "know", we may find that the presuppositions persistently creep back into our reflections" ( p. 47).

During the interviews I became aware, and quite excited at times, as participants quoted phrases almost word for word from texts I had read, and described experiences I had observed with patients for whom I had cared. I found it difficult not to vocalize these thoughts to the participant, but supported them to continue with their story. The awareness of one's own experience of the phenomenon can be very similar to the experiences of others, as I discovered. van Manen (1990) suggests "phenomenology always addresses any phenomenon as a possible human experience. It is in this sense that phenomenological descriptions have a universal (intersubjective) character" (p. 58).

My intention for this project had always been to focus on the patients' and families' points of view related to music, long before my understanding of van Manen's approach to phenomenology developed. As far as I am aware, this is the 
first New Zealand research project that investigates the experience of music in palliative care from the perspective of family members involved in caring for the dying patient, and nurses working in the area of palliative care. There is evidence of increased interest from researchers in all aspects of music therapy, but most research relates to the measured physiological impact of music on symptoms, such as pain and anxiety. Some examples of research that focus on the use of music and phenomenology as a research method are mentioned in the following paragraphs to provide evidence of the increase in the interest of music as a therapy and phenomenological research.

Snyder and Chlan (1999) focused on a review of studies involving the use of music therapy. They state " the number of published research studies increased almost exponentially from 1980 through 1996. Only one research report on music was published in 1981. The number increased to eight during 1990 and 17 in 1995" (p. 4). Hogan (2001) a music therapist who works at Bethlehem Hospital in Melbourne contemplated a quantitative approach to her research about the possible reduced use of analgesics when music was played for terminally ill patients. After further consideration of this question in relation to the needs of palliative care patients, the researcher states

that the relevancy of this question started to diminish. For many terminally ill patients their priority and, often, preoccupation is to achieve psychological reconciliation and self- actualisation over physical comfort. One of the primary goals of music therapy, therefore, is to facilitate this process of existential exploration and harmony by creatively stimulating internal and subjective changes. (p. 2).

Hogan (2001) explains that because the many facets of music are complex, a quantitative approach would not answer the question in depth. Her research question changed from a "measurable physical response to one that was qualitative in design and sought to uncover the constituents and essence of a multifaceted, 
creatively intricate and complex lived experience - how terminally ill patients experienced music therapy" (p. 2).

Hogan adopted phenomenology as the research method. Nine terminally ill patients participated in individual semi-structured interviews conducted by the researcher or research assistant. "Phenomenological analysis of the data involved 16 steps, including various procedures of transformation, regrouping and synthesis as well as six steps of data verification" (Hogan, 2001, p.1). The stories told by the participants to the researcher revealed the essence and complexity of the phenomenon of music therapy, because they shared their personal experience of using music when they were dying. It also supports the phenomenological approach to research in palliative care, and music therapy.

McKinley (2001), a New Zealand nurse researcher, used phenomenology to describe the experience of patients who were inpatients in a palliative care setting. She used van Manen's phenomenological methodology, and "explored the experience of care as described by six New Zealand patients on the journey to death" (p. 22). McKinley states

there is a mystery about the journey of dying, which situates in the realm of the only-partially understood. There will always be conflict between the known and the unknown, what should be investigated and what should be hidden. Lived experience conveyed through story expands this understanding (p.22).

van Manen (1990) supports this concept of the personal recognition of life experience, and the freedom it enables for the participant. van Manen states

Human science operates on the principle of the recognition of the existence of freedom in human life. And self-consciously free human beings who have acquired a deepened understanding of the meaning of certain human 
experiences or phenomenon may in fact be less susceptible to the effective management or control of others (p. 21).

McKinley (2001) developed a 'Circle of Care' that encompassed the 11 themes that emerged from the interviews, which she states "form a pattern of lived existence which is complete in itself'(p. 25). She describes how 'identity' was the central theme as this expression of the personality of the patient and their relationship with their family was the leading question in the interviews. She concludes that

care is the central object on the speciality of palliative care, yet who decides which aspects of care are important, the staff, or the patients, or perhaps the patients' supporters? Only people who are living with all that it means to be dying- the symptoms of the illness, the threat to mortality, the anticipated grief and losses, the look in their loved ones eyes, the inevitable fatigue, and the mental clouding- can state what is of value to them (p. 27).

Phenomenology enables questions to be answered by the people experiencing certain phenomena. It asks what is this or that kind of experience like? van Manen (1990) claims that phenomenology is not like any other research methodology, "as the links with the results cannot be broken", but with most other research, "results can be severed from the means by which the results are obtained"(p.13). That is why van Manen states, "when you listen to a presentation of a phenomenological nature, you will listen in vain for the punch-line, the latest information, or the big news" (p.13).

This research was undertaken to try and understand what effect, if any, the use of music can have on a person who is dying from the experience of the relatives and nurses caring for the patient. I am convinced that the most appropriate method to fully grasp this concept is phenomenology, as "it attempts to describe and interpret these meanings to a certain degree of depth and richness (van Manen, 1990, p.11). 


\section{Summary}

My initial plan was to send out a questionnaire to approximately 200 postgraduate nurses, who had undertaken Module two of the New Zealand hospice palliative care modules, which included teaching sessions related to music therapy in palliative care. This was to evaluate the effectiveness of the use of music for palliative care patients and the teaching of music therapy to nurses. The decision not to follow this through was made after consultation with my supervisor, who suggested this was too large an undertaking for a project of this size. My thoughts regarding the most valuable participants to share their experience of the use of music in the terminal phase of an illness, were palliative care patients. This raised the concern of researcher bias, as the patients I knew who were using music in this way were patients I was nursing, which was not appropriate.

After careful consideration and discussion with my supervisor, it was determined that the numbers of nurse participants would need to be reduced significantly, and the patient involvement would need to be through other nurses' contact. As already stated, my original intention of conducting quantitative research had changed as my understanding of qualitative research, particularly phenomenology, revealed that this research explores the experiences of people, and enables the researcher to examine the experience as it is lived by the participants. Also questions of bias and sampling that apply to quantitative projects, do not apply to qualitative research (Roberts \& Taylor, 2001).

\section{Ethical considerations and approval}

Because of the sensitive nature of this research it was imperative that the participants, especially the family participants volunteered to be involved and did not feel co-erced into sharing such personal and emotional information without adequate support. When they agreed to participate the family/ies and nurses contacted me. Included in the written information was the option to use a pseudonym during the interview as the community where the research was carried out is a small one, and the potential for participants being recognised was a 
possibility. Participants were also made aware that the interviews could cease at any time if they wished and resume again when they were ready. Professional support was also offered to the participants if they felt it was required following the interviews. This was because of the emotional feelings that reliving the stories of their loved ones may evoke. The same applied for the nurses as they were revealing stories about patients they had cared for, so they had to feel confident that their patients identity would be protected by using a pseudonym. After setting realistic criteria for participant involvement, ethical approval was applied for to the Canterbury Ethics Committee in June 2002. Ethical approval was granted in October following some minor changes regarding nurses'/patients' identities (Appendix 2).

\section{Selecting Participants}

Because of the relatively small community, and the smaller numbers of nurses who work in palliative care it was decided to include two patient families, and two nurses. As it was not possible to interview patients who had experienced the use of music in their care, because they were deceased, I decided the most appropriate people to share this experience of music, would be families who had used music in their care of a loved one. Nurses who worked in palliative care, and were aware of families who met these criteria were asked to contact the family and inquire if they would be prepared to be part of this research. As the researcher I made no contact until the families agreed to receive further information from me, in the form of a letter (refer Appendix 4) outlining the intended research. The participants then made personal contact with me by telephone. This conversation reiterated what was in the information letter and also answered any further questions the participants may have had related to the research. The offer to participate in the research was verified, and an appointment was made to meet with the family/families to explain, and fill out the consent form (refer Appendix 6). On completion of the consent form, a time and place that was acceptable to both the participants and the researcher was made for the interviews. 
Two participants responded who met the criteria. One was a woman, Ngaire, in her sixties, who had cared for her husband, who had cancer. He had died at home, and had used music extensively during his illness and dying. She was unsure if she would be able to cope emotionally, but felt this research was important, if it meant other people may benefit from the results. I assured her that professional help was available if she required it at any time during the research process. The second participant was an English woman Joan again in her sixties, who had also cared for her husband at home, following many years on renal dialysis, which resulted in secondary cancer. Music had always been important to her husband, and the family. As a family they all wanted to be involved in the research. These participants will be more fully introduced at the beginning of their transcriptions in Piece Four. Included in the interviews with these participants was the first thesis question: Does music have any value in the care of someone who is dying?

Nurses who worked in palliative care, who had used music in their care of palliative care patients, in any clinical setting within the Mid Canterbury area, were also invited to participate in the research. This was achieved by a personal approach to managers of the various care facilities in the area, to ask of they would approach their staff if they met the criteria for inclusion as participants. This was to explore the second question of the research: How can nurses be assisted in introducing music in the planned care of their palliative care patient'.

A number of nurses expressed an interest in being a participant, but following initial discussion about time involvement, availability, and the experience of the nurses in the field of palliative care and music, two nurses volunteered to participate. These nurses will be fully introduced at the beginning of their transcriptions in Piece Four. The nurses contacted me when they had read the information letter (refer Appendix 5) Following agreement to participate, they were presented with a consent form (refer Appendix 6) to complete and further queries were answered regarding the research. A mutually agreed time and place was discussed to conduct the interviews. 
Because I intended to include a compact disc of music I had to obtain permission from the original music producers.

\section{Compact disc permission}

As stated at the commencement of this project in the Piece entitled 'Ad libitum', I explained the inclusion of a compact disc, which can be played while reading the work. The experience of music differs for each individual, but throughout the years that I have used music for patients, there are some compositions that are repeatedly requested by patients. With this in mind, the idea of including some of this music with the thesis was evolved, to enable the reader to experience some of music most favoured by patients. To achieve this I sought permission from the producers of the compact discs to record the music onto a separate compact disc. The selection of music was from five compact discs, 'Songs from a Secret Garden', 'White Stone', 'Dawn of a New Century', and the four 'Enya' compact discs entitled 'A box of Dreams'.

Email contact was made with the appropriate producers explaining the content of my thesis and the reason for the request. Both music producers responded to my request in a positive way and were supportive of including the music (refer Appendix 7 \& 8).

\section{Method of data collection}

I used interviews to elicit participants' experiences of music therapy in the care of someone who was dying. According to van Manen, (1990) it is easier to talk about personal experiences rather than write them down, because "writing forces the person into a more reflective attitude, which may make it more difficult to stay close to the experience as it is immediately lived" (p.67). Interviews conducted in qualitative research are usually formatted in a 'semi-structured' way, but care must be exercised that the research question is clear, so that the interview focuses totally on the question about which the interviewer is seeking clarity. 
Using a qualitative interview method for a small number of participants enables 'rich' data collection, as it encourages the participant to express their story in their own individual words. It is more like a free-flowing conversation, where one person, the interviewer, may sit quietly attentive, and offer encouraging direction if it is required, while the respondent is able to recollect and share their experience of the phenomenon. Brooks (1994, p. 50) suggests "the relation of teller to listener is as important as the content and structure of the tale itself".

The interviews began with each of the participants introducing themselves to gauge distance from the microphones and to allow them to feel comfortable and less self-conscious about the audiotape recorder. I asked the four of them to introduce themselves, and in the case of the nurses, to speak of their work experience in palliative care, and their current place of employment. The family participants also introduced themselves and spoke of the spouse they had cared for at home. I expected to ask a specific question related to music therapy, but in each instance, the participants brought music into the initial conversation without any prompting. Perhaps this was related to the letter of information that the participants were given at the beginning of the research process, which outlined clearly the intentions of the research and what I hoped to achieve with the interviews. The participants continued to follow their accounts of music therapy in the care of the person who had died, interspersed with their personal use and views of music. I occasionally encouraged them to expand and provide a more indepth description if it was appropriate. Each interview was on average, an hour long. Following the interviews, the accounts were transcribed word for word by a transcriber who had signed a confidentiality agreement not to discuss or impart knowledge of any of the recorded information or participants (refer Appendix 9). 


\section{Research diagram}

The research diagram ( figure 6) overleaf, is an attempt to visually describe my project of music therapy in palliative care. Meriam (1998), an American researcher who writes about qualitative research in education, believes that it is beneficial to envision the connectedness of the data variables when writing qualitative research. With this in mind I have illustrated this project with a diagram to show the relationship between music, patients, nurses, students, and teacher, both in the community and the Hospice.

The inner core circle of 'music' is central to this study, as it connects to all the other circles, and is part of the larger circle. I believe circles are an expressive symbol of continuity, as they have no beginning or end. The four smaller circles each represent those involved in the process of music therapy (eg. teacher, nurse, student, patient) and as the two-way arrows indicate, each circle has an impact on the other. No matter where we are in the circle, whether as a teacher (educating about the use of music) a nurse (applying music in our care) or a student (learning about music therapy), or a patient (experiencing music therapy), all that we experience and learn impinges on the other. It is definitely a two-way connection and could be more than two-way as we learn from each other. The outside circle encloses us all, either in the community or the hospice setting, providing a safe, encompassing environment that smoothes out the edges, and enables continued learning, and experience to encircle us. This diagram may be an appropriate way to visually describe the value music can have on all those involved in the palliative care setting following the analysis and interpretation of the inquiry. 


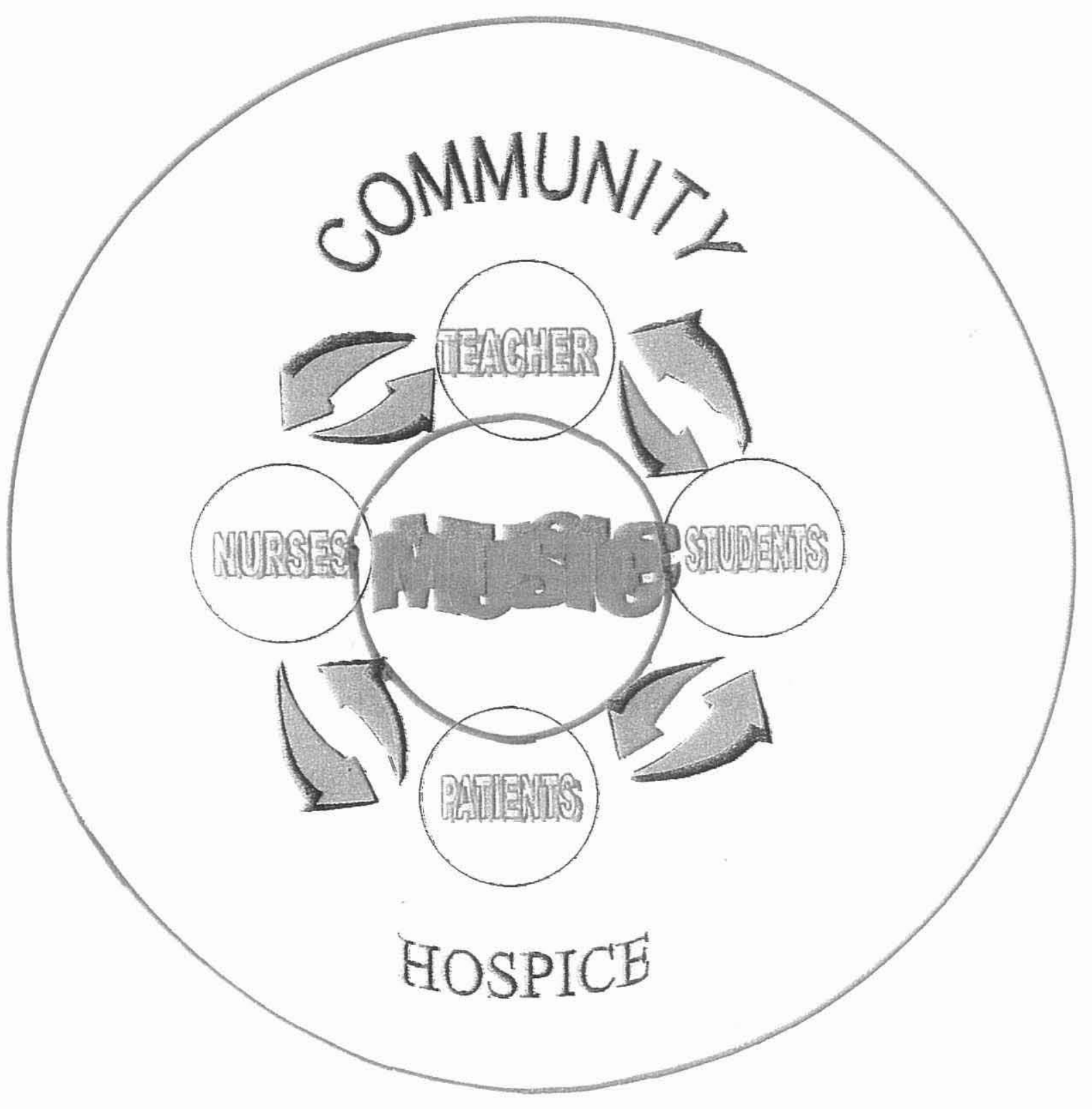

Fipune 6: Music Therapy Research Diagram 


\section{Data Analysis}

According to Lofland and Lofland (1971, p. 69), "qualitative research can be described as a strategy of "calculated chaos"'. This is an excellent way to describe the feeling when you are surrounded by pages of amazing text, which you have read repeatedly, and you know has the responses that will validate your thesis questions. But how do to you find them amongst this wealth of generously shared experiences?

Rice and Ezzy (2000) explain that qualitative research is both calculated and chaotic. They say that qualitative inquiry is calculated, as it has " established procedures, techniques, and methods for conducting qualitative research and for analysing qualitative data" (p. 190). Qualitative research can also be chaotic when the aims are not clear. Rice and Ezzy go on to explain that if the answers were already known to the question, or " it was clear that a theory would explain a particular experience, if the benefits of the research could be demonstrated with certainty, qualitative research would be irrelevant" (p. 191). This statement clarified the meaning of my research, as I came to the understanding of what music had meant to these families and nurses, a description in their own words that had meaning for them alone. In his book related to 'lived experience', van Manen (1990) dedicates over 20 pages to 'reflection' of phenomenological research. He states:

to do human science research is to be involved in the crafting of the text. In order to come to grips with the structure of the meaning of the text, it is helpful to think of the phenomenon described in the text as approachable in terms of meaning units, structures of meaning, or themes (p. 78).

As I read and re-read these amazing personal stories, I became totally immersed in the emotions, and experiences that the participants shared and explained. van Manen (1990) describes this as "a free act of "seeing" meaning"(p. 79). During the reading of the texts, I needed to be constantly aware of the meaning of these 
experiences that were being explained so I could make sense of their 'lived experience,' which enabled me to formulate into words (themes) what the focus of the phenomenon of music therapy was for these people. van Manen (1990) describes themes as "the structures of experience"(p.79). He also reminds researchers that we are trying to explain a 'lived experience', and that it would be "simplistic to imagine we could think of themes as conceptual formulations or categorical statements" (van Manen, 1900, p. 79).

In choosing to interview the participants for this research, I was able to listen, and read their words without any alteration. I could listen to the tone of their voices, share in the memories of happiness and sadness, and listen to the silence as they regained composure, and shared in the silences as they completed their stories. I was humbled by the degree to which people were prepared to openly share their feelings about a very personal private experience. This aspect of research, particularly phenomenology, emphasises the value of this type of approach, as it gives permission for these stories to be told. It would not be possible to statistically measure the episodes of silence, that speak volumes, as far as emotions are concerned, Bollnow (1982, cited in van Manen, 1990) describes how good conversations often end in silence, when participants are 'fulfilled'. He states

and when the conversation finally does sink into silence, it is no empty silence, but a fulfilled silence. The truth, not only of the insight that has been acquired, but the truth of life, the state of being in truth that has been achieved in the conversation, continues to make itself felt, indeed becomes deeper, in the course of this silence.

van Manen (1990) also explains how silence is part of our everyday language, and the power that silence can have in a conversation, particularly in human science research. He explains; "phenomenologists like to say that nothing is so silent as that which is taken for granted or self-evident. Therefore, silence makes human science research and writing both possible and necessary." 
The themes were developed according to the thesis questions, which meant I had two processes for data analysis; one involved the families stories, and the other the nurses' stories. As already stated, to ensure the interviews were accurate and unbiased, the transcriber typed the conversations word for word. Copies of the transcripts were returned to the participants to read and verify that they were correct. This assisted in improving the projects trustworthiness. The emerging themes were highlighted throughout the texts as I continued to 'listen' to what the stories were telling me about the use of music in palliative care. This approach to identifying themes is one of the three suggestions from van Manen, (1990) which he describes as the 'the selective or highlighting approach'. The other two approaches are ; "the wholistic or sententious approach and the detailed or line-byline approach" (pp.92-93). van Manen explains the use of the highlighting approach by stating

in the selective reading approach we listen to or read a text several times and ask, What statement(s) or phrases(s) seem particularly essential or revealing about the phenomenon or experience being described? These statements we then circle, underline, or highlight

I chose the highlighting approach because I had already read the texts many times and had noticed that particular words and statements were repeated in the texts, and appeared to adequately explain what the participants were saying about the value of music therapy.

Each theme was identified as the data was read over a period of weeks, and an appropriate word or phrase was used that revealed what the experience described. For example, Roberts and Taylor (1998) in their definition of analysis state "analysis involves reviewing research data systematically with the intention of sorting and classifying them into representational groups and patterns" (p.337). This method of analysis enabled me then to focus on the literature related to music 
therapy in palliative care and match the developed themes to previous research and data to see if there was a connection. It was also the stage in the project where I could revisit the aims of the work, what I had intended to research, and the reasons for choosing the research approach of phenomenology, in other words, whether there was methodological congruency throughout the work. Roberts and Taylor (1998) assert that congruency in qualitative research is necessary because "it helps them (researchers) to prepare for interpretation. It also means that they will be able to provide a strong rationale for readers of the research, of what they have done, why, and how" (p. 342).

\section{Interpretation}

Throughout this project the focus has remained firmly on the experience of music for someone who is dying, in the hope that those shared experiences would give meaning to the phenomenon of music therapy as an aesthetic practice for palliative care nursing. The stories of the lived experience of music therapy have to be told, and written down, so that an attempt can be made to describe the phenomenon to others. Particularly those who work in palliative care so they can gain some insight into the true meaning of this complementary therapy. As van Manen (1990) states

" there comes a moment when the researcher needs to communicate in writing what he or she has been up to" (p. 125). The data collected in this project needs to be interpreted, and this can only be achieved by putting it onto paper, which van Manen believes can "speak to us more powerfully, moving us more physically and emotionally to such an extent that one can feel speechless" (p. 129). In other words, the story in the written word can impact deeply on the reader's emotions, and create an understanding far greater than oral language. This was my intention from the conception of this work, to write the stories of people who had experienced music therapy in the care of someone who was dying, and not to rely solely on what has been written in another part of the world, or some other person's interpretation of the phenomenon. 
This is the reason I chose the technique of interviewing families and nurses, and then relate their unedited stories to current research, by including sections of their actual transcripts to support the research related to music therapy. It may be thought that phenomenology is devoid of techniques, however, van Manen (1990) believes that the constant questioning, the writing and rewriting can be called 'cultivated thoughtfulness' rather than technique, and that this can enable rigorous inquiry of the thesis question. He explains "to write/theorize is to bring signifying relations to language into text. Language is a central concern in phenomenological research because responsive-reflective writing is the very activity of doing phenomenology" (p. 132).

\section{Issues of rigour}

To demonstrate trustworthiness in qualitative research, the researcher needs to show that the conclusions drawn from the research are worthwhile, but also to be careful not to lose the essence of the art of 'lived experience,' that is at the heart of phenomenology. Qualitative research does not rely on numbers and statistics, to interpret and validate findings as does quantitative research.

To remain faithful to the personal expressions and experiences in the participants interviews, I chose to do a single interview that was transcribed word for word. I did not want to alter any of the essence of their story by paraphrasing their experiences. By applying van Manen's thematic approach to the data, I was able to uncover words or phrases that illuminated the true experience of using music for someone who was dying. There are widely held views about trustworthiness in relation to qualitative research, but there are some common threads recognised by Maggs-Rapport (2000) in her research about 'combining methodological approaches in research' she states that:

data can only be validated, or seen as trustworthy, if a combination of issues are considered collectively - the activity of the research, the cognitive processes of validating data and the involvement of external 
measures, second opinions and the subjects' own perception which add weight to the decisions reached by the researcher (p. 221).

Roberts and Taylor (1998) define the terms 'credibility, fittingness, auditability' as the criteria for trustworthiness in qualitative research. The fourth term of 'conformability' is met when all the above have been achieved in a project. Credibility is achieved when the stories related by the participants can be recognised by the reader as similar to their own experience. The second category of fittingness relates to the relevance of the research to those who read it. The third term of audibility explains how the research can be examined by others who may have an interest in further research related to the same topic methods, and processes. As this is possibly the first New Zealand inquiry into the value of music in palliative care there is an opportunity for others who work in this environment to apply the same approach to the research and arrive at the same outcome.

The issues of validity for this research were met, firstly by the voluntary method of involving participants, sharing stories that readers of the research who are familiar with music will understand. Secondly by transcribing the interviews without any alteration, and thirdly by verification of the transcripts by the participants themselves. A further way of improving trustworthiness in qualitative studies according to Mishler (1990) is by "including substantial parts of, or complete, primary texts in the research report. This provides the reader with a "clearer sense of the evidence on which the analysis is based" (p.437). As the researcher I was also familiar with the application of music therapy and the nature of palliative care, which enabled informed interpretation. External measures were applied as the project was reflected upon and assessed during the project time frame, and then by the academic examiners during evaluation of the project on its completion. 


\section{Conclusion}

This Piece has provided detailed information related to the methods, and processes, and the methodology applied in this study. I have included the reasons I chose a qualitative approach and the application of van Manen's interpretive phenomenology approach to explain the lived experience of music therapy for someone who is dying and from the palliative care nurses perspective. The ethical approval for the research, and for the compact disc recording was also discussed. The research design has been illustrated as a diagram to visually clarify the use of music therapy, and the impact on all those involved in its use. The method of data collection, data analysis, interpretation, and trustworthiness of the project completed this section of the study.

The following Piece includes sections of the interviews and discusses the analysis and interpretation of the research. 


\title{
PIECE FOUR
}

\section{Theme: Analysis and Interpretation}

\author{
Music is a strange thing. I would almost say it is a miracle. \\ For it stands halfway between thought and phenomenon, \\ between spirit and matter, a sort of nebulous mediator, \\ like and unlike each of the things it mediates \\ spirit that requires manifestation in time, and matter \\ that can do without space.
}

(Heinrich Heine 1797-1856).

\section{Introduction}

The subtitle for this Piece, entitled 'Theme' alludes to the musical term, which means 'unifying idea, image, or motif, repeated or developed throughout a work' (Collins English Dictionary, 1979, p.1506). This terminology explains clearly the meaning of this chapter, as it describes the individual responses that appear to 'unify' the use of music therapy in the care of someone who is dying, and the personal experience that can be shared by those who have stories to tell about the phenomenon which is 'developed throughout' the work. This section introduces each participant at the beginning of their transcript. There are two sets of data analysis and interpretation, as the intention is to provide the views of the families, and the nurses. This is undertaken to answer the two research questions. It will also explain how the patterns were identified, and how the final five themes connected to the patterns. These themes are then related to the participants' transcripts and the available literature about music therapy in palliative care. 


\section{Identifying themes}

The first 'rule', when looking for themes, according to Roberts and Taylor (1998, p. 312), "is to know what you are looking for". This can be achieved by revisiting the aims and objectives of the study so that the researcher is able to recognise a theme when the text is read. The objectives of this study were to find out if music therapy has any value for someone who is dying, and how nurses can be assisted in introducing music into the planned care of their palliative care patients.

As I have already stated, during the interviews with participants, I became acutely aware of words and phrases that were repeated by participants, and those with which I was familiar from literature related to music therapy. During the reading and re-reading of the transcripts certain phrases and words became easily identifiable. These explicit words and phrases were easier to identify, because they were relevant to the use of music therapy of which I was already aware.

It was only through total immersion in the words of the storytellers that I began to grasp some understanding of van Manen's concept of "seeing" meaning. Themes, according to van Manen (1990) "give control and order to our research and writing", but the ultimate goal of human science is to be "concerned with meaning - to be human is to be concerned with meaning, to desire meaning" (p. 79). It would be unjust to the participants to think that, as the researcher, I could attempt to have complete understanding of the essence of the phenomenon of music therapy for someone who is dying. I have not had that experience, but as the researcher, I can reflect and report on my understanding of the description given by the participants, which gives textual meaning to their experience. Therefore, the use of 'theme' to give structure to the text is an appropriate word to use, as literally, and in music it means a " unifying idea, image that is repeated or developed throughout a work" (Collins English Dictionary, 1990, p. 1506).

As I initially examined the texts that had been shared with me, I began to grasp some ideas of what music therapy 'could do' for someone who was dying. 
However what emerged as I read and re-read the texts was the deep and more reflective 'feelings or emotions' that surfaced for the patients and families when music was played. van Manen (1990) supports this by stating "we try to unearth something "telling", something "meaningful", something "thematic" in the various experiential accounts - we work at mining meaning from them" ( p. 86).

The participants were generous and sincere in their endeavours to give me as much information as they could. They wanted this research to be informative, so that health professionals, patients and their families could benefit from their experience of using music. Amongst the richness of the texts were experiences that held deep emotional and reflective memories for these participants, but they continued to share their real life stories. As the researcher, I felt very humble, as they built up a rapport with me, and acknowledged this by trusting me with their stories. The art of transferring the participants' thoughts, stories, emotions and experiences into writing is the essence of phenomenology. According to van Manen (1990)

writing fixes thought on paper. It externalises what in some sense is internal ...the object of human science is essentially a linguistic project: to make some aspect of our lived world, of our lived experience, reflectively understandable and intelligible( p.125-126).

\section{Discovering the themes}

There are many ways for lived experiences to be expressed, for example, in conversations, written responses, stories, film, poetry, and diaries. I chose audiotaped conversations that were transcribed without alteration, and then proceeded to develop themes that could be reflected and interpreted upon, in relation to the phenomenon. I chose van Manen's selective approach to uncover thematic aspects in the text, namely, the 'selective or highlighting approach'. This process of reading, listening, and repeating these tasks many times meant many hours of reflection with the texts. After this process I highlighted words and phrases that 
related to the objectives of the study, or had meaning about the use of music therapy. Examples of these phrases or words in the patients' texts were:

- family history of music

- emotional response to music

- variety of music

- music and past events

- ignore surroundings

- part of life

- controlling symptoms

- calming music

- music as escape

- atmosphere

- significant days

- different music, different mood.

The number of words or phrases added up to 40 from the patients' texts. From these phrases I then reduced them into groups that had similar meaning, without losing any of the significance of what was being described. For example, all the comments that related to physical response, such as ' relaxed', 'smiling', 'toe and hand clapping', 'head nodding', 'crying', 'calmness', 'focusing', 'communication', I merged as a sub-theme named 'responsiveness'. This was continued until I had six sub-themes, which were:

- personal

- $\quad$ interest in music

- $\quad$ symptom control

- memories

- communication

- responsiveness 
To achieve the specific themes I refined the sub-themes further while remaining faithful to the essence of the experience of the participants and not losing any of their uniqueness. van Manen (1990) gives many examples of what theme is, but the one that relates the ideal of theme to me is a "theme describes the content of the notion. A good theme formulation somehow seems to touch the core of the notion we are trying to understand" (p.88). The 'notion' refers to the experience or phenomenon under study. The final three themes that emerged from the patients' texts were:

- Music as part of life

- Physical response to music

- Impact of music on memories

The same procedure was followed for the nurses' texts to allow focus on the second aim of the study linking the use of music by nurses in their planned care of palliative patients. Many of the same phrases and words appeared in their transcripts, but there was also a focus on patient choice, and holistic care. Examples of the 55 words and phrases taken from the nurse's stories were:

- calming and soothing

- consent first

- relaxing

- atmosphere

- mixed emotions

- grief

- own music

- own space

- patient's choice

- independence back

- pain relief

- individuals 
- patient and family memories

- peacefulness

- young and old

- catalyst

Grouping the words or phrases with similar meaning, again being aware not to alter the meaning of the text, then developed the sub-themes. An example of grouping was the word 'communication,' which included all words or phrases that relate to the topic, for example, facial expression, family involvement, emotions, own space, reminiscing, own choice, in control, problem solving. The ten sub-themes developed were:

- holistic care

- different music, different time

- background

- family response

- meaningful for families

- no rules

- communication

- complementary therapies

- company

- symptom control

Trying to determine the themes was not easy, as I had to continually ask the question: 'What is the meaning that is being described by the participant?' van Manen (1990) clearly explains this dilemma when he discusses the issue of theme; "after all it is lived experience that we are attempting to describe, and lived experience cannot be captured in conceptual abstractions"( p.79). It is a lengthy process that involves making sense of what has been said, and trying to give some order to the process that will have some relevance to those who read it. 
The final themes that emerged from the nurses' transcripts focused on the patient as an individual, and the importance of patients making their own choices. The strong overall theme that was illuminated from the nurses' texts was communication. Therefore, the final themes were:

- holistic, individual care

- communication with patient, family and nurse.

Once the themes achieved this high level of extraction, the next step was to interpret, by describing the meaning of the experience of music therapy, as verbalised by the participants using their words from the texts, and also to compare the findings to the literature. According to van Manen (1990) "themes are not exhaustive of the phenomenon ... but they allow a systematic investigation" (p.168).

\section{Introduction of family participants}

The insights that I was able to gain from this study were due to the generosity and personal sharing of the participants. The validity of a qualitative study cannot guarantee 'absolute truth', because qualitative work does not rely on "absolute, indisputable truth and facts" (Roberts and Taylor, 1998. p, 338). To add to the degree of trustworthiness of this work, I will introduce the participants to the reader, to reflect the involvement and knowledge these people have had in caring for someone who was dying, and using music as part of that care. All the participants had decided to use their own names in the interviews, and those of their family members.

\section{Ngaire}

The first woman who willingly shared her story was Ngarie, a woman in her late fifties, who cared for her husband at home during his illness until he died. Graham was diagnosed with bowel cancer with liver secondaries, and was told he had six to 12 months to live. Graham died three years ago, but the memories and stories 
about his life, and the part music played in his life were still very vivid in Ngaire's memory. Ngaire was concerned that she would find the interview difficult, and might breakdown, but she was also adamant she wanted to do the interview. I assured her that if this occurred we could stop, and resume at some other time. As already stated I also reassured her that professional assistance was available for her, to enable her to express her grief if that was required. Ngaire and Graham had married in 1985, and both had children from previous marriages. Seven years before Graham died he had a serious back injury, which was operated on without success, and left him with considerable pain. Ngaire's comment to me regarding her reasons for agreeing to participate in this research was that, if her story about using music was helpful to someone else, she was prepared to talk about it.

\section{Joan}

The second person Joan, also a woman in her sixties, who had cared for her husband John for five years when he was on home dialysis, and continued to care for him at home during the terminal phrase of his illness. Two family members also agreed to be a part of the interviews, as they were also closely involved in John's care. They were Paul, a son, and his wife Paula. John and Joan originally came out from England with their family and settled in New Zealand. John developed cancer secondary to his medical condition, and was cared for at home by his family until his death in 2002. The family were keen to share their experiences of music throughout their Dad's life, and especially at the time of his death. They believed music should be available to everyone in hospice and palliative care, and hoped that out of this research something would eventuate.

\section{Interpretation of family texts}

In the following interpretations, the participants' words are written in italics, and the researcher's comments are written in normal font. 
'Music as part of life' was a theme that emerged as having significant importance to families in their care of the person who was dying. They generally began their stories by recalling what impact music had in the patient's life from childhood, through their teens, courting, and into married life. When asked about the part that music played in their lives, both men had experienced music in some form in their lives, whether it was passive listening or active involvement. Earliest childhood recollections were through the influences of other family members and events.

It did, but not to a great degree then. John's mum always had the radio on from six o'clock in the morning, and it would be left on all day. Barbara, Dad's sister, she played the drums. [Joan]

Where the music side came into it was apparently Greta and Lillian, (Graham's older sisters), they had beautiful voices and I think they were encouraged to sing at church. Lillian and Greta always sang together. But when Graham was going to school as a little one he went to a Catholic school, and the nuns said that he had a good voice and he sang in the concerts at school. So music was always, even in childhood, a big part of Graham's life. [Ngaire]

Again in their young adult life, the significance of music was evident from the stories their spouses shared about music in their working, and social life.

The other incident I do remember when television first came into Liverpool, Mum and Dad were the first to get a little black and white set, and Johnny said, one of his first memories when he was home from sea and we had a programme on, and a lot of the neighbours came in to watch ... and we had the whole programme of Madam Butterfly, and I cried all the way through it, and Johnny was sitting next to me and he kept saying, 'Don't cry, it's only a film', and that was one of the first times of music coming into it. 
When he (John) was at sea, he always had a radio, yes it was very important to him. And then as we got older he was the one who always had the radio on in the mornings, always. .... and he always had the radio on when he was working in the shed ... [Joan]

He (Graham) was a teenager in the forties and he had the 'ducktail' because he 'thought' he was Elvis Presley apparently ... they had moved to Blackpool so the Blackpool promenade thing with the lights and that, well they used to go to dances and things like that. With his pocket money and that, he bought a lot of records, he always had a lot of the latest records ... and always had a big box of records, and he took records everywhere and being at sea, records were his mainstay ... They had parties and things like that and there was always a lot of singing and music ... [Ngaire]

Some of their stories spoke of the patients musical ability, and how this enhanced family life, and what it meant for other family members to be part of this.

John and I shared a lot of classical stuff which was really, really good, and I remember the house always having some sort of background (music), both here and in England, but more particularly out here, and when Dad was taken ill five years ago ... The boys were still into Pink Floyd, but the boys made this poor man lie down ...with a speaker on either side and they played 'Time' and it begins with alarm clocks going off ... so you listen to the very deep base and you relax and then all of a sudden ... it was a bit cruel ... he leapt off the floor but he loved it, and the boys actually taught him how to listen to stereo music. [Paula] We were in a local pub ... 'Too Young' had just come into the charts and I sang 'Too Young' and Johnny said afterwards, that he fell in love with me after I sang that. 'Too Young' was our song because, every time Jimmy sang it, we used to get all emotional about it ... [Joan] 
Graham taught them (his daughters) to sing and really pushed for the girls to go up (on stage) and sing ... One of the songs he used to sing to the children when they were going to sleep was 'Danny Boy', that was one of his favourites. There was dancing and singing, and we seemed to like the same music and that particular night they played the theme from the 'Deer Hunter', and that was always a great favourite of Graham's and mine, we both liked it... the one thing that really won me over was he use to sing to me and he would sing 'Memories' that was one of his favourites, and 'Spanish Eyes' and all those sentimental sort of songs, and he had a lovely voice, well I thought he did, and it was really, really soothing and that really made me fall for Graham with his singing. [Ngaire]

These experiences described by the family members could be the experiences of many people, as almost everyone has had, or can recall a piece of music that has had a profound effect on them, whether it is happy or sad, that piece has become a lasting reminder of a particular event. Alvin et al (1996) cited in Salmon (1993) have proposed a " psychodynamic meaning of music, pointing out that music can operate at id, ego, and superego levels, thus covering the whole range of human experience." (p.49).

The patients' 'physical response to music' was also relevant to both these men as they endured long episodes of illness that impinged on their daily activities. Both families focused on this aspect in great detail, because they were the people who had most contact at this time, and it was something that touched all of them, because they were involved in the patient's care. Joan and her family had five years of caring for John while he was on dialysis. Much of their story relates to the initial diagnosis and the trauma faced by John, and how his family supported him during this time, and up to his death. 
I remember the very first time he went on dialysis he was very, very tense because the nurse reckoned he was only touching the table with the back of his head and his heels. and he did say, that he was literally terrified. [Paul] Paul brought him his CD player, and some CD's, and a set of headphones and it was great to see Dad settle into his music and just kind of forget about the machine and all the apparatus and this thing out of his neck and just settle down ... depending on what he was listening to. The nurses would say, Jazz today, BP's up, you've got to calm him down. It was great whether he was on dialysis here or up in Christchurch he would have his headphones on listening to something, and you could tell by his facial expression or the movement of his hand or toe tapping what he was listening to and what he was in to, which was really good. [Paula]

When he was sick and he would be on dialysis and I would be busy round the house, I would go in, he would be lying on his back in his chair with his feet up and he would be have the music on and his toes would be going up and down, up and down and he would have jazz on his boom box, as we called it, and he would be oblivious, I could walk in and stand alongside him, and he wouldn't know I was there. [Joan]

With Dad's life, really over the last four years, he was pretty well confined a good eight to ten hours a day in the dialysis room, and so it was either TV, reading or music, and obviously chatting with visitors and so on, but the music added a different dimension, rather than the blot out of just listening to TV chatter. I think it allowed him to do a lot of thinking and quite often he would drift off to sleep, and it was a decent sort of sleep, instead of five minutes catnap type thing, it was a decent sleep, which obviously enabled him for the day to go quicker. [Paula]

Even then he was really into music, relaxed him and kept him calm ... every time I went in to visit he would have the headphones on, and he would be in bed, and you would see his hands, and his hands would be going, or his feet 
would be going, he enjoyed music ... If he was in pain I used to say watch the telly it will take our mind off it. John would say, "I don't want to watch the telly, it's rubbish, rubbish, put something on for me", and I would put on a CD, and I would say "What do you want?" and he would choose Judy Collins or Stephan Grapelli, he had all the jazz masters ... but towards the end I don't think he ever listened to jazz, he listened to calmer quiet music. [Joan]

He'd just been turned or he'd had meds or anything like that, his breathing would be quite harsh and erratic and almost like a fighting thing, you know when you are in pain and couldn't actually acknowledge that, but with a little bit of head massage and a bit of hand rubbing and listening to some quieter music he was good, it settled him down into a decent sort of rest state.

It was Acker Bilk, it was two CDs that he was into in the last few days, it's such a lovely $C D$, It's not too highly jazzed, it's just really gentle stuff, very mellow and sitting with Dad you know we would have the odd moment of consciousness, we would actually communicate a little bit, eat a little icecream or something, and I said you're tired, go for a sleep, I'll put this on, I mean Dad's affinity with the sea was just huge, and it was one of those tranquillity CDs that was very sea-like, you know, rolling waves and various things. And 'Stranger on the Shore' there is a lot of sea-type music in that, you can hear the sounds of the waves. [Paula]

The stories above reflect on the effect that music played during the patient's episodes of pain, and how it just happened out of concern and love for the patient. There was no one to instruct them as to what was right, they knew instinctively that music was important in the person's life, so therefore it was right to use it, and it was effective. The management of pain is always of concern to the carers and families, so for nurses and doctors an awareness of this treatment modality is 
vital if good palliative care is to be maintained. Families need to feel reassured that they and the patient, will be listened to, so as to achieve a collaborative environment with all who are caring for the patient.

Much of the literature about music therapy is related to its use in the control of pain, for example, Munro (1984), Mandel (1991), Lane (1992), Magill-Leverault (1993), and Trauger-Querry and Haghighi (1999). Magill-Leverault (1993) in her article about 'Music Therapy in Pain and Symptom Management' suggests "music therapy is one of the non-pharmacological interventions that is being used to improve levels of comfort, and enhance well-being in patients, as well as in family members"(p.42). One of the advantages of a multidisciplinary approach to pain control is the ability to address all the aspects of pain that can be involved in a patient's care not just the physical aspect. Trauger-Querry et al (1999) supports this when they suggests "there is an understanding that pain is complex, and includes physical, psychological, social, spiritual and emotional components. The origin of pain is not always physical" (p.26). They also suggest that most hospice teams are capable of treating pain with chemical, surgical, and radiation therapies. But they go on to explain that according to their research " pain may be resistant to these therapies when emotional, spiritual, and social issues of the dying person are not addressed" (p.26).

A further comment relating to treatment of total pain according to Ley (1993) states "pain embraces the whole person" (p.174). As nurses we are reminded that pain is subjective, therefore we cannot allow our assumptions of pain to impinge on our care of patients, it is their perception as an individual. John's family did not have the advantage of the knowledge about the research that supports that use of music for someone who is in pain. What they did have was first hand understanding of observing a loved one who was experiencing pain, and instinctively knew that when they played his favourite music it made a difference, by improving John's physical and emotional wellbeing. 
Graham also suffered from severe pain for a number of years before he died. Graham learnt to control the pain his own way, and managed to live a full life because of this, mainly self-taught ability involving music.

Seven years before Graham died, he had a back injury ... he was in a lot of pain and he had a breakdown because of the pain and he went to Burwood clinic where he was very disruptive and got everyone wound up ... but in two weeks he learnt to listen to relaxation taped music and a lot of that was water music, and I think that was part of their treatment to learn to relax by music. If the pain was really severe, he put on the relaxation tapes ... he learnt, and that was the first time he had anything to do with that sort of music, but he was able to control his pain through that music. [Ngaire]

Graham had also been on morphine, (an analgesic) at different times with varying degrees of success for the back pain.

Graham learnt to do it when he was starting to get pain and working its way out ... so that part of music did help him, and even when he came home and things were bad at home at night and he couldn't sleep, because he used to take a lot of sleeping pills and things like that, but even that didn't work for him, he played relaxation music and that helped ... Well I hated it but Graham loved it (Twin Peaks theme) and he played it over and over ... about four years before he died he got into Tai Chi and Tai Chi has got quite relaxing, tinkly sort of music, like that Twin Peaks music ... For hours he would do Ti Chi and that would help him too, the music, and right up to the week before he died, his legs he couldn't move or do the actions with, but it did relax him. He would go outside and do the arm movements of Ti Chi, up to about the last week before he died, to the music. He would have the headphones on and he would just do it and he could shut off and even then he could control his pain with that Ti Chi music and do the actions. I think it was he could relax and he had something to focus on. 
Graham could cut himself off, like if I'm troubled I think everyone has a centre point, mine is telly, Graham's is music, so he could wind himself down and control his pain ... [Ngaire]

These personally shared recollections of what music did for their husbands enables us to be involved in the text by seeing a description of an event that is unique. The recollections also enable us to become involved as observers with the text, and requiring us to respond to the question about this phenomenon of music therapy and it value for someone who is dying. van Manen (1990) believes "phenomenological text succeeds when it lets us see that which shines through, that which tends to hide itself" (p.130). Writing these words is what phenomenology is about, because it is in and through the words that the "shining through (the invisible) becomes visible" (van Manen,1900, p. 130).

The third theme 'impact of music on memories' was significant in both transcripts, the memories associated with particular events throughout the life of the patient and their family, and also the incidence of using music to bring back those memories. It has been stated that up till the 1960's, "the expression of reminiscences by aged adults was considered to be an unhealthy activity" (Dobrof, 1984 cited in O'Callaghan, 1996, p. 12). Authors of music therapy have challenged many times since this statement, and as Butler (1963) contend "life review is a naturally occurring process characterised by the progressive return to consciousness of the past experiences" (p.66). It may be thought that the use of passive music, that is listening to music, is not really music therapy, but in the following incidences using music in this way evoked memories that provided comfort, relaxation, and a connectedness with those who were important to the patient. The feelings that emerge from the stories clearly demonstrate how the music was able to give the patients a sense of control, at a time when control is not perceived to be possible. These lasting memories that the 'musical memories' have recalled has enabled the families to share, and remember. 
But I know the type of music that he chose to listen to in certainly the last week of his life, we moved the CD player into his room, and I took a selection, and he was actually able to say, "no, I'll listen to this or I'll listen to that" or whatever, but it got narrower and narrower, and fine tuned, so that the last couple of days really the music was three or four CD's that just got rotated, and it was basically whale songs and a bit of tranquility music, and just really soft, gentle music ... Dad's affinity with the sea was just huge...

There was a tranquility $C D$, and coupled with, I could use a bit of mental visualisation with him you know, about riding on the waves and. ...[Paula]

The family spoke about the value of music for them at this time.

I think, for me personally, it was good to have the music on because it covered any discomfort, it was always there in the background, you could listen to the music and switch off to his breathing, because his breathing became quite..., so it was good in that respect, for me anyway. [Paul]

It did take the quietness out of the room. The room was sort of alive, and I think that is why we continued the music through. I don't know was it even turned off, I don't think it was, I think we just turned it down really, really sort of pin drop sound, right through until Dad actually left us.

Music was playing after he died. When all the family arrived, the music in the background seemed to be so calming, and yes it did make a difference. I don't know why it made such a difference, but it did [Paula]

I was on my own with him, said my goodbyes, and the music was still playing in the background, and I looked at him, and I touched his cheek, and 
he starting to get a bit cool, and I thought that music has been really, really worthwhile ... and nobody ever suggested turning it off ... I came back in half an hour, and then when I went back along the hall and looked in and the lights were all low, the music still playing.

He looked so peaceful and gorgeous, he was young, he went right back, all the lines had all gone, and he looked really beautiful and I stood there ... and I said "come and have a look at him kids", and his mouth was turned up into a smile. Do you remember?

I think the music did make a difference. The kids were all walking in and out, and they all went and said their goodbyes, had a one on one session with him, and told him all the things they perhaps felt they should tell him or could tell him, that they perhaps hadn't told him while he was with us, and I think that lasted all evening. It was wonderful wasn't it for all of us. [Joan]

I think, why did we leave the music on, people were sort of in and out after Dad died, but it was like, oh music stopped, change it over. It was just an unconscious thing and everybody took part if the CD stopped, they would just continue it. Although it was turned down quite quietly there was just an atmosphere in the room, it was just so calm, it was good for everyone to actually be there, for me it was not clinical, you know it was not clinical at all ... it just personalises it, it was family. [Paula]

I think having the music going in the background and all the family being there, I think all the boys appreciated it, and their partners, and even my youngest granddaughter Patricia, she was lying on the bed alongside of him, and that was a hard thing for a youngster like that to accept. [Joan]

To me it's like a man can't play cricket anymore... he can't ride a horse, or any of those things, but if music has been part of or it is still something that is part of life, it is part of that person still and therefore why shouldn't it be 
... if hearing is one of the last senses to go then surely it should be filled with beauty. [Paula]

One of the last pleasures, it was a pleasure for him to listen to music, it really was and he use to say ...I don't smoke, I can't drink, and sex is out the window, but I can listen to my CD's. [Joan]

He (Graham) was in a lot of pain, and he would get really down, and get these black sort of periods, but Pavarotti and the Three Tenors and ones like that helped him and he seemed to drift off into his own little world ...he loved the outdoor life, and I think in the latter part when he had the little pond and we had the waterfall music and things like that, I think when he used to drift off near the end, he was perhaps re-living the music and the bird songs because he was very into nature ... I think it sort of brought his past life and he could hear it, and he was the sort of person that most probably could cut himself off what he was going through and think he was there in the forest and the birdcalls. I think he could most probably drift off and pretend he was in those places and that blocked out the bad things for him, when he knew things were bad, he could block it out with music, because he would just go off on his own sometimes and just listen to whatever he wanted to.

Even when Graham was dying, by night he couldn't sleep, and we were in our room, and Linda, (his daughter) had come over to see him ... and he was singing, and he must have sung for about an hour or an hour and a half, and Linda said it really cracked her up because she sat in the hallway outside our door and didn't tell us she was there listening, and crying.

48 hours before he died, I can't remember who sings it, 'Slipping Away' and it kept going round and round in my mind, I couldn't get it out, it just kept going. I was sitting by the side of the bed with him and I said to him-you 
know Graham there is this song that keeps going round in my mind and I started to sing it, and he said "No don't sing it, don't sing that", so he must have known he was slipping away.

... one of favourites that he really liked 'Power of Love' and about a month after he died I came in here, I use to cry at the slightest little thing ... because I miss his singing, when I get uptight, I miss his singing to me, and I thought I will go through the tapes because a lot of them were his, and there were a lot of blank ones, and I put this one on and for a while there was nothing and then I thought I would switch it off, but for some reason I kept it going, and it was him, singing ... I had to keep playing it [Ngaire]

Graham's ability to use music to transport him to places that held special memories is a technique called 'guided imagery' developed by Helen Bonny in 1973. It can be a powerful medium for patients to take themselves 'out' of the hospital or bedroom walls to a place that has significance and possibly thoughts associated with earlier times in their lives. The close relationship that Ngaire and Graham shared was centred around music and was obviously tied closely to their emotions, as special songs had special meanings for them. Salmon (1993) discusses the many ways music and emotional life are connected but perhaps she says "their greatest similarity lies in their non-verbal dimension" and "music and emotional life are both essentially rich, complex, multidimensional, often mysterious, and deeply human experiences" (p.14-15). Many times in the last weeks of Graham's life, both he and Ngaire shared times where the spoken word was not needed, and music was the catalyst that allowed a togetherness that Ngaire now treasures. This story also gives understanding of what music is capable of, and illuminates to us as nurses, and all those working in palliative care, how it can improve our aesthetic knowledge in nursing. Susan Munro (1992) in her explanation of the varying music techniques beautifully describes the possibilities that can be achieved for individuals when music is used as an element of approach: 
It has intricate associations with the histories and life stories of men, women, and children. It serves as a powerful means of expression in which tone, colour, frequency, intensity, intervals, rhythm, and tempo transmit potent nonverbal messages. It touches emotions beyond cerebral command. (p.40)

\section{Insights from the texts}

I will begin with the family stories, and discuss the common themes relating to the value of music for someone who is dying that emerged from their stories. The themes were; Music as part of life; Physical response to music; Impact of music on memories.

\section{Family texts}

During the many years I have read, listened to speakers, spoken about, and searched out literature about music therapy, the phrase 'that's only anecdotal evidence' has been used many times in relation to music therapy. Yet van Manen (1990) devotes almost seven pages in his book to this specific word as a "methodological device in human science to make comprehensible some notion that easily eludes us" (p.116). He speaks about anecdote as a story, and how this method of imparting information has become popular amongst those who are presenting human science research. He speaks of anecdote as "a special kind of story"(van Manen,1990, p.115). Anecdotes have been used by scholars, biographers, and historians for centuries, because to try and explain something in a direct manner was sometimes too difficult. So the anecdote was a means of humanizing, as it was a story taken from everyday life experiences that people could relate to. van Manen (1990) qualifies this when he states:

anecdote particularizes the abstracting tendency of theoretical discourse; it makes it possible to involve us in pre-reflectively in the lived quality of 
concrete experience while paradoxically inviting us into a reflective stance vis-a-vis the meanings embedded in the experience ( p. 121).

The two stories related by the families for this research are 'special stories' as they enable the reader, to become part of an experience that would not normally be available. The stories impart an understanding of a phenomenon directly from the individual/s involved that was their unique experience. As the readers, we may put our interpretation on what they are saying, but it is also a privilege to share in their stories and learn from the thoughts and feelings that these people have expressed. This enables us to then grasp some concept of the value of music therapy for someone who is dying.

\section{The phenomenon of music for someone who is dying:}

\section{The families}

Both families were convinced that the use of music by the patient throughout their lives was fundamental to its use when they were dying. The two themes of "music as part of life', 'and impact of music on memories' appeared to merge occasionally throughout the transcripts as the families talked about the importance of music in the patients life and how particular music was mentioned at a specific time during their lives. The ability to relate music, particular songs, or specific incidences during life where music was involved, enabled both the patient and the family to feel secure in their choice of music at a time when they, patient and families, needed to feel safe and supported. Hogan (1997) speaks about the value of memories as one of her categories in her research. Her synthesis of this category found that:

During the music therapy sessions, participants associated the music with memories of significant events, people and places they had experienced in their lives. Some participants relived these past experiences through their 
kinaesthetic, auditory and or emotional senses, allowing one participant to feel connected to the recalled place, event or person/s. These were perceived by some participants as meaningful experiences. The associated memories evoked feelings ranging from luck, youthfulness, good fortune, love, enjoyment and /or pleasure, to sadness and/or regret, and were described by some participants as fun, good or marvellous to recall (p. 285).

Many of the above experiences were shared by families during their interviews for this research, and show similarities to Hogan's research and her findings. The overriding conclusion for the families and the patients, appears to be that music had always been part of their life, so it was essential that it was part of their dying. The family's personal knowledge of the patient's likes and dislikes was invaluable at a time when their loved one was unable to make choices. This was very significant for the families, as they were able to provide the expertise that was needed at this time, and feel very much part of the team of carers.

Salmon (1993) also concludes that the inclusion of music for a family and patient can only be beneficial to their relationship as "music often becomes a valuable tool for addressing the complexities of human relationships" (p, 11). In interviews with families they were able to recall the significance of particular music or songs that allowed them, and the patient to relive or revisit cherished memories and thus enabled special moments to be shared. O'Callaghan (1996) also notices in her music therapy sessions with palliative care patients that "music therapy can be a gentle, non-intrusive way of offering support, comfort, and reassurance ... patients may project their feelings onto the music, or reflect upon associations of the song lyric with their own lives" (p. 7).

O'Callaghan (1996) also discusses the advantages of live music as opposed to taped music, but does conclude that "the optimum is to give the patients a choice of either live or taped music"( p.7). The family interviews did not raise this issue as it did not appear to have any significance for these particular families. In reality 
the choice was not offered at the time of illness because live music was not an option for people in their homes. The option of taped music was their only choice, and was readily accepted as the appropriate method of providing music for them as a family.

O'Callaghan (1996) also comments that in many of the hospitals where she works as a music therapist, taped music and headphones are available to patients for their use, and the tapes are also used by families and staff. This issue of taped or live music is important to this research, because as I have already stated, there are not sufficient music therapists available to palliative care patients throughout New Zealand. The evidence provided by the families regarding the use of taped music is beneficial to support the value of taped music as part of the planned care that is put in place by nurses, who have been trained in the use of music therapy. Munro (1984) supports this in her book when she states:

the nurse is readily accepted at the bedside whereas the music therapist may be perceived as an intruder. A nurse, sensitive to music and its role, and place in people's lives, can discover the 'music person' in her patient just as the therapist would as long as she is familiar with this concept. The nurse and patient may exchange their perceptions about music while a bed bath is given; the patient doesn't feel interviewed and attention may very naturally shift from hospital and illness to memories and life issues (p.62).

In both Graham's and John's stories, music was used frequently at night when noone else was around, except family. In a hospice or hospital setting as at home, a music therapist would not be available at this time, so again the obvious choice would be the nurse caring for the patient. As I have experienced too, patients may choose music at odd times that suit them, so the advantage of taped music is that the patient can choose when they want to listen to music. By using taped music with headphones they can also give consideration to other patients/family who may be close by. The ability of the patient to play music when they want to also 
allows some control, and feeling of being in charge at a time when they are gradually loosing some of these capabilities. John was able to make these decisions about his music throughout his illness, and then his family was able to continue, safe in the knowledge that they were confident about the choice of music for their husband/father.

There was a secondary theme to the 'memories' theme that is worth mentioning, as both families talked about it. That was the lasting memories they have now that are rekindled when they here music that reminds them of the their husband/ father, and the time of their dying. Both Joan and Ngaire spoke of the value music had when their partners were dying and the families were present. The music acted as a catalyst for emotional and physical sharing at the time of dying, between patient and family members. The role of music also played a part immediately following the death of their loved one, as the quiet void that was left was made more bearable by the gentle, unobtrusive, and soothing sounds of music that echoed through the house. Ngaire explained that the emptiness that was evident in her life following Graham's death was due to the fact that she was no longer able to hear and enjoy his singing, which was so much part of their courtship and marriage. When she discovered the tape with Graham singing 'The Power of Love' she was initially overwhelmed with grief, but was so grateful that she now had a lasting memory of his voice that she could listen to whenever she wanted too. The use of music after death is not something that I have read about in any of the literature so far, but obviously has an impact that is worth noting. It is not surprising that this use of music was mentioned as it follows through the concept of music as a catalyst for many life experiences, and the way music is tied closely to our emotions.

The second theme identified by the families was 'the physical response to the music' by the patients and, in some cases the family members too. Research related to the physiological response to music has already been discussed in this work, Burns et al (2001), Evans (2002), so the stories that the participants were 
able to share about this aspect of music therapy were invaluable to this study. However caution is needed when generalising about the physiological response to music as the effects of music will differ for each individual, and the type of music played. Farnsworth (1969) points out that there are three important variables that will determine the effect of the music on the listener: "the presence or absence of abrupt tempo changes, the acceptability or unacceptability of the composition, and the personal association the music has for the listener" (cited in Cook, 1981,p. 258). In this study the three variables were not a consideration as the participants and patients were well versed in the type of music that was acceptable to them. The importance of assessment when applying music as part of care is recommended, because the outcomes could be less than satisfactory for the patient, and may even cause added stress or anxiety.

The two patients discussed in this study both had a long history of pain, and music was the adjuvant to pain medication that they used to control this symptom. Graham's back pain was something he lived with, and learnt to control with Tai Chi and the music that accompanied this discipline. His capacity to maintain pain control right up to his death, was a remarkable testament to the way he could totally focus on something like music and remain in control. Magill-Levrealt (1993) writes; "music can engage, activate and alter affective, cognitive and sensory processes through distraction, alteration of mood, improved sense of control, the use of prior skills and relaxation"( p. 48).

The ability of music to aid relaxation is well documented in many research articles, such as Munro and Mount;(1978), Munro (1984; Mandel (1991) and Magill-Levreault (1993). Graham was able to achieve relaxation with his choices of classical and environmental music, which appears to be a pre-requisite for music to be successful in the reduction of anxiety, as stated by Hanser (1985). Hanser concludes that music has "considerable potential to reduce stress but warns that the selection of music, or deciding what constitutes relaxing music, can be 
difficult, as music that is relaxing for some might not be for others" (cited in Biley, 2000, p. 674).

Ngaire was always impressed with Graham's determination and confidence that the music would enable him to shut out the pain and induce relaxation, and therefore aid his sleeping. She was also aware that some of the music that was affective for Graham was not something she found relaxing, and realised that this individual choice was most important. Graham was also able to use visualization with certain music which facilitated his ability to transport himself back to the places he remembered and cherished. He was able to articulate clearly 'where' he was, and what he was experiencing when listening to his environmental tapes. For a person who had lived and worked in the outdoors most of his life, this ability to take himself to his special places, was extremely relaxing and comforting. In my experience I have found that environmental tapes have been accepted often by men like Graham, who yearn for the chance to be part of nature again when they are physically incapable of achieving this. I have also met with resistance when I have first suggested this type of music. But on most occasions the patient has bought up the topic again when they are ready to accept it, and enjoyed the experience. It was very reassuring to Ngaire as well to know that Graham could achieve something that was special to him, and gain comfort from it.

John's and Graham's experience of music and pain relief was similar. Music promoted relaxation when they were anxious, allowing them to drift off into a peaceful sleep. It provided an avenue for memories of favourite places and people, which acted as a distraction and therefore encouraged relaxation. It also alleviated fears of treatment by promoting a calming environment. John's reaction to music was visually physical at times, sometimes of which the family were aware, and thankful for because they knew he was relaxed and able to escape into the music. This was noted by his toe and hand tapping, his smile when music was playing, his complete immersion in the sound of the music, and being oblivious to others around him. John's family played music continually when they were performing 
personal care for him towards the end to provide a calming atmosphere, but also to take away the quietness, which covered the discomfort of some family and visitors present. They also felt that the use of music made the caring more personalised, as it took the edge off the clinical aspect of what was being done for their father.

The issue of music as a medium for treating pain and anxiety has been examined by a number or researchers including McCaffery (1990); Beck, (1991); Good et al., (1996), McCaffrey and Good, (2000). McCaffery and Good (2000) in their account of a phenomenological study related to pain following surgery, describe their third theme as 'distraction from pain'. Their conclusion states "all participants indicated that they were distracted from fear, pain, and anxiety when listening to familiar music. This distraction allowed them to be calmer and, in many instances, fall asleep. (p.84). Although this research is related to surgery, anxiety, fear and pain are also significant for palliative care patients. Their research presents the lived experience of their participants. This descriptive experience is based on individual experiences so is relevant to this study.

The personal musical knowledge enabled these families to 'administer' symptom control, as they were aware of the type of music that was beneficial to the patients when they were in pain, anxious, or unable to sleep. The rewards for the families are immense when they know they have the opportunity to lessen problems for a family member by the simple act of applying music as a treatment modality.

\section{Introduction of nurse participants}

The two themes that emerged from the transcriptions were:

- holistic, individual care

- communication, between patient, nurse, and family. 
Excerpts from the nurses' transcripts are written in italics, and the researcher's comments in normal font.

The value of music for someone who is dying was the centre of this investigation when I first considered it. But over the years my personal involvement in the practical use of music, and the positive reactions I have witnessed have encouraged me to further this study by exploring the option of nurses incorporating this therapy in their planned care of palliative care patients. In the music therapy teaching sessions with which I have been involved over the last eight years I have found nurses are genuinely interested, and are enthusiastic about the possibility of adding another dimension to their nursing care, if it is beneficial to their patients. There are a few references to nurses, and the use of music therapy, but no studies by nurses about the outcomes of using music in their practice. Biley (2000) in his paper The effects on patient well-being of music listening as a nursing intervention: A review of the literature', discusses the numbers of discussion papers that describe the potential benefits of music therapy, and also includes data to encourage nurses to use music as a therapy. Cook (1981) in her review of Music as a Therapeutic Intervention concludes "although apparently used relatively little by nurses in the past, music appears to have a wide variety of applications in the patient care setting" (p. 264).

The two nurses who volunteered to be part of this study have many years of experience in palliative care, and were very willing to share their thoughts and experiences of using music therapy in caring for patients who were dying. Both nurses agreed to participate because they believed that sharing their stories may be worthwhile so that other colleagues in the profession could grasp some understanding of the concept of music therapy, and its possible wide-ranging effects. 


\section{Sondra}

Sondra has 30 years experience as a nurse working in the public health system, mainly in palliative care. She has just recently moved to the private sector, where her skills in palliative care have been acknowledged by her appointment to palliative care nurse specialist in the hospital section of the Rest Home. Sondra describes herself as having a passion to do the best she can for the dying, and a genuine concern to help these people end their lives in a more comfortable way.

Sondra's introduction to music therapy was quite by chance, when she came across some music tapes in the palliative care nurses' bookcase, and asked what they were for. Sondra mentioned that she was caring for a woman who was distressed, and could she try the music tapes. When the tape was played for the patient, Sondra was amazed at the response, which was the almost immediate calming effect it had on the patient. Sondra then began to seek out more information about the use of music therapy, and has continued to apply it in her every- day practice.

\section{Christine}

Christine is also a nurse with considerable years of experience, and the time of her interview had been the Nurse Manager of a local Rest Home for seven years. Previous to that she worked as a District Nurse for thirteen years, caring for patients in the community. Christine has been part of the nursing workforce most of her life since graduating in the seventies. Her interest in music for those who are dying became part of her practice about 10 years ago, when it was becoming more common to investigate other ways of assisting people to cope with their particular issues. Such as caring for people in their homes which created opportunities to involve families in the care of the person who was dying, and it was in this environment that Christine discovered the value of music, and other complementary therapies for patients. Christine has continued to explore the use of music in the Rest Home setting, and although she believes it is only just being 
recognised that residents are there to receive terminal care, (but not all cancer related), there is a need for holistic care, and a need to look 'outside the square'.

\section{Interpretation of the nurses' texts}

The first theme that developed from the nurses' texts was, 'holistic, individual care'.

One of the first questions I asked the nurses was how they introduced music to their patients, and the format they use to gauge a patient's interest in music. Rather than just include short phrases to seek out the answers, I have included most of the nurses' conversations to enable a clear, descriptive picture of the way music therapy became part of the holistic care that these nurses provided in their individual care settings. The nurses' abilities to provide vital background information about their patients, the environment, nurse and family involvement enables a clear picture that sets the scene for their stories. To exclude any of this information would have detracted from the total concept of their care. This also adds rigour to the inquiry by enabling a real sense of the evidence that will form the basis of the analysis and interpretation.

Sondra began with her description of the first time she used music with a patient.

I had talked to her. We had been discussing what we could do to help, and I thought of getting in books, and I had talked to the relatives, perhaps they would sit and read a book. She said, ' no, she didn't really want to listen to a book" and then I remembered about the music tape. I said, "well would you like a wee bit of music going in the background, you know, I know you are a very nature sort of orientated person", so she just said "that would be quite nice". She said "what do you have in mind"? I said, "well I wasn't really sure, but knew there was some soft soothing music, which I would bring back and see what she thought about it". So I came back with this 'water-music tape', and I remember saying, "the picture looks good on the outside, shall we give it a go"? She said, "all right, all right", so I put it on. First of all I 
had it too loud and she got a wee bit upset about that and she asked me to turn it down, and that is how it came to be really. I got their (patient and family) consent first, and it was sort of a mutual agreement amongst all of us. [ Sondra]

Sondra continued her story which included the reaction of the lady's family and the staff.

What I probably noticed was that the relatives became quieter and they weren't all talking together all the time and they were sort of listening to the music too and they were more relaxed, sitting back in their chairs, some with their feet up even on the lazyboy and just listening to the music. Someone even came into the room once and they put their finger up to their mouth indicating ssshhh, you know that was really ... but I noticed the staff showed a bit more respect too, and if they came in when it was playing they wouldn't rush out and do what they were going to do or say, they sort of, they were more respectful. This lady just seemed to be more relaxed and she seemed to really enjoy the music going in the room, as long as it wasn't too loud. Wasn't long before they (family) were bringing in tapes too, and she was having music going, in fact there was music going a lot of the time, even well into the night, she kept the music going. Just before she died the music was going all the time. So, I left it, it was their choice, their decision, but it really made me think that music is important.

There was another man who use to listen to Foster and Allen 24 hours a day, seven days a week, and I said - " don't you ever get sick of it?"- he said, "No never". Even when he was dying he knew his choice of tapes, he knew what he would want, and Foster and Allen was playing right up to when he died and I felt very, very comfortable with that scenario. 
I nursed a lady in her own home too and I became very, very involved there, and she liked music, but she liked it when she was ready for it, what she wanted at the time, it was a big choice, what tape she wanted to use and it was a major decision for her to pick out the tapes, how long it was to go for and.... yes we played music a lot but as I said it was her rules with the music, which was fair enough. I had offered to bring over some of my tapes, but no her tapes were used, obviously they had meaning ... Personal choice, I feel strongly about personal choice. They seem to have got a little bit of their independence back because they are the ones making the choice, their decision ... I just think that it is very important for the young and the old, right through every age. It just improves their everyday living really and gives them another aim, another thought and whether it be modern music, spiritual music or whatever, their choice. [Sondra]

Christine described her experience of the importance of the individual's choice.

But then, particularly for people who have had music as a key part of their life, they will often come in with their own equipment. They will either have their own stereo or little tape recorder, or they will have something, you know that is a clue for us too that they have got an interest, and we have got a few little tapes and disks up our sleeve that we can use if we are not sure what people enjoy and we have a portable that goes from person to person. But, where people have got their own collection, obviously that is a very good place to start, and that is the beauty of it, that they bring it all in with them and so you know what they like for a start, and you can use that as a starting point.

As part of our social assessment on admission because often it is not immediately that you get that information, but from admission onwards we collected information and actually do a formal assessment which looks at their previous leisure activities, what they enjoyed doing, what they now 
enjoy doing, what they can't do now that they used to do then and sometimes some of the things they have enjoyed are limited by their physical ability now. While they might enjoy music, they might not be able to get up, cross the room, and put on a CD. So, you know, perhaps looking at the things they have enjoyed in the past and that does include looking at what part music has played, whether they were a musician in their own right, with an instrumental type interest or whether they were more interested in choral music or involved in choirs, and a lot of the women of course do, and are very happy to talk about that, and we document all that and from there an activity plan is formulated for that person and we keep a record of their involvement and any changing interests they have. So, we probably update that about every three months. [Christine]

Christine then reflected on her time as a District Nurse, and one of her first experiences of music as a therapy in the care of a patient at home which was initiated mainly by the family, but encouraged by the nursing staff as well.

That family struck me a great deal because they were prepared to search for anything that helped really and they were very disinclined to use drugs to achieve that if there were other alternatives. So they were very open I think, which made it much more feasible as professionals going in to pick up on some of their cues. Their background in music was far more extensive than mine but they were willing to look at anything that they had enjoyed together as being a way of trying to often settle Tom down and he usually responded quite quickly to that. It was interesting, I do recall, even though it is going back a number of years now, it depended on what his symptoms were as to what type of music he responded to and as time went on he settled, became less restless, less inclined to throw himself around when he became bedridden. It was quite different music than that had been effective when he had been more mobile. So there was quite a change in him and the family recognised that different things were working and so, there were no rules to 
follow, just what seemed right at the time and what worked, so I guess the thing that stood out for me was the variety of things that worked at different times. They had a huge repertoire of their own and didn't really need a lot in the way of resources that we as nurses could come up with. I guess going back to that time with Tom it re-enforced that there are other things you can think about and it was looking at other complementary therapies as well, such as aromatherapy, and often the two works in harmony somehow.

I can recall when, his level of consciousness did vary as his disease progressed, and there were periods when he seemed to be in some sort of twilight zone somewhere, and he did respond, respond to physical stimuli, but he didn't really speak and seemed to doze off very rapidly into a sleep state and I found that the problem for me was that when we used to visit him we were essentially going in to provide physical care as much as anything, especially in those latter stages, and so by its very nature we were disturbing him. So, even though you may have music playing while you are doing that care, we often created the problem of restlessness and so on because we would be moving him, we would be turning him, we would be repositioning him and he would inevitably become quite restless during that process. He didn't really call out in pain, but it was more his restlessness that you know you had disturbed what was a very fine balance, so it took a little time after the care was completed to settle him down again and you could actually see that happening and as his disease progressed further, it took longer. I found that, you know, and I would be concerned about that, and say, "look now we have left you with a worse problem than what you had before we came" but his wife would say "Don't worry, it won't take long, he will settle down".[Christine]

Yes, the family continued to play the music after, during and after the care, but it didn't work while we were providing the care, but it did seem to be effective afterwards, and it took an increasing period of time for that to be 
effective once the disease was quite advanced, but she was always confident it would, and she always told us it did. So, unfortunately we didn't always stay there long enough to see that happen, but they believed it did. They had a great faith of their own anyway and this was like, almost, a real expression of peacefulness on their face, music was something they believed in, almost, in its therapeutic value. They had a great belief in it and it did work for them, whereas in my current experience I don't know that I could categorically state that it always works for everyone you may try it with, it doesn't and you have got to again explore those things as well, and while you have got a few ideas about what might work, or help that person, you don't know until you try and you have to be prepared to get it wrong a few times. I guess to, perhaps my situation has been dealing with people who are not always able to communicate effectively and therefore you have to go really by the response you get. I can't necessarily expect them to tell me or tell their caregiver whether they like or not. I think more recently dealing in my own situation in a residential care facility, often you have to go searching for suitable music and you don't know if it is going to work for that person, and it depends what you are trying to achieve, what works. For some people it may be that they become less anxious and less restless, for others it may be that it helps them to sleep and for others you can see agitation increasing, so you know you have got it wrong.

I think we have found that we have such a diverse group of people, all totally different backgrounds, people that would never choose to live together if they could avoid it, so what you end up doing is providing a variety of things for those folk so that they can you know, ignore if that's what they wish to do, make themselves scarce if that's what they wish to do, or participate if that's what they want to do. We find that a variety of music is particularly effective for getting a response either to sing along or to just the pure rhythm. We have a lot of Irish and Scottish music that seems to be very popular. Also a lot of the war time music, particularly Second World War music and there is 
quite a lot of that type available. We find too, that not only do we have the passive listening to music sort of arrangement, we also have a regular slot where it is really encouraged to sing along and that seems to be very enjoyable, more, it has a sort of roll-on effect that once you get a few people, then a few more join in, then a few more, so you get a much wider response and it becomes an okay thing for everyone to end up singing along and the staff participate too. But, the men are an interesting group really, much harder to elicit a response I find, very reluctant often to tell you that they enjoy music. They will put it down - "oofff, I suppose I'll listen to the odd bit of music" they'll say, but they won't really be very explicit about it, they won't tell you and it is often only by watching them when something is happening that you will know you had an effect. As part of our social assessment on admission because often it is not immediately that you get that information, but from admission onwards we collected information and actually do a formal assessment which looks at their previous leisure activities, what they enjoyed doing, what they now enjoy doing, what they can't do now that they used to do then and sometimes some of the things they have enjoyed are limited by their physical ability now. While they might enjoy music, they might not be able to get up, cross the room, and put on a $C D$. So, you know, perhaps looking at the things they have enjoyed in the past and that does include looking at what part music has played, whether they were a musician in their own right, with an instrumental type interest or whether they were more interested in choral music or involved in choirs, and a lot of the women of course do, and are very happy to talk about that, and we document all that and from there an activity plan is formulated for that person and we keep a record of their involvement and any changing interests they have. So, we probably update that about every three months. [Christine]

Christine's explanations of music in the Rest Home setting for a group of individuals are suggestive that even with a large group of potentially palliative care patients, there is an opportunity to evaluate the possibility of introducing 
music as a therapy in the larger group, and as an individual therapy, if staff are encouraged to provide holistic, individual care. Munro (1994) explains the value of music as a group activity when she states " by its nature music facilitates social interaction, nurtures feelings of community and helps to draw out individuals out of their isolation and into shared experience" ( p. 79).

Following the introductory question related to initiating the use of music for patients, the nurses continued to give further examples that provided evidence of the holistic value of music and the importance of individual care, and some of the responses that the music elicited from patients and families.

I guess the times that I have found using music as part of the total care package has been working with people with dementia and I guess even though they may not be terminally ill in the accepted way of looking at things, in many respects they behave as though they are terminally ill, by which I mean that the often have loss of function, they may have a loss of communication and the pain is the one thing that is very, very hard to evaluate in someone with dementia and you see a lot of the same patterns with dementia as you do in terminal illness, so even though it varies from person to person, trying music therapy that way or for that person with a dementing illness who is at the end of their lifespan and obviously suffering perhaps from the effect of the loss of brain function largely, is very satisfying too. You can get some very interesting results experimenting with music.

I have actually got a lady who is terminally ill at the moment and who does have advanced dementia. She has gradually lost her ability to communicate. She no longer speaks and hasn't done for some time now but the very interesting thing with her is that in her younger days she absolutely adored Irish music and if we play Irish music now we notice she becomes a lot calmer and she is really at the end of her life in terms of her dementia, she 
has all but no function left at all and the way that works for her is just amazing.[Christine]

Christine then described the effect that the music had on this woman.

She would open her eyes, when she normally had them closed. She would appear to try and mouth, there was no sound, but you could see there would be a lot of action around, her facial expression would change, she would look more relaxed, and she has a lot of repetitive movement, whether she is in bed or whether she is in a chair, it matters not, she has a lot of repetitive movement, particularly of her lower limbs, that even drug therapy hasn't been able to manage really, and that settles down too. I guess thinking about some of the other residents we have had in the past, some, as a general rule I guess, a lot of men I find don't seem that interested, whereas you often get a better response, or an interest expressed by women, more than men, and yet it is often the men who respond very well if you give them variety. I think men can be quite reticent about those sorts of things, however it is interesting to observe that when you do have something that does appeal to them in a group setting, you will see the toes tapping and fingers tapping and you know, the eyes may be closed but the head might be nodding as well. So you know you have got the right sort of formula there for that person.

Another person I can think of who has very advanced multiple sclerosis and has lost not only physical function but she has also lost her ability to communicate which is extremely frustrating for her. She is not an elderly person at all, she is quite young, relatively young and she loves country music, and even though she is very limited in even being able to take her out now, the staff will crawl over broken glass to take her out to a country and western show if there is ever anything on here and so people know, the staff know what the residents enjoy and the other thing I find them doing is copying tapes and bringing them in, you know from their own collection. So 
they make a personal commitment almost to that person to look for what they enjoy, so I find that you don't have to do that, that comes from them as individuals so I think that is perhaps some mark of having achieved something is when staff actually see somebody with an interest and they bring a bit of themselves to help meet that, and that happens all the time. Children singing are wonderful, that always has a very great response from, almost without exception, residents respond dramatically to children singing.

You can see their expressions lighten. They are often smiling. They will often clap along and they always seem to hone in on one child who reminds them of somebody, but it is like, it elicits a response of the whole person, rather than just, - "oh I enjoyed that", you actually see their whole body respond. They might be tapping their toes, they might be humming along, or they might be just basically smiling at them and that is very common. I would say that is probably the 100\% guarantee you will get a response is using children. It can be something really simple, like the new entrants class for the next door school, coming in singing their latest nursery rhymes, it doesn't matter what they are singing, it seems to be the voice and the child and some magic formula that goes with that, creates a response, even to the most unlikely people.

Umm, I think I recall somebody saying it reminded them of singing when they were children, singing with their grandmother, you know just sorts of things that they would have sung together, so I think perhaps it does take them back to their. childhond. or. to their. swn experiences, they, do identify, with that. And, of course not everyone has dementia either, but you can certainly see it in a number of people that do have dementia that again one of the features of advancing dementia is increasing agitation and anxiety and we see that is one of the hardest things to manage because life becomes very stressful when you have big chunks of your memory doesn't work and everything. And I notice we have people who do have a lot of anxiety and 
agitation later in the afternoon, which is a fairly common feature with dementia, and sometimes finding something that will assist them through that period of the late afternoon, their so called 'sun downer's period' that is when you often do have to have something quite individual, some individual programme in place for them, it has high staffing needs and it has high demands on everyone around them really.

So, where we have those sorts of issues, obviously we deal with them in a number of ways but one way we do include is looking at whether music may help. You need to be a bit cunning to try and organise some of those things, especially in a group setting, but we try and find somewhere that is quieter. There is a number of things you try and do but if we know that music works then we will try and find a quiet place and it may not be their room, because that in itself, being on their own, being alone, may be anxiety provoking, so you have to be a wee bit, it is a bit of detective work really, trying to figure out what is going to work for that person. What you also learn is, what works today probably won't work tomorrow, a bit like children really. So you have to have a whole range of things in your therapeutic kit that might be effective in any one day. But, we often do have calming type music at that time of day in general anyway, because that seems to be the time when tempers become a little frayed, people's tolerance level drops and you are looking for things that have a calming effect and music certainly is one of those.

We have actually just spent quite a bit on some new dics in the last wee while and we have looked at some flute type music, pan pipe theme, Enya too, we use that a little bit as well. It is not something that they often relate to but it is just that background, using it as a background, rather than as a direct therapy for an individual. So, that has been quite useful too, but you need to think about the time of the day you are using some of these things, whereas you know, dance and band music might be highly appropriate in the morning 
when people are more alert and active, you find you need something quite different at the end of the day. [Christine]

Both Sondra and Christine clearly articulated with their stories the value music can have for patients when individual choice is recognised, and encouraged. They also demonstrated how, with ingenuity and holistic thinking they made a difference in patient's lives that will be remembered by the families, and give them beautiful, lasting memories of their loved ones.

The second theme, 'communication between the patient family, and nurse' that developed from the nurses' texts was focused around communication, not just for the patient, but communication between the patient and the nurse, the patient and the family, and finally the patient, nurse, and family members. Communication is our human way to connect with another person, to feel togetherness or sharing with others. Often as nurses working in the palliative care environment, we are aware of a lack of communication at this critical time in a person's life between family members and the patient. It is sad to witness this obvious division or anger, or the inability to really express what they want to, that prevents those final days from being a time of togetherness, and support. Palliative care teams use all their skills in these incidences to try and improve this situation that can have life-long repercussions for those left behind, and extreme distress for the patient. Music can sometimes be a way of communication when all else fails, it can bridge gaps between families following years of separation, and it can speak an understanding that does not require words, by healing the heart and soul of those listening to the music. The following stories relate how music was influential in weaving its magic for patients and families in those final days and hours.

Then there was another man who found out he had cancer ... he didn't want to die in hospital, he wanted to die at home but he had to come in for some reason and we could see that he was actually going to go quite fast and I didn't really think he would even get home again, and his family were in his 
room and they were there on mass and there was a lot of activity, a lot of noise, they had brought their children. It was about 6 o'clock at night, they intended to stay all night which they did, come the next day the room was stale and smelly and they were still all going and talking about things and they were pretty naïve about death, they didn't really understand what was going on and I heard someone say that they were going to stay again the next night and I thought oh, I will have to do something about that.

I took them all out and we had a wee discussion out in the waiting room. They went away for a walk while I went back into the room, and I was talking away to the man as I was washing him and opening up some windows to get some fresh air and I started talking about music, would he like a tape going, he said he would love to but there was just so much noise he would never hear it. So, I got a tape and I asked him his choice of music and it seemed to take his mind of things as he was going through tapes and choosing a tape and, I put it on a really nice soft light going on in the corner of the room and we turned the lights off and it looked really nice and it sounded really lovely, then I went out to the relatives and said would they like to have a look at him and perhaps they might decide to go home for the night and just let him have a bit of peace and they were just so thankful.

They walked into the room and they saw the quietness, they heard the music going and one of them said - "that's Dad's music", and I said "yes it was his choice" and they said, "that's his music" and they started crying and then they did go home and the man did die the next day but they were all there with him.

I just think they had lost all reasoning, they had lost control of themselves really, it was all beyond them, it was out of their control, I think they thought we were taking over and they knew that they were going to lose their father very soon and they had no concept of death. They had asked me what a 
death would look like and what was going to happen after he died. I think that was just all their emotions were just all mixed together and they were just totally confused and they didn't want to let go and in their way they were kind of being selfish, probably really to themselves, but really wanting to stay with their dad for as long as they could and then you know a bit of familiar music just filtering in there, just quietly in the background, it wasn't invasive at all and I think they just realised, well he is comfortable.

Going right back to the very beginning with that man when that lady was standing at the door and she said - "oh that is Dad's music", and I said to her at the time - "why is it Dad's music"? - and she said he used to play that to us when we were young, and right through my training if I have ever given or played music for anyone and it is their choice, there is always a memory, there is always something, that bit of music that will remind the father the day their mother was on the farm, or their dad used to play the banjo and they used to sing along and that sort of music would take that... and each memory jogs people along and they start reminiscing and nothing makes them happier or gives me greater pleasure than listening to people reminiscing about what they did years ago and then I can build on that.

As I said with the music and all the reminiscing many of the families and the patients themselves start talking about what they did years ago and oh it just gives them so much pleasure, because I can build a great conversation on that because I genuinely am interested in what happened in their lives years ago because gee some of them worked hard and had horrific lives and some of them deserve medals listening to their stories. You can just build so much. You know I have had so many conversations with people starting off with music and building up into. A chap that died just recently I spent three quarters of an hour one day just talking, we started off with music and we were talking about music and then he said do you think I would be strong enough to play my harmonica? I said yes, just get the family to bring it in 
and within three quarters of an hour, before I had got out of the room again, the harmonica had been brought in, I was wrapped up in their lives and it was just absolutely incredible and when I went to go, they thanked me so much for taking time out. They thought I was taking time out to listen to them, but I was there because I wanted to be there and I loved every minute of $i$. When that harmonica did come in, he did manage to get a few puffs out of it but the smile on his face was everything to me and the family.

Even when they (patients) are unconscious we have always been taught that the last thing to go is your hearing so I always encourage relatives to carry on talking and tell their loved ones anything they want to tell them before they die. When that man blew on his harmonica for the last time and we just reminisced again, he was actually dying then and still they started carrying on and they talked as though he was still hearing and I know he would have heard it, he didn't acknowledge the fact that he heard it, but I was there with them when it happened and I just feel I am privileged to be there when someone dies.

We had another man that had music when he was dying and he was a farmer and it was playing and he cried as the music was playing and the family were there. I said what is the matter, I said is this music reminding you of something and he said, "Yes it reminds me of my dog", and I said, "Do you want to see your dog, is your dog still alive"? And he said "Oh yes", and I said to the family how about bringing the dog in, and they said, "Oh we can't bring the dog in here", I said my oath you can, I said you go and get your dog. Anyhow I made arrangements and I said sneak it in the back way, I don't even care if you come in the front door I said but we will sneak it in the back way and I made a big thing of it and they thought it was great so they brought this huge sheep dog in and they opened up the side doors and this dog recognised his master straight away and jumped right up over to him, on his face and on him, and he just cried and cried and he just 
held onto this dog and I am not lying but that man died in about the next 10 minutes. And as soon as he died that dog jumped off his bed, ran outside and wouldn't come back in no matter how much the family called for the dog to come back in, he would not go back into that room, and that is odd. That man died crying but he was crying because he knew he had his best friend there, but I just wonder whether the dog had actually injured him, when he jumped up on him but that was just wonderful. Probably looking back I could probably spend hours talking about it, but the baseline is that it is probably music, but I have never thought really until now just how strong the music part does play.

She used to listen to a lot of music and I used to watch her and she would get very relaxed, totally relaxed, you could see her lying back as though she didn't have a care in the world, she didn't want to know anything that was going on around her and we respected her for that. If people came to see her during this time we didn't let them into the room until that particular tape was finished. But I just seemed to notice that when she was really, really listening to the tapes she would have near-death experiences and I never used to believe in that, but I do now. And even though a doctor told me it was probably her brain being deprived of oxygen I disagree with him because she spoke to me a lot afterwards, sensible things in just normal everyday conversations and I believe that she knew exactly what was going on.

So I attribute some of these near-death experiences she had to this music because she would be lying there after the tape had clicked off and I stood in her room one day she called her husband who had been dead for years and she said "I'm coming" and I don't know what he replied and she said "I am coming and yes I will take the apron off", and I don't know what he said and she said "please don't go, please wait for me, it's so warm, it just smells so nice, I want to come" and then with my big mouth I said .... thinking she was 
going off her rocker, I said - are you all right, and she said - "Is that you Sondra? Am I still here, I haven't died, I'm still here, it really is you? " and I said yes, were you disappointed?, and she said "yes I am". She said - "put the music back on". And I will never forget that, it was really uncanny, really, and then she got really annoyed because we would play a tape and it would stop and I would still be there and she used to resent me.

It was about the time that Princess Diana died and I said well you can't go yet because God is very busy with Princess Diana at the moment and then when Mother Teresa died she was none too pleased because God was twice as busy and she was never going to get there, so she got a wee bit angry about these two deaths and she wouldn't even come out and watch Princess Diana's funeral on TV because she felt that she had deprived her from going up to heaven. She died not long after, but music meant a lot to this lady and it was just wonderful. I am sure the music had something to do with the near-death experiences because she was just so relaxed. I have been very lucky and fortunate to witness all this.

They (patients) seem to have got a little bit of their independence back because they are the ones making the choice, their decision so. Apart from control and relieves anxiety, to me it is another form of pain relief. I personally feel it should be prescribed along with medication, yes that is how I feel. Well people when they can operate the tapes themselves you sort of have no control over that, that is their choice, their decision, but I think when it gets beyond that you really need to get their consent, I think it is important that you ask, would they be happy to have music and if so, what sort of music and then at some stage, how long do they want it on for. Everything is their choice; their right and I think there is a lot of music out there. I know when I said to the girls where I am working now that I hope to run a palliative care course at some stage, one of them (staff) said to me, are you going to include music therapy and I said yes. because I am very interested in music 
therapy and aromatherapy, they were keen to see that attached too. Most nurses I would work with would do anything for their patients to make their last days on earth more comfortable. [Sondra]

I think the exception to that rule probably would be Tom, who going back to him, he was somebody, or they as a family had discussed what they really enjoyed, both of them, not just him, but they as a couple enjoyed, and they used that, they had a list, they had written a lot of that music down. They had you know an array of tapes, because tapes were the popular thing then, and they had a huge array of music available but these key ones that they seemed to use a lot of. They also, I think, used music not only for them and their well-being but they also used it and almost applied it for their visitors who, it was around Christmas time, so they found that by having Christmas carols, which did seem a bit bizarre given the circumstances, but they found that that was actually helpful to their visitors as much as it was to them.

We find too, that if you are dealing with somebody who perhaps has memory loss, that the family is often a very good assistant with coming up with that assessment because they may not be able to tell you particularly, but working with the family you can often find out what part music played in their lives and whether it is still relevant to them and whether they enjoy. [Christine]

Christine then commented about the use of music for patients who become terminally ill in the Rest Home, and who have already indicated their involvement with music.

Absolutely, music is useful and especially for somebody who has clearly had music as part of their life, where they have enjoyed it, in their leisure time, even when they've been in care. Sometimes you find it is families that like to have that as the background for them, who find sitting with somebody who is dying can be very draining, so sometimes families almost take over that 
responsibility and the staff just sort of may suggest it and then you will find families pick up on it. But, I wonder whether it is as much for them as it is for the resident. There are people who you know, clearly you use music right to the end. But, in others, it seems to make no difference to, so you perhaps don't persevere with it, I am not sure whether that is right or wrong, I think you tend to sit down and problem solve as a group of staff and look at things that might help, and pick everyone's brains as to what, you know,.. I remember when he used to like to listen to so and so ... oh, well let's try that, so it can be sort of like a group planning session almost, when you do sit down and figure out some of those things, but again you don't know until you try. But I do find families who are choosing to sit with somebody often do enjoy the music as well. They mightn't want it on all the time, it is not necessarily long playing, and it is maybe something they have for a short period.[Christine]

Christine then elaborated on what they have noticed when music is used for a patient and the family.

Yeah, I have had families say ... oh I quite enjoyed ... it wasn't really so bad sitting with mum, I had the music and I had the telly, or I had whatever ... but they sort of see it as something that helps them too. Again type of music doesn't seem to matter, it is what works for that person or that family. One of the things that is quite distressing is when people become quite restless and that is often the time that you will search actively for something to help them at that point because if you have a resident who is a terminally ill person, then you also have restless relatives as well because they are often very distressed by that, so they are looking for answers too, so they are often very open to what you suggest. [Christine]

Oh, absolutely, I am looking for something beyond medication. I mean you deal with those basic things as part of your nursing care but you also, when 
you have done the care that is needed at that particular time, you go away and you leave that person alone maybe for a period of time, so that is often when you choose to put on some music so that you know that they have a sense that they are not alone. [Christine]

Christine went on to comment about nurses and carers, and their reactions to music therapy.

I guess thinking about when I started music in the home, apart from what was a structured programme goes back to fairly early in my time here. At that time we didn't really have much in the way of registered nurses, it was largely caregivers but a lot of them were older experienced care staff that knew what they were about really. They weren't people you had to actually tell a great deal to and they were very receptive to anything that helped. I think it is probably fair to say that in those early years I found that those established care staff took a lot of pride and got a lot of satisfaction from caring for somebody who was dying. They almost treated it as though it was one of their own families and so therefore they looked for anything that was going to be helpful. So, there was no real resistance, there was quite a willingness to look at trying anything that might help with that person and I largely think people who have an interest or background in music are always willing to try anyway. Those who have never had an interest in music are perhaps the harder ones to convince that it may be helpful.

As time went on and the type of care we offered changed, and we certainly ended up having a lot more residents who would be terminal, and were often a lot sicker for a longer period of time, but they were in our care at a much more advanced health need at that point and we got more registered nurses on because we became a hospital rather than a rest home. Nurses are pretty practical creatures largely, especially any who have worked in community and we have had some excellent registered nurses who were very open to 
exploring other treatment options and so it really wasn't hard at all to introduce music as a treatment option. I mean, it is very much a part of our day-to-day life of the home anyway so it is only half a step further to really look at using it to help specific people at specific times. [Christine]

Christine continued to explain how she educated her staff about the use of music as a therapy, and how it has developed over the time she has been there as Nurse Manager.

We invited a palliative care nurse specialist to give us some advice and help and we ran, on two separate occasions, we ran evenings or short courses in fact that staff could attend to look at how they could help specifically using music and from there we got some resources that we could apply and we keep a resource folder for those sorts of things now. Those are the sorts of things that you can always revisit too, because (a) you have different staff and (b) you have different experiences that you can apply it to. That is when it becomes meaningful when you think, oh yes, I did that and it worked. So you start to build up your own repertoire of experience that you can apply to another situation. So I think it hasn't been difficult but there has been several good reasons for that, not least of all is having some very good registered nurses who are very open to holistic care, who really pride themselves on caring for somebody, not just the person with a disease you know in a bed, I think they... and they also look very openly and positively on caring for the whole family too. They see the family as very much a part of that scene. So, unashamedly we employ the family to assist in terminal care and if it means sitting with the person, making sure that aromatherapy needs are met and musical needs are met, and physical care needs are met, it is a team effort really. It hasn't been a hard thing to do, I think nursing has probably come of age in that way, I think we are a lot more open to things and a lot more prepared to try things and a lot less bound by what is acceptable and what is not, what works for the person. I think nursing, in 
some ways I think it has gone quite wrong and in other ways I think it has got a few things right and I think nurses openness to try other things at the place people are at has actually come a long way in the last twenty years. [Christine]

These two nurses, although in different roles, explained how communication can be enhanced for all those involved in a patient's care by using music. Their initiatives enabled difficult situations to be handled with love and dignity, and included all those who were important in the patient's life. The stories clearly demonstrate what can be achieved with some careful planning, consideration, and education of self and other colleagues.

\section{Insights from the texts}

\section{The nurses}

The second question in this study was to seek data to support the education of nurses as providers of music therapy to patients they are caring for in the palliative care setting. The two themes that immerged from their transcripts were 'holistic, individual care' and 'communication with patient, nurse, and family'. Both nurses were able to articulate clearly the role of nursing in introducing and supporting patients in their choice to use music as a therapy in the terminal phase of their patient care. Their stories eloquently explain their nursing philosophy, and the role of music in palliative care. Because of the diversity of the nurses' work experiences, and the different positions they held, they were able to offer varied opinions about the possibilities for the use of music from different perspectives. Their stories clearly illustrate their aesthetic knowing that enables them to provide nursing, that is not practised within boundaries, but is expanded to include all aspects of care that is supportive and fulfilling, to the nurse, patient and families. What is important is to support their actions with the available research, and perhaps encourage further research by nurses for nurses, about this phenomenon of music therapy in nursing care. 
In a ward setting, holistic, individualised care was central to Sondra's nursing ethos, and came through clearly in her transcripts as she sought out ways to improve patient, and family/patient outcomes. Her stories mainly evolve around her ability to enhance communication with patients at more than a superficial level. Her interest in the patient as a whole person is evident, as expressed in her stories. Sondra conveys her experience and genuine concern for the patient's wellbeing by the measures she takes to improve outcomes, and meet the special needs of her patients. The concept of caring as it applies to palliative care nursing has already been discussed in the literature review, Piece Two, however it is prudent to reiterate the value of partnership when caring for people who are dying, as this is central to a nurse's understanding, if they wish to include music in their planned care of patients.

A definition by Manning (1992) explains the importance of partnership in caring "the ethic of care involves a morality grounded in relationship and response" ( p.1). As professionals we must not lose sight of the importance that caring has for patients, especially those whose illness cannot be cured, even with advanced skills and knowledge. Care does not remain static, it is always changing to meet the required needs. Baker and Diekelmann (1994, p. 66) suggest that "by remaining committed to the centrality of caring to nursing practice, nurses are uniquely situated to attend to the meanings patients and families form around the experience of recovering or of living toward death".

Sondra's understanding of music therapy was self taught, as she sought out information from appropriate sources, and read articles related to the topic. As she increased her knowledge base, she was able to put her skill into practise as part of her nursing care, and also share this concept with other colleagues. Herth (1978) believes that the increased articles appearing in nursing literature indicate that nurses are gradually becoming more aware of the role of the nurse in the "judicious integration of music into total, individualised patient care" (p. 23). 
Sondra's advanced level of practice demonstrates the direction that nursing is heading in this century, and will encourage others in the professions to seek out ways to improve our understanding of patients' experiences, and enable nurses to empathize and perceive patient needs. Cook (1981) supports this when she states:

Although apparently used relatively little by nurses in the past, music appears to have a wide variety of applications in the patient care setting. If fully appreciated and used judiciously, music has the potential of becoming a valuable intervention toward the achievement of comprehensive patient care. (p. 264).

The themes that illuminated the role of music in the nurses' transcripts are encouraging as they provide some validity to the research literature. Many times in the interviews, the nurses emphasized the importance of patient choice, the use of music in relieving symptoms, and family involvement. Both nurses were prepared to 'think outside the square', or perhaps step beyond conventional practice to meet the individual's needs.

Christine's position as Manager of a Rest Home gave a further dimension to the concept of team involvement, and how every team member is crucial in the provision of care. Her past experience as a District Nurse, caring for patients in their homes, enabled her to really listen to the patient and their families, as they formed a partnership of trust and respected each other's wishes. The early experience of music therapy in patient care, nearly 15 years previously, had a lasting impression that has influenced her approach to holistic care in the Rest Home. To provide music to a large number of people living in the same environment, all with individual tastes in music and complex diagnoses, is a huge challenge that Christine has addressed with her personal knowledge of music therapy, and education of her staff. 
Christine has shown imagination and creativity, and provided avenues for learning that her staff have responded to, because they are willing to accept an awareness of their patients' personal needs, and an understanding that this is acceptable practice. All the Home staff are enthusiastic about the use of music, and this provides support for the second thesis question related to the education of nurses in providing music therapy to palliative care patients. Christine's assessment phase at the time of admission is vital in the provision of music therapy, as it provides information that facilitates the patient's personal response to music, so that the staff have the knowledge to assess, and skill to apply music in response to disease progression.

The education of nurses in music therapy is vital, and needs to be addressed if the use of music in planned care is to be promoted in the future. Palliative care has already challenged the traditional medical model, by being acknowledged as a speciality, with the emphases on cure being replaced by effective symptom control and holistic care. This challenge has been now been expanded to include music therapy, as well as other complementary therapies such as aromatherapy and massage, as a modality that nurses can learn and apply. It also endorses the philosophy of palliative care, one that supports the patient in their choices. Christine has already undertaken this challenge by using her acquired skills and those of her staff, to uphold the palliative care philosophy. Although this is the result for one manager in one rest home, it supports the concept that music therapy can be of value to terminally ill people if staff education and involvement is encouraged. Sondra has also developed her skills in music therapy and has demonstrated the value it can have for some people when applied carefully and supportively. Both nurse participants acknowledge that this treatment modality has its place in palliative care, but reiterate the need for careful assessment, education, and continual evaluation, as with all planned nursing care. Evans (2001) concludes that: 
it is suggested that listening to music become an option available to all patients during hospitalisation. Additionally it is anticipated that many uses for music have yet to be fully explored, and so nurses should creatively pursue situations where listening to music may produce beneficial outcomes for the hospital patient (p. 16).

Although the above review does not specifically mention palliative care, it discusses the effects of music on anxiety, pain, and patient mood which are all similar symptoms experienced by palliative care patients. Evans also suggests that because there is evidence to support the use of music as a therapy, which is effective, it should be offered to patients while in hospital as part of routine care.

\section{Conclusion}

This Piece entitled 'Theme' unified the work by bringing together the 'lived experiences' of two families, and two nurses, as they shared their stories about the value of music for someone who is dying. It provided a background of the participants, allowing the reader to step into their world for a short time and become intimately familiar with them as wife, son, daughter, and nurse, as they cared for a loved one, or patient who was dying. These are unique experiences that provide an opportunity to understand the deep, meaningful interaction that music can provide for patients and families. They include music as part of life, the impact of music on memories, the physical response to music, individual holistic care, and communication. The stories evoked personal memories that families were willing to share in the hope that the information would be valuable to others, and to encourage the inclusion of music therapy in as a treatment modality in palliative care. The stories were discussed in relation to the thesis questions, and supported with some of the available literature.

Nurses are in an extraordinary position when someone is dying, as they are in close contact with a patient, as they experience the turmoil of emotions that usually accompanies dying. It is a poignant encounter at a time that is incredibly 
personal, but can be made more bearable with the presence of music, if it is appropriate. 


\title{
PIECE FIVE
}

\section{Coda: Discussion, implications, and conclusions}

\author{
There are no barriers to this universal art
}

(Alexander Waugh, 1995).

\section{Introduction}

This Piece may be the final section for this thesis, as the title suggests, but for music therapy in palliative care, hopefully this is the beginning of a journey. A journey that will provide the initiative for exploration by nurses of this treatment modality, to ensure that all palliative care patients are given the opportunity to listen to music in the future. Included in this Piece will be discussion about the research as a whole, the implications for patients, nurses, and all other professionals working in palliative care, research limitations, and the need for further investigation into the effectiveness of music as a therapy.

\section{Discussion}

\section{What did the stories tell us?}

The choice to use phenomenology for this research was decided upon following reflection of why I wanted to do this research. I knew I did not want to gather large quantities of empirical data that held no personal meaning of the use of music, or produce a theory about music therapy that was governed by limitations. I already had personal and practice knowledge of the phenomenon of music therapy, but what I did have was a question - what is the real meaning of music for someone 
who was dying? The only way this question could be answered was to ask those who had experienced the use of music. Phenomenology is about 'meaning' as van Manen (1990) says " phenomenology attempts to explicate the meanings as we live them in our everyday existence, our lifeworld" ( p. 11). While the focus of the phenomenon of music as a therapy was my concern it was the lived experience of the participants that gave meaning to the phenomenon. Through the participants generosity this research has not only endorsed my previous thoughts and feelings about the therapeutic use of music for someone who is dying, but the actual conversations with the participants, reading, and re-reading their personal stories, and then transforming their spoken word onto paper has been a very moving experience. This was not an expected outcome when this project was commenced, but when engaged in human-to-human experiences, I believe this is inevitable. My hope for this work is that those same experiences will be shared by the readers of this project. My aim for the research was to include personal life experience, and those who have had influence on my life, professional growth throughout my working life, and the substantial contact with music during my life that has been the catalyst for this work.

Human science research is not possible if this expression of self is not a consideration, because for phenomenology to be understood and accepted, the researcher has to be aware of the phenomenon, which enables an understanding connection with the participants and their experiences. To add support to the project it was vital to include relevant literature about the use of music therapy, and also the fundamental act of caring, which is central for nursing to be effective in providing holistic care. By combining this contextual data I was then able to focus the research on two thesis questions; does music have any value for someone who is dying; and, how can nurses be assisted in introducing music into the planned care of their palliative care patients? Have these questions been answered? van Manen (1990) would say 'no', because that is not what phenomenology is concerned with. The human science approach allows the researcher to develop his or her own steps of demonstrating the phenomenon, and 
uncovers an experience that can be reflected upon by the reader. van Manen (1990) explains this when he states:

Human science research as writing is an original activity. There is no systematic argument, no sequence of propositions that we must follow in order to arrive at a conclusion, a generalization, or a truth statement, because that would be to see writing itself as technical method ( p. 173).

The thesis questions which were presented, gave permission, and an opportunity for stories to be told, the experiences to be shared, that possibly would not have been otherwise communicated with anyone else. These transcribed interviews were then made available by the act of writing them down so that the personal description of the phenomenon could be illuminated to the reader and enable " an understanding that goes beyond language and description (van Manen, 1990, p. 173). The shared experiences, provide meaning of what it is 'to be' involved in the use of music for someone who is dying. It is therefore up to the reader to seize the opportunity to read and learn about the phenomenon of music therapy for someone who is dying, by being aware of their 'lived experience'. The themes from the interviews were insights that emerged from the texts following reading, and rereading of the stories. Although the themes are from my interpretation of the researcher, they become transparent by complete immersion in the words of the participants, and the personal contact I had with them. The themes are a reflection of the experiences of the participants, because I was there when these stories were shared, and was privileged to be part of the conversation, as a listener, aware of the pauses, silences, and emotions that were stirred when memories were recalled with family members. The point of phenomenological research according to van Manen (1990) is:

to " borrow" other people's experiences in order to better to be able to come to an understanding of the deeper meaning or significance of an aspect of human experience, in the context of the whole of human experience (p. 62). 
So what were some of the understandings that emerged from the experience of using music for someone who was dying as told by the families? For these two families there was a positive reaction to the use of music as a therapy for their family member who was dying. They were able to support this in their stories by describing the place music played in their lives, and the importance that music had on memories, and the physical and emotional impact it had during the patient's illness and dying. These reflections have been reported in the available literature regarding music therapy, for example, Munro and Mount, 1978; Munro,1984; O'Callaghan, 1984; O'Callaghan, 1989; Lane, 1992; Magill-Leverault, 1993, so we know that the families' stories support what has already been written. Because there is very little qualitative literature relating to music therapy in palliative care, these reflections provide an excellent understanding for professionals who work in the area of palliative care. They give a clear definition of the role of music therapy for someone who is dying.

The second thesis questions concerned the attitude of nurses towards the application of music for someone who is dying, and the possibility of nurses as the providers of music therapy in the palliative care setting in the future. Both nurses' stories about the use of music in their practice, provided positive outcomes for their patients. Sondra's experiences highlighted the impact music can have on communication with patients, family and nurse, and demonstrated what one person could achieve with some education regarding the therapy, and sharing this knowledge with other staff members. Sondra's holistic care confirms that a nurse with an interest in providing excellent care to her patients is capable of extending her care to include complementary therapies, such as music. Her enthusiasm is evidenced in the transcripts, and supports the concept of nurses providing this aspect of care.

From the perspective of a nurse manager, Christine was able to introduce the concept of music therapy as one of the daily activities in a rest home, and the 
challenges that presented when caring for a number of diverse individuals from varying walks of life. Her descriptions of how music was used was further evidence of the possibilities that can be achieved by someone whose imagination, creativity, and knowledge can be built upon following past clinical experience of music therapy. Christine's ability to include music in daily planning, both in the group setting and for individuals, is an indication of the commitment shown by Christine and her staff. The patient's response to the use of music does fluctuate, but this is expected when attempting to provide music to a large group of people with different tastes. What it does highlight is the importance of individual choice when assessing music as part of a person's care. This was achieved in the rest home by a musical assessment at time of admission, and reassessed during the patient's time in the home, which also included family input if the patients suffered dementia and were unable to provide the information.

Christine also stated that the type of music played differs at certain times of the day, for example livelier music tends to be played in the morning, and quieter, calming music in the late afternoon. This observation has been supported by Smith and Morris (1976) which looked at the effects of different kinds of music on test anxiety. They conclude that "whilst sedative music might be appropriate in order to help relaxation, stimulative music may help sustain cognitive ability" (p. 1191). The late afternoon reaction of restlessness by patients who suffer from dementia, has been clinically recognised in many rest homes and dementia units, and is commonly called 'sundowners syndrome'. The presence of calming music at this time of the day has provided positive effects for patients in the home managed by Christine. Her selection of 'New Age' music has also been supported by Mornhinweg (1992) who reported similar results when New Age music was played, by proving to be most effective at inducing relaxation.

What does all this say about the phenomenon of music therapy? Music has 'come of age' again in its application for those who are dying. By 'again' I mean that music has come the full circle, from its use thousands of years ago in religious 
practice and use in medicine up to the present day in the $21^{\text {st }}$ century. Music adds a dimension to palliative care that enhances caring, because it encourages care of the whole person, including body, mind and soul, which may be in turmoil when a life threatening diagnosis is made. Palliative care has also emerged in the last twenty years as a specialized area that offers compassion as well as knowledge, and expertise. Music has the unique ability to 'speak' when words are difficult to find, it can transcend time and space, it can be many things to many people, and it is readily available to everyone. Music therapists have shown the way with their involvement in studies supporting music for people who are dying. However sadly there are not sufficient therapists to provide this service to all palliative care patients. The logical people to provide this complementary therapy to patients who are dying, are nurses, as they are involved as members in the hospice and palliative care multidisciplinary teams, and have the intimate contact with patients that is vital if music is to be involved in patient care.

\section{The implications of music in the future for palliative care}

\section{For patients}

The potential for music therapy to be supportive for people who are dying was the object of this study. Music is able to achieve so much for someone who is dying, and as nurses we need to promote the use of music therapy in the planned care of patients. For the two patients presented in this research it was a life thread that connected them to past memories and also provided opportunities for closeness with their families at the end of life that is now treasured by their partners and children. Music is capable of tapping deep into the mind and releasing emotions that otherwise might stay locked in at this traumatic time, and isolate patients from the ones they love. The language of music enabled both families to take an active role in the care of their loved one by enhancing that special bond they already had, that special connection with music that they had all shared throughout their lives. Even in the presence of pain, music was able to offer a non-pharmacological management of this symptom that the families were able to 'administer', because 
they were aware of the type of music that would provide diversion, and therefore reduce the pain. The patients themselves were 'in control' because even up to the last few days, they could choose the music they enjoyed, something that is important to palliative care patients, who may have lost the power to maintain independence in some cases.

Patients who are dying have the right to the special emotional and physical 'healing' powers that music therapy can offer. Music is a caring gift that is not difficult to give, is inexpensive, is usually accepted with gratitude, and enables an intimate sharing that will sustain the giver and the receiver in that personal healing moment. If caring is central to nursing, and total care is seen as providing physical, emotional, and spiritual care to people who are dying, then music's ability to support this total care needs to be recognised in future education for palliative care.

\section{For Nurses}

I have already mentioned the increase in the literature written about music therapy in the last few years, which gives positive encouragement that music is being seen as a treatment modality. According to Cook (1981) " not only has a historical precedent been set for the therapeutic use of music, but scientific studies have attested to its physiologic and psychologic effects" (p. 264). Herth (1978) also comments that there are an increasing selection of articles being written in nursing journals, which may indicate that nurses are becoming more aware of the positive effects of music.

There are a number of implications for nurses who practice in palliative care arising from this study. The lessening of anxiety and other symptoms for patients, assessing music requirements at time of admission, nurses education about the application of music therapy, and music therapy as part of planned care. 
The reduction of anxiety by using music appears a number of times in the literature and the families' stories, which would suggest that nurses are in the ideal position as carers to assess and introduce music as a therapy for palliative care patients. Anxiety can have devastating effects on palliative care patients, as any hospital patient, as it can impinge on many aspects of treatment. For example, the cycle of pain can be never ending if the primary cause of their pain is anxiety, and has not been recognised. Because music has been seen to effectively reduce anxiety, it may provide the rational for music to become part of routine care.

This would mean that the use of music would be assessed at admission of the patient and their music preferences recorded, enabling all patients the opportunity to have music as part of their care if that is their choice. Not all nurses will have the knowledge or interest in music as a therapy, but if this information is obtained as routine admission, it is then available for those staff that have the interest and the skill to introduce music in planned care.

Palliative care education has developed and evolved since becoming a specialised area of medicine and nursing, and has extended its philosophy to include the importance of the patient as an individual with all that being human encompasses. Palliative care is not totally focused on technical and theoretical aspects but includes the emotional components such as fear, loss of control, suffering, anxiety, and loneliness that accompany a terminal condition for the patient, and their families. Nurses who work in this area are already facing these emotional challenges, and these challenges also provide opportunities for nurses to step outside the traditional role to meet the needs of their patients.

The addition of music as part of that care could be readily accepted, I believe, because nurses are familiar with the concept of total care. Music therapy is not going to break the budget either. Music is readily available and most palliative care teams and hospices have access to tape decks and compact disc recorders. Starr (1999) suggests that " music is as common as the air we breathe; all of us 
need to take advantage of its powers. One need not be a musician or a highly specialised music therapist to use music in a nurturing way." (p. 742).

With some initiative and education music could become a routine part of nursing care. Nurses also need to be pro-active about its use and pursue opportunities to provide research that supports the value of music for people who are dying, as this is the only way to establish music as a recognised treatment modality. Nurses can also use the skill of reflective practice as suggested by Taylor (2000), to focus on patient care, that has involved music, and question the effects that were observed. Then share these revelations with colleagues and members of multidisciplinary teams to bring an awareness of the impact music can have for patients. The opportunity for music therapy education could be a suggestion to education facilitators in hospitals so that all staff can receive information about this aesthetic modality. Music provides collaborative approaches to care, but nurses need to be the instigators that provide the evidence about the diverse qualities that music can achieve for people who are dying.

\section{Research limitations}

To my knowledge this project is the first phenomenological study in New Zealand that investigates the value of music for someone who is dying. It is a beginning exploration that seeks to understand the possibilities of music as a complementary therapy for palliative care patients. The study sample is small, and both family participants were caring for male patients. A further limitation is that both patients were cared for at home. I would suggest that future research is warranted and needs to include a larger number of participants of both genders, who are cared for in both the home and hospice setting to offer further support about the experience of using music as a therapy. These limitations do not however, undervalue the personal stories that have been shared in this study, and which give supportive evidence that can be further developed by those who work in palliative care in future studies. There is also the opportunity for nurses who are using music therapy to share their experiences by completing further studies. 


\section{Cadence: 'Concluding harmonies'}

This final section harmonizes the transition from a personal idea to the composition of a completed musical journey. It has been an extraordinary journey that has been travelled with some amazing people who have allowed me to be part of their lives, some at a very intimate time. To them, I am extremely grateful, as this research would not have been possible without their willingness to share their personal experiences of the use of music for someone who was dying.

When I first discovered this notion of music therapy nearly ten years ago, I was very enthusiastic about the prospect of using music for patients whom I was caring for. It enabled me to indulge in the two passions that have held a life-long interest for me- music and palliative care. From that initial reading of Susan Munro's book and meeting Dr. Balfour Mount, I have continued to focus on the positive responses from patients, and the profound experiences I have been humbled and privileged to be part of throughout the last 20 years. Many of these experiences have never been shared, but the writing of this journey has enabled me to relive, and revisit those poignant moments.

I have found it difficult sometimes to find the words to adequately portray that special moment that is forever held in your heart. Perhaps they could be called 'sacred moments'. The people who shared these moments will always remain with me, because I learnt so much from them. Their faith, their joy and sorry, and the inner strength they seem to find, the absolute trust they have in me, is deeply humbling. Music therapy can give permission for these experiences to be shared if it is meant to be. The non-verbal value of 'soothing sounds' can never be underestimated. A quote that I believe gives understanding to the use of music in the medical world is by Rima Starr, a music therapist in New York:

Music enters the medical environment in a non-threatening way, like a friend, like a soothing balm, like play, like a pleasant surprise, like joy. It 
breaks through the technical environment and makes it more humane. Through musical interaction, two people create forms that are greater that the sum of their parts (1999, p. 742).

\begin{abstract}
A further writing about music that has had a lasting impression on me, and with those with whom I have shared it, is a poem about what music can achieve, which reflects the picturesque images that could describe the physical, emotional and spiritual experiences of palliative care patients. It truly explains music as a therapy.
\end{abstract}
Music is a symbol and a source
It comforts and soothes
It inspires and delights

It weeps

And builds solid structures

From tears

$$
\begin{aligned}
& \text { It lights } \\
& \text { To vision }
\end{aligned}
$$

Beyond our understanding

It dares to dream

To reflect and clarify

Music reminds us of our common heartbeat

Through time and space

It celebrates our eccentricities,

Our uniqueness 
It leads the way to the future
Without denying the past

\author{
It laughs with new laughter \\ Never laughed before \\ Yet resembling an echo \\ From some distant hall \\ It floats and suspends \\ To calm, coax, and cleanse \\ It provides a framework \\ From which to make choices
}

It is the history of sound

Of the continuity of life

\author{
It breathes \\ It stretches, yawns \\ To a new day \\ Music transforms \\ If we will only hear
}

Bereznak Kenny (Munro, 1984, p. 85)

The concluding page overleaf is a picture of a tapestry embroided by my daughter as a gift, it sets the challenge for the future of music therapy;

If music be the food of love, play on. 





Appendix 1
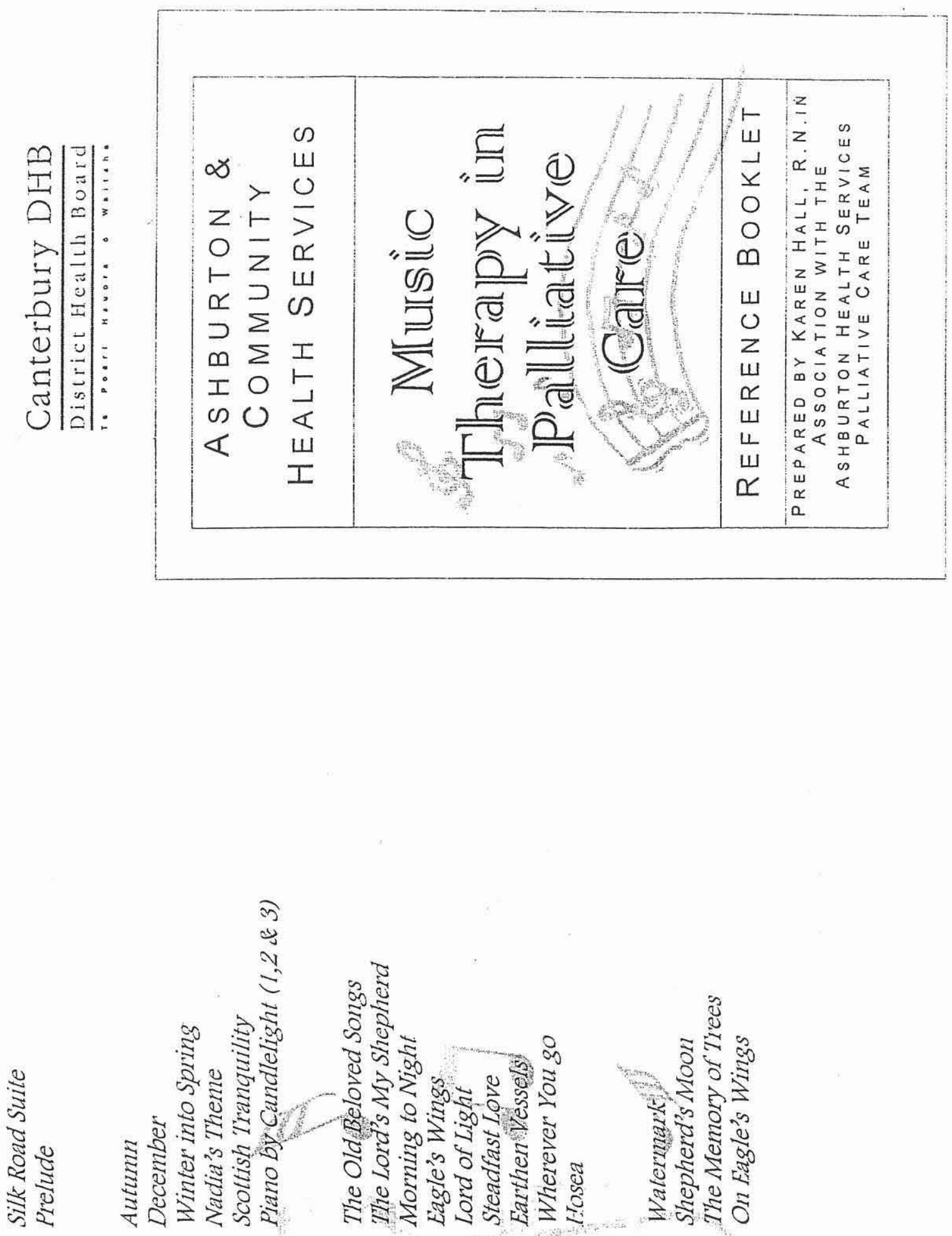
"AFTER SILENCE THAT WHICH COMES NEAREST TO EXPRESSING THE UNEXPRESSABLE IS MUSIC"

- Aldous HuXley

\section{OBJECTIVES OF MUSIC THERAPY}

1. To be aware that music has a very personal and intimate meaning for each individual a fact that demands a great deal of respect.

2. To improve the quality of life (whatever that means to the individual) by involving the use of music in their overall care.

3. To use music in such a way as to have some impact on the five principal parts of the human being physical, psychological, cognitive, social and spiritual.

4. To be aware of the patient's personal music resources so these can be used as initial suggestions for the music sessions.

ลิ宀

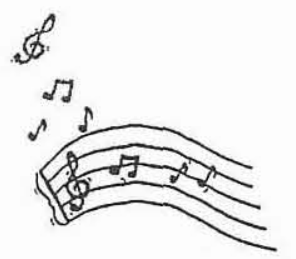

CLASSICAL

Bach:

SUGGESTED MUSIC LIST

Beethoven:

Brahmis:

Chopin:

Debussy:

Handel:

Liszt:

Mozart:

Pachelbel:

Saint-Saens:

Schubert:

Vivaldi:

Weber:

Air on a G String

Jesu, Joy of Man's Desiring

Pastorale

Moonlight Sonata

Pathetique Sonata

Lullaby

Nocturne in $G$

Clair de Lune

Water Music

Liebestraum

Laude Dominum from The Vespers

Canon in D

The Swan

Ave Maria

the Four Seasons

Pie Jesu

MOVIE SOUNDTRACKS

Born Free

Chariots of Fire

The Sound of Music

COUNTRY AND WESTERN

Willie Nelson:

Denver \& Domingo:

Don McLean:

64

Stardust

FLUTE

Adrian Brett:

James Galway:

Various Artists

Echoes of Gold

Songs of the Seashore

Pan Flutes of Love

GUITAR

Will Ackerman:

Alex de Grassi: 
Karen Hall

Ashburton

\section{Dear Karen}

"SOOTHING SOUNDS" An investigation into the use of music in palliative care Investigator: Karen Hall Supervisors: Rose McEldowney, Prof J Duke, A/P C Moss Ethics reference: $02 / 17 / C P D$

Thank you for your response to the points raised. I am pleased to advise that, using the delegated authority granted her by the Committee, the Chairperson of the Canterbury Ethics Committee has given final ethical approval for this study to proceed in Canterbury.

A change is requested to the statement on consent form for nurses, "I understand that my identity and that of my patient/s will be protected throughout the study, if that is my choice". Although it is optional for the nurse to use a pseudonym, the privacy of any patients referred to in the study must be protected.

Approval is until 31 October 2003.

A final report is required at the end of the study and a form to assist with this is available from the Administrator. If the study is not completed by the above date, please forward a progress report and an application for extension of ethical approval.

Please refer to the above ethics reference number in all correspondence related to the study and advise the Committee of any adverse events, if the study does not commence or is altered in any way.

The Committee wishes you weil with your research.

Yours sincerely

Sally Cook

Ethics Committee Administrator 


\section{LETTERS FOR PARTICIPANTS ENTERING INTO THE RESEARCH}

"SOOTHING SOUNDS" An investigation into the value of music in the care of those who are dying?

\section{McMurdo Street}

Ashburton.

01.10 .2002

Dear

This letter is to invite you to be part of my research involving the use of music in care of those who are dying. You have been identified as a person/ or family who used music in the planned care of a family member who was dying. The nurse who cared for you at that time has forwarded your name following discussion with you and your agreement to allow your name to be given to me as the researcher.

Please take time to read the enclosed information regarding my research, and if you are willing to participate in the research, I would be delighted if you would contact me.

I look forward to hearing from you and please contact me if you have any questions or concerns about the proposed research.

Kind regards,

\section{Karen Hall.}




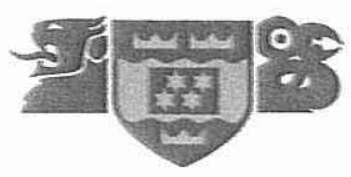

\section{INFORMATION SHEET FOR NURSES}

My name is Karen Hall and I am working towards completing a Master's Degree, (Applied) in nursing. My research is entitled, "Soothing Sounds"; an investigation into the value of music in the care of those who are dying. Music therapy in palliative care has been acknowledged in many overseas studies but as far as I can ascertain there is no research in New Zealand about this topic. I have been involved in introducing music therapy in the planned care of our patients in the Ashburton hospital and for those patients who choose to die at home. During the last seven years, I have also been involved with educating post-graduate nurses in the use of music for those who are dying through the palliative care modules. I would be grateful if you would agree to participate in this study by sharing your thoughts and experiences of the use of music in the care of your patients.

This will be achieved by audiotaped interviews that will be transcribed, with no editing, so as to reflect your true personal experience of the use of music.

I would envisage one, one hour to one and half hour interview, which will include introductions, informed consent and broad questions about your experience of using music in the planned care of your patients. There will be time for reflection and comments at the conclusion of the interview if you wish. At the completion of the interview, the tape will be transcribed with no editing, by a transcriber who has signed a confidentiality agreement. I will give you a copy of the interview for your validation and to use further as you wish.

\section{YOUR RIGHTS;}

Your rights as a participant are listed below;

- Your confidentiality and privacy will be maintained at all times throughout the study.

- You may withdraw at any stage of the research process up to the writing of the thesis and your stories will be retumed or destroyed.

- Your tapes will be kept securely locked in my personal filing cabinet at home during and at completion of the study. 
- You may choose to use a pseudonym of your choice throughout the interview. Please indicate your wish on the consent form. The identity of the people you are talking about will also be protected by your choice of naming them, eg $\mathrm{Mr} \mathrm{T}$.

- By signing the informed consent it means you are satisfied, and agree with the details of the study.

- You have the right to contact me at any stage of the study for clarification or concerns. You can also contact my supervisor, Rose McEldowney, Lecturer, Victoria University of Wellington. (Rose will not be available from July to the end of December). During this time you are welcome to contact Professor Bev Taylor, my second supervisor. If you wish to contact Bev, I can notify her and she will make a call to you.

- You have the right to choose the time and place for the interview and you are welcome to bring a support person if you wish.

- If you have any queries or concerns regarding your rights as a participant in this study, you may wish to contact your professional organization.

- Whether you participate or not or withdraw will not effect your employment within the organization.

Because you are sharing personal experiences, it can sometimes be an emotional time. If you feel you need a break at any time, we can stop the interview and resume at some other time. I would be able to offer immediate support, I would also be able to arrange professional support if you feel the interview raise concerns for you.

Thankyou for considering being part of this study.

Karen Hall. 


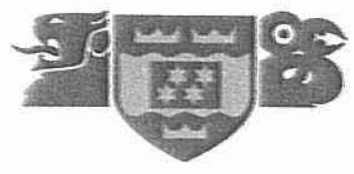

\section{INFORMATION FOR PARTICIPANTS.}

My name is Karen Hall and I am working towards completing a Master's Degree, (Applied) in nursing. My research is entitled, "Soothing Sounds"; an investigation into the value of music in the care of those who are dying. Music therapy in palliative care has been acknowledged in many overseas studies but as far as I can ascertain there is no research in New Zealand about this topic. I have been involved in introducing music therapy in the planned care of our patients in the Ashburton hospital and for those patients who choose to die at home. During the last seven years, I have also been involved with educating post-graduate nurses in the use of music for those who are dying. What I would like to do now is find out if there is any value in using music for someone who is dying.

I invite you and /or your family to participate in this study by sharing your thoughts and experiences of the use of music in the care of your family member.

This will be achieved by audiotaped interviews that will be transcribed, with no editing, so as to reflect your true personal experience of the value of music. Your tapes will be stored in a locked filing cabinet in the researchers home both during and after completion of the research.

You may withdraw at any stage of the research process up to the writing of the research and your stories/tapes will be returned to you or destroyed.

I would envisage two separate interviews of one and half hours, which will include introductions, informed consent and broad questions about your experience of the use of music in the care of your family member. There will be a time for reflection, comments at the conclusion of the interview if required.

At the completion of the interview, the tape will be transcribed, with no editing, by a transcriber who has signed a confidentiality agreement. I will give you a copy of the interview for your validation and to use further as you wish. 
Appendix 5

\section{YOUR RIGHTS.}

Your rights as a participant are listed below:

* Your confidentiality and privacy will be maintained at all times throughout the research study.

* You may withdraw at any stage of the research process up to the writing of the work and your stories/tapes will be returned or destroyed.

* Whether you participate or not or withdraw will not affect yours or your family's future health care.

* Your stories will be kept securely locked in my personal filing cabinet at home.

Because I am writing your stories about a personal experience for my study that could be read by many people, you may wish to use a pseudonym of your choice. Please indicate your wish on the consent form. By signing the informed consent it means you are satisfied, and agree with the details of the study.

* You have the right to contact me at any time during the study for clarification or concerns. You can also contact my supervisor, Rose McEldowney, Lecturer, Victoria University, Wellington. (Rose will not be available from July to end of December). During this time you are welcome to contact Professor Bev Taylor, my second supervisor. If you wish to contact Bev, I can notify her and she will make a call to you.

- You have the right to choose the time and place for the interviews and you are welcome to bring a support person/persons if you wish.

* If you have any queries or concerns regarding your rights as a participant in this study, you may wish to contact a Health and Disability Services Consumer Advocate, 0800377766 within the South Island or 3777501 in Christchurch.

Because you and /or your family are sharing very personal experiences, it can sometimes be an emotional time. If you feel you need a break at any time, we can stop the interview at anytime and resume at some other time. Caring for families is part of my job, so I would be able to offer you immediate comfort and support. I have also arranged for a counsellor to be available to you, at no cost, if you feel the interview raises concerns for you that need to be addressed.

Thankyou for considering taking part in this study.

Karen Hall. 
Appendix 6

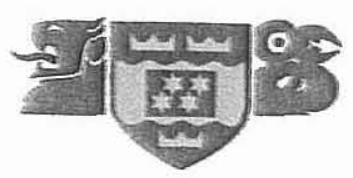

\section{Contact Details}

\section{Karen Hall RN. ADN}

Nurse Specialist in palliative care. Phone no; 3084897 (home)

134 McMurdo St. 3078455(work)

Ashburton.

Email; matthew.c.hall@xtra.co.nz

Professor Bev Taylor

Phone no; 0266203156 Australia

Supervisor

Southern Cross University.

Rose McEldowney

Supervisor

Graduate School of Nursing \&Midwifery

Phone no; 0800108005

Victoria University of Wellington. 


\section{matthew. c hall}

From: $\quad$ "Brett, KerryAnne (WMI, New Zealand)"

To: '"matthew. chall'" <matthew.c. hall@xtra.co.nz>

Sent: Tuesday, 30 July 2002 5:47 p.m.

Subject: RE: re Enya CDs

Hi Karen,

This is all fine as it's not for public broadcast or display.

Thanks,

Kerry-Anne

-----Original Message-----

From: matthew. c hall [mailto:matthew.c.hall@xtra.co.nz]

Sent: Monday, July 22, 2002 2:43 pm

To: kerryanne.brett@warnermusic.com

Subject: re Enya CDs

Karen Hall

134 McMurdo St .

Ashburton.

033084897

$\mathrm{Hi}$, my name is Karen and I work as a nurse with people who are dying. This year I am completing a Master's Degree. My thesis is a study about the value of music in the care of those who are dying. For the past seven years I have promoted the use of music in hospitals and hospices by teaching nurses the type of music to use for their patients. From my experience the' Enya' CDs have been some of the favourites for many patients. My request to you is permission to add some of the popular tunes/songs from my own Enya CD's onto a separate $C D$ as a presentation with my written work. This would enable the examiner to experience the type of music that has proven to be acceptable for patients who are dying. I have no intention of using the CD for any other purpose except for presentation of my thesis. The only other time an opportunity may arise to use the CD would be at a Palliative Care conference, where I would be presenting my thesis result. I would appreciate your comments about my suggestion. If you require any further clarification, please contact me. thankyou, regards, Karen 


\section{matthew. c hall}

From: "Barry Matheson"

To: "matthew. c hall" <matthew.c.hall@xtra.co.nz>

Sent: Monday, 15 July 2002 9:51 p.m.

Subject: RE: SECRET GARDEN.

Dear Karen,

Thank you for your mail. You have our permission to use some of the music with your written thesis. I must stress, however, like you do in your mail that the use is only for this one purpose and that any further use will require further permission.

Best regards and good luck

Barry Matheson

--.--Original Message-.-.-

From: matthew. $c$ hall [mailto:matthew.c.hall@xtra.co.nz]

Sent: 13. juli 2002 10:49

To: barry.matheson@powertech.no

Subject: SECRET GARDEN.

Karen Hall

134 McMurdo St.

Ashburton.

033084897

New Zealand.

Hi, my name is Karen and I work as a nurse with dying patients. This year I am completing a Master's degree. My thesis is a study about the value of music in the care of those who are dying. For the last seven years I have promoted the use of music in hospitals and hopices by teaching nurses the type of music to use for their patients. From my experience, I have found the Secret Garden CDs have been one of the favourites for many patients. My request to you is permission to add some of the popular songs/tunes from the 'Songs from a Secret Garden,' 'White Stones' and 'Dawn of a New Century' onto a CD as a presentation with my written thesis. This would enable the thesis examiner to experience the type of music that has proven to be acceptable for patients who are dying. I have no intention of using the CD for any other purpose except for presentation of my thesis. I would appreciate your comments about my suggestion. If you require any further clarification, please contact me. Thankyou, regards Karen. 
Appendix 9

\section{CONFIDENTIALITY AGREEMENT}

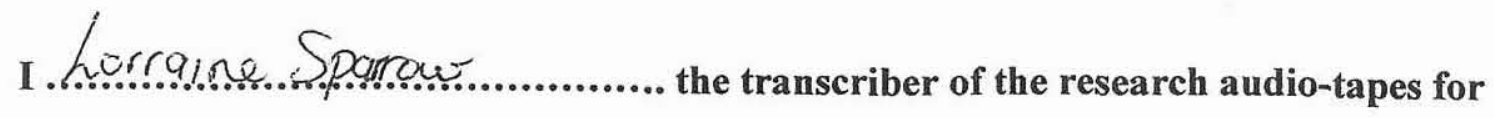
Karen Halls thesis, entitled, Music Therapy in Palliative Care, do promise to keep the information that I will be transcribing confidential.

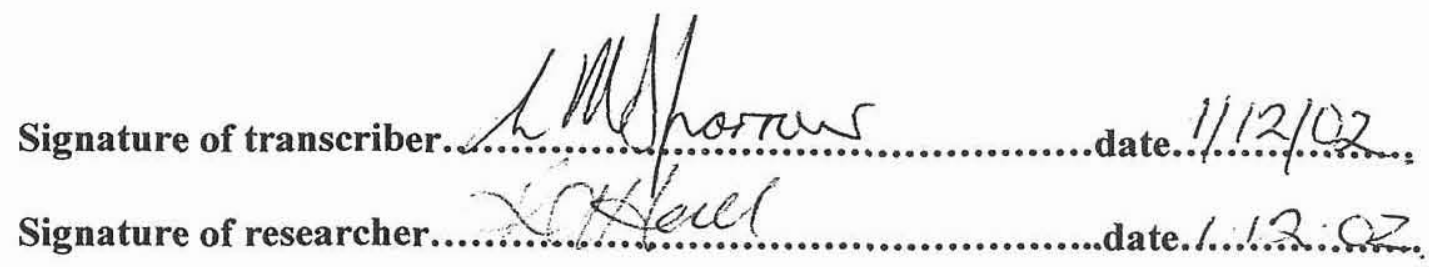




\section{REFERENCES}

Alvin, J. (1966). Music therapy. John Baker Publishers: London.

Bailey, L. (1984). The use of songs in music therapy with cancer patients and their families. Music Therapy, 4(1), 5-17

Bailey, F. (2000). The effects on patient well-being of music listening as a nursing intervention. A review of the literature. Journal of Clinical Nursing, 9(5), 668-77.

Baker, C., \& Diekelmann, N. (1994). Connecting conversations of caring: Recalling the narrative to clinical practice. Nursing Outlook, 42, 261-266.

Baum, F. (1995). Researching public health: Behind the qualitative quantitative methodological debate. Social Science Medicine, 40 (4), 459-468.

Beck, S. (1991). The therapeutic use of music for cancer-related pain. Beck. Vol, 18(8), 1327-1337

Benner, P. (1991). The role of experience, narrative, and community in skilled ethical comportment. Advanced Nursing Science, 14(2), 1-21.

Benner, P.,\& Wrubel, J. ( 1989) The primacy of care: Stress in health, coping and illness, Menlo Park, California: Addison-Wesley.

Biley, F. (2000). The effects on patient well-being of music listening as a nursing intervention: a review of the literature. Journal of Clinical Nursing, $9(5), 668-77$. 
Bolwerk, C. (1990). Effects of relaxing music on state anxiety in myocardial infarction patients. Critical Care Nursing Quarterly, 13(2), 63-72.

Bright, R. (1978). The role of the music therapist in the management of grief reactions. Fourth National Music Association Conference. August, 48-53.

Brooks, M., \& O'Rourke, A. (1992). A time for music. The place of music in the care of the elderly.

Brooks, P. (1994). Psychoanalysis and storytelling, Blackwell, Oxford.

Burns, S., Harbuz, M., Hucklebridge, F., \& Bunt, L. (2001). A pilot study into the therapeutic effects of music therapy at a cancer centre. Alternative Therapies in Health and Medicine. InnoVision Communications. January, Vol:7, (1), 48-60.

Butler, R. (1963). The life review: an interpretation of reminiscence in the aged .Pyschiatry, 26, pp 65-76.

Collins paperback English Dictionary (2 $2^{\text {nd }}$ ed). (1990). William Collins Sons \& Co. Ltd: Glasgow.

Cook, J. (1981). The therapeutic use of music: A literature review. Nursing Forum, Vol: XX.(3),252-265.

Cook, J. (1986). Music as an intervention in the oncology setting. Cancer Nursing, (10), 23-28.

Cooper, J. (1991) Music and dementia. Fourth National Music Association Conference. August: 1-6. 
Denzin, N., \& Lincoln, Y. (1989). Handbook of qualitative research: Entering the field of qualitative research. Newbury Park, CA: Sage.

Evans, D. (2001). The effectiveness of music as an intervention for hospital patients: A systematic review. Journal of Advanced Nursing, 37(1), 8-18

Farnsworth, P. R., (1969). The social psychology of music, Ames, Iowa: Iowa State University press.

Grout, D., \& Palisca, C. (1996). A history of western music. (5 ${ }^{\text {th }}$ ed). W W Norton \& Company: New York. (pp. 1 - 18)

Harcourt, L. (1988) Music for health. NZ Nursing Journal, January: 24-26.

Herth, K. (1978). The therapeutic use of music. Supervisor Nurse, 9, 22-23.

Hogan, B. (1998). Approaching the end of life: A role for music therapy within the context of palliative care models. The Australian Journal of Music, 9(-), 18-34

Hogan, B. (2001). "When words fail music begins" (H. Heine): A phenomenological research project investigating how terminally ill patients experience music therapy, 1-8.

Huxley, A. (1931). Music at night \& other essays. Chatto \& Windus, London. University Press: Edinburgh.

Jones, A. (2000). Some experiences of professional practice and beneficial changes derived from clinical supervision by community Macmillin nurses. European Journal of Cancer Care,10 21-30. 
Kenny, C. (1982). The mythic artery. The magic of music therapy. Satascadera, Ca, Ridgeview Publishing.

Lane, D. (1992). Music Therapy: A gift beyond measure. Oncology Nursing, Forum Vol 19, (6), 863-866.

Leight, S. B. (2002). Starry night: using story to inform aesthetic knowing in woman's health. Journal of Advanced Nursing, 37 (1),108-114.

Leininger, M. (1986) Care facilitation and resistance factors in the culture of nursing; Topics in clinical nursing, Thorofare, NJ: Slack.

Ley, D.C.H. (1993). Spiritual care in hospice. In K.Doka (Ed), Death and Spirituality (pp. 170-179) Amityville, NY: Baywood Publishing.

Liamputtong Rice, P., \& Ezzy, D.( 2000). Qualitative research methods. A health focus. Oxford University Press.

LoBiondo-Wood, G., \& Haber, J. (1994). Nursing research; Methods, critical appraisal, and utilization. ( $3^{\text {rd }}$ ed.) USA: Mosby- Year Book, Inc.

Lofland, J., \& Lofland, L. (1971). Analysing social settings. Wadsworth, Belmont, CA.

Maggs-Rapport, F. (2000). Combining methodological approaches in research: ethnography and interpretive phenomenology. Journal of Advanced Nursing, 31(1), 219-225.

Magill-Leverault, L. (1993). Music therapy in pain and symptom management. Journal of Palliative Care, 9:4. 37-55. 
Mandel S. (1991). Music therapy in the hospice: 'Musicalive' Palliative Medicine, 5, 155-160.

Manning, R. (1992). Speaking from the heart: A feminist perspective on ethics. Rowman \& Littlefield Publishers, Inc.

Maranto, C. (1993). Music therapy and stress management. P.M. Lehrer \& R. L. Woolfolk (Eds.), Principles and practise of stress management ( $2^{\text {nd }}$ ed.) (.407433). New York: Guilford.

McCaffrey, R., \& Good, M. (2000). The lived experience of listening to music while recovering from surgery. Journal of Holistic Medicine, 18(4), 378390.

McCormick, P. J., Copper, R., Sutherland, H. (2001). The safe use of syringe drivers for palliative care: An action research project. International Journal of Palliative Nursing, 7(12), 574-580.

MacLeod, R. (1998). Assessment and management of pain at the end of life. Conference presentation paper. Dunedin. September.

McKinley, E. (2001). With in the circle of care: Patient experiences of receiving palliative care. Journal of Palliative Care, 17, 1/2001, 22-29.

Mayeroff, M. (1971). On caring. New York: Harper Collins.

Meleis, A. (1991). Theoretical nursing; Development and progress.( $2^{\text {nd }}$ ed. $)$ Pennsylvania: J.B.Lippincott Company.

Meriam, S. (1998). Qualitative research and case study applications in education. San Fransisco: Jossey-Bass. 
Ministry of Health, (2000). The New Zealand Palliative Care Strategy. Discussion Document.

Mishler, E. (1990). 'Validation in inquiry' -guided research. The role of exemplars in narrative studies. Harvard Educational Review. Vol 60. No 2. 41542.

Montgomery, M. (1993). Healing through communication; The Practice of Caring. California: Sage Publications, Inc.

Mornhinweg G. (1992). Effects of music preference and selection on stress reduction. Journal of Holistic Nursing, 10(2), 101-109.

Mullett, S. (1989). 'Shifting perspectives: A new approach to ethics,' in L. Code et al., (esd), Feminist Perspectives, University of Toronto Press, Toronto, 109-126.

Munro, S. (1984). Music therapy in palliative/hospice care. Gustav Fischer Verlag Stuttgart: New York.

Munro, S., \& Mount, B .(1978). Music therapy in palliative care. CMA Journal, November 4, Vol.119. 105 - 262.

Munro, S. (1992) Music therapy perspectives in palliative care education. Journal of Palliative Care, 8(2): 39-42.

Munro, S. (1994) The supportive role of music. European Journal of Palliative Care, Vol 2, (2): 77-80. 
Newman, M., Sime, A., Corcoran-Perry, S.(1991). The focus of the discipline of nursing. Advances in Nursing Science, 14(1)1-6.

Nightingale, F. (1859). Notes on nursing: What is it and what it is not. Dover Publications: New York.

O' Callaghan C. (1984) Musical profiles of dying patients. The Australian Music Therapy Association bulletin, Vol.7, (2), 5-11.

O' Callaghan, C. (1996). Music and wellbeing: Music Therapy and Palliative Care, September: 4-19.

O 'Callaghan, C. (1996). Complementary therapies in terminal care. Pain, music creativity and music therapy in palliative care. The American Journal of Hospice \& Palliative Care, March/April: 43-49.

Packard, S., \& Polifroni, E. (1991). The Dilemma of nursing science: Current quandaries and lack of direction. Nursing Science Quarterly, 4(1):7-13

Polifoni, E., \& Welch, M. (1999). Perspectives on philosophy of science in nursing. An historical and contemporary anthology. Lippincott: Philadelphia.

Quill, T. (2001). Initiating end-of-life discussions with seriously ill patients: Addressing the "elephant in the room". The Journal of the American Medical Association, Vol.284(19), 2502-2507.

Rice, P., \& Ezzy, D. (2000). Qualitative research methods: A health focus. Oxford University Press.

Roberts, K., \& Taylor, B. (1998). Nursing research processes: An Australian perspective . Nelson ITP, Melbourne. 
Salmon, D. (1993). Music and emotional expression in palliative care. Unpublished article. 2-18.

Schroeder- Sheker, T. (1993). Music for the dying: A personal account of the new field of music thanatology- history, theories, and clinical narratives. Advances, The Journal of Mind-Body Health, Vol.9, No. 1.pp1-26.

Schullian, D. M. (1948). Scoen, M. (ed). Music and medicine. Schuman: New York.

Smith, C. A., \& Morris L. W. (1976). Effects of stimulative and sedative music on cognitive and emotional components of anxiety. Psychological Reports, 38(4), 1187-1193.

Snyder, M., \& Chaln, L. (1999). Music therapy. Complementary Therapies, 17(3), 3-25.

Starr, R. (1999). Alternative and complementary therapies: Music therapy in hospice care. American Journal of Hospice and Palliative care, 16(6): 739-42

Street, A. (1995). Nursing replay; Researching nursing culture together. Melbourne: Churchill Livingston.

Taylor, B. J. (2000). Reflective practice - A guide for nurses \& midwives. Allen \& Unwin: St. Leonards, NSW.

Taylor, K. (1995). The ethics of caring. Honoring the web of life in our professional healing relationships. Hanford Mead Publishers: Calfornia. 
Tong, R. (1998). The ethics of care: A feminist virtue ethics of care for healthcare practitioners. Journal of Medicine and Philosophy, Vol. 23, No. 2, 131152.

Trauger-Querry, B., \& Haghighi, K. (1999). Balancing the focus: Art and music therapy. Hospice Journal. 14(1): 25-38.

Updike, P. (1990). Music therapy results for ICU patients. Dimensions in Critical Care Nursing. 9(1), 39-45

Van Manen, M. (1990). Researching the lived experience. Human science for an action sensitive pedagogy. The Althouse Press: USA.

Watson, J. (1998). New dimensions of human caring theory. Nursing Science Quarterly, 1(4), 175-181.

Waugh, A. (1995). Classical music: A new way of listening. De Agostini Editions: London.

Wilkinson, S. (1995). The changing pressures for cancer nurses. European Journal of Cancer Care, 4.69-74

Wright, S. (1987). Pain control: The use of therapeutic touch in the management of pain. Nursing Clinics of North America, Vol. 22(3). September.

Yates, P. (1997). Palliative Care: Explorations and Challenges. Maclennan \& Petty: Sydney.

Zimmerman, L. M., Pozehl, B., Duncan K. \& Schmitz R. (1989). Effects of music on patients with chronic cancer pain. Western Journal of Nursing Research, 11(3), 298-309. 